\title{
Aging Effects on the Microstructure, Surface Characteristics and Wettability of Cu Pretinned with Sn-Pb Solders
}

\author{
Heidi Sue Linch \\ Master of Science \\ Department of Materials Science and Mineral Engineering \\ University of California \\ and \\ Center for Advanced Materials \\ Materials Sciences Division \\ Lawrence Berkeley Laboratory \\ University of California \\ Berkeley, CA 94720
}

November 1993

This work was funded by Sandia National Laboratory in Albuquerque, New Mexico using facilities at Lawrence Berkeley Laboratory supported by the Director, Office of Energy

Research, Office of Basic Energy Sciences, Materials Sciences Division of the U.S. Department of Energy under Contract No. DE-AC03-76F00098 


\author{
ABSTRACT \\ Aging Effects on the Microstructure, Surface Characteristics, and Wettability of $\mathrm{Cu}$ \\ Pretinned with $\mathrm{Sn}-\mathrm{Pb}$ Solders \\ by \\ Heidi Sue Linch \\ Master of Science in Materials Science Engineering \\ University of California at Berkeley \\ Professor J. W. Morris, Jr., Chair
}

This study investigates the effects of aging in air and argon at $170^{\circ} \mathrm{C}$ on $\mathrm{Cu}$ coupons which were pretinned with $75 \mathrm{Sn}-25 \mathrm{~Pb}, 8 \mathrm{Sn}-92 \mathrm{~Pb}$, and $5 \mathrm{Sn}-95 \mathrm{~Pb}$ solders. Coatings were applied using electroplating or hot dipping techniques. The coating thickness was controlled between 3 to $30 \mu \mathrm{m}$ and the specimens were aged for 0 hours, 2 hours, 24 hours and 2 weeks. Wetting balance tests were used to evaluate the wettability of the test specimens. Microstructural development was evaluated using $\mathrm{X}$-ray diffraction, energy dispersive $\mathrm{X}$-ray and Auger spectroscopy, as well as optical and scanning electron microscopy. The wetting behavior of the test specimens is interpreted with respect to observed microstructural changes and as a function of aging time, solder composition, and processing conditions. 


\section{TABLE OF CONTENTS}

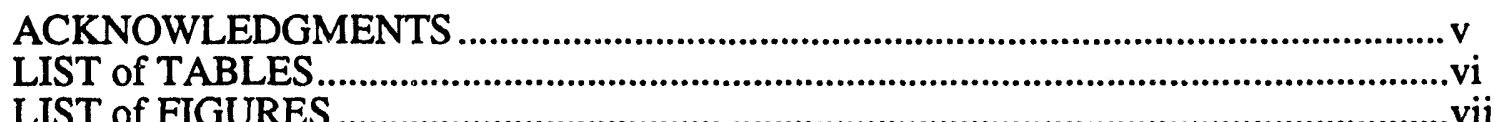

1. INTRODUCTION ...............................................................................................

2. BACKGROUND

2.1. Concepts of Wetting and Solderability.......................................................

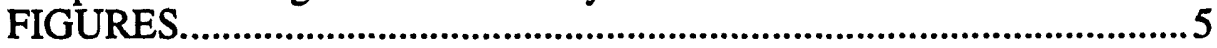

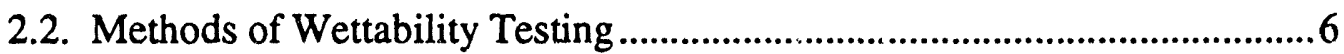

2.2.1. Globule Method .....................................................................6

2.2.2. The Parallel Plate Method.........................................................6

2.2.3. The Sessile Drop Method............................................................6

2.2.4. The Rotary Dip and Edge Dip Methods ....................................... 7

2.2.5. The Wetting Balance Method....................................................... 7

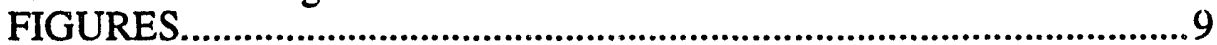

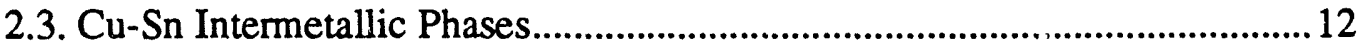

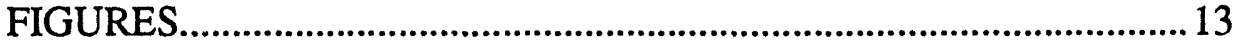

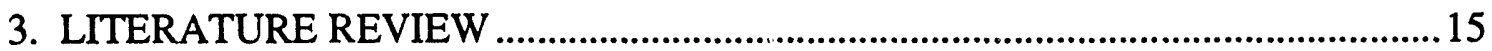

3.1. Accelerated Aging Methods .....................................................................15

3.2. Previous Aging Studies.............................................................................16

3.2.1. Intermetallic Formation and Growth ............................................ 16

3.2.2. Effects of Solder Thickness ......................................................... $1 \%$

3.2.2. Effects of Solder Alloy .................................................................. 18

3.2.3 Mechanisms of Solderability Degradation..................................... 19

3.3. Oxidation of $\mathrm{Cu}-\mathrm{Sn}$ Intermetallic Compounds ..........................................2

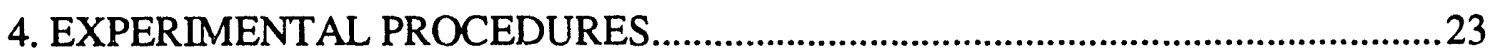

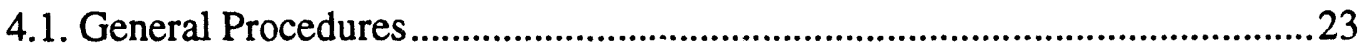

4.2. X-ray Diffraction Analysis Set Up and Sample Preparation .......................2 24

4.3. Metallographic Sample Preparation............................................................2 24

4.4. Scanning Electron Microscopy Sample Preparation....................................225

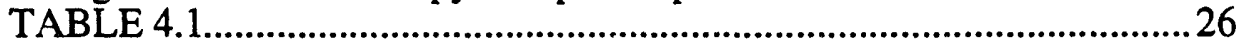




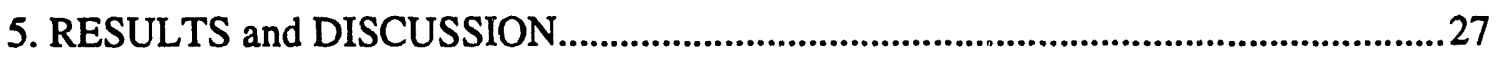

5.1. Sn-Rich (75Sn-25Pb) Electroplated Samples....................................................2

5.1.1. Wetting Balance Test Results..........................................................27

5.1.2. Microstructural Changes................................................................28

5.1.2.1. X-ray Diffraction Analysis .............................................28

5.1.2.2. Microscopy and EDX Analysis ........................................29

5.1.3. Surface Characteristics.........................................................................30

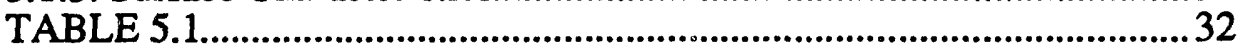

FIGURES........................................................................................ 33

5.2 Pb-Rich (8Sn-92Pb) Electroplated Samples................................................51

5.2.1. Wetting Balance Test Results........................................................51

5.2.2. Microstructural Changes...............................................................51

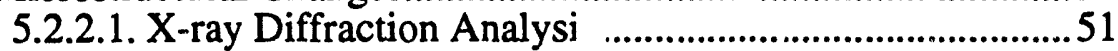

5.2.2.2. Microscopy and EDX Analysis ......................................52

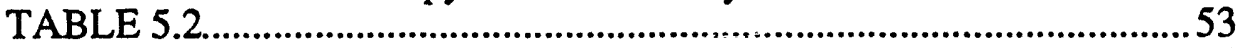

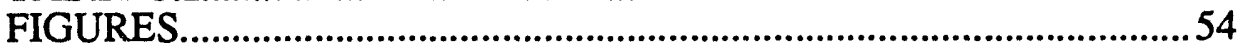

5.3 Pb-Rich (5Sn-95Pb) Hot-Dipped Samples ..................................................58

5.3.1. Wetting Balance Test Results.........................................................58

5.3.2. Microstructural Changes..............................................................58

5.3.2.1. X-ray Diffraction Analysis .............................................5

5.3.2.2. Microscopy and EDX Analysis .........................................58

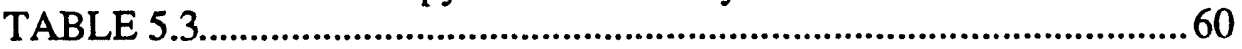

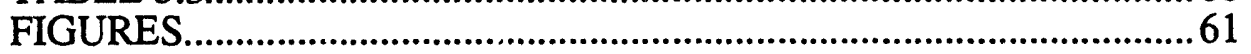

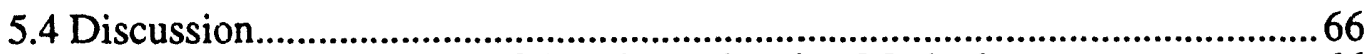

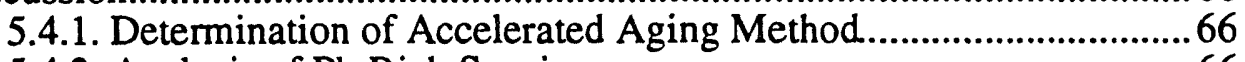

5.4.2. Analysis of Pb-Rich Specimens.....................................................66

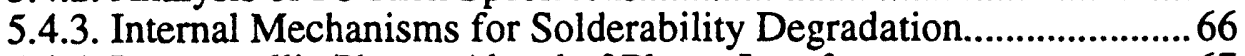

5.4.4. Intermetallic Phases Ahead of Planar Interface..............................67

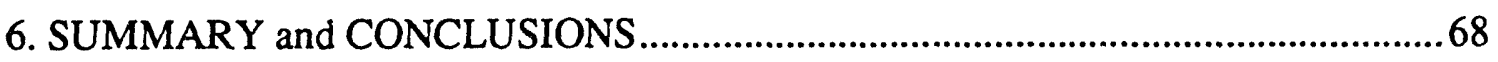

6.1. Aging Effects of $\mathrm{Cu}$ Pretinned with Sn-rich Solder (75Sn-25Pb) ................68

6.2. Aging Effects of $\mathrm{Cu}$ Pretinned with Pb-Rich Solders ( $8 \mathrm{Sn}-92 \mathrm{~Pb}$ and $5 \mathrm{Sn}-95 \mathrm{~Pb})$.

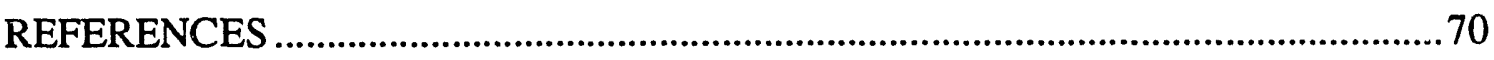

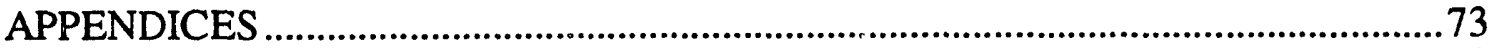

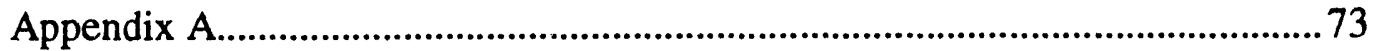




\section{ACKNOWLEDGMENTS}

I would like to express my appreciation to my research advisor and committee chair, Professor J. W. Morris, Jr., for his support and guidance. The past two years have been a positive, growing experience and I feel fortunate to be part of "the Morris Group". I would also like to express my appreciation to Jane Fortado for her encouragement and assistance. A warm smile on a cloudy day really makes a difference. Thanks also go to the other members of my thesis committee, Professor F. M. Doyle and Professor A. T. Bell for their time in reviewing this manuscript.

Special thanks go to Dr. Alton Romig of Sandia National Laboratory for his advice and support upon starting my graduate school career. Thanks also go to Dr. Darrel Frear, of Sandia National Laboratory, for continued funding and support.

Thanks you to all of my co-workers in the Morris group. In particular, I would like to thank Dr. Zequn Mei for his assistance and helpful discussions during thae early stages of this work. Special thanks also go to my office mates Pamela Kramer, Julia Freer Goldstein, and Hiro Hayashigatani for their suggestions and assistance.

Finally, I would like to say a very special thank you to my family and dear friends for all of their love and encouragement. I am truly blessed by those who believe not only in who I am, but more importantly, who I will become. Thank You.

This work was funded by Sandia National Laboratory in Albuquerque, New Mexico using facilities at Lawrence Berkeley Laboratory supported by the Director,

Office of Energy Research, Office of Basic Energy Sciences,

Materials Sciences Division of the U. S. Department of Energy

under Contract No. DE-AC03-76F00098. 


\section{LIST of TABLES}

Table 4.1. Wetting Balance Test Parameters

Table 5.1. Sn-Rich Electroplated Samples - Microstructural Phases Detected using $\mathrm{X}$-ray Diffraction

Table 5.2. Pb-Rich Electroplated Samples - Microstructural Phases Detected using $\mathrm{X}$-ray Diffraction

Table 5.3. Pb-Rich Hot-Dipped Samples - Microstructural Phases Detected using $\mathrm{X}$-ray Diffraction 


\section{LIST of FIGURES}

Figure 2.1. Illustration of the concept of surface tension of a liquid: a) A molecule near the center of the liquid; b) A molecule at the surface of the liquid [1].

Figure 2.2. Illustration of typical contact angle: a) $\theta>90^{\circ}$, non-wetting or de-wetting; b) $0<\theta<90^{\circ}$, adequate wetting; c) $\theta=0^{\circ}$, complete wetting. [2]

Figure 2.3. Schematic illustration of the five stages of a wetting balance test.[5]

Figure 2.4. Forces exerted on a specimen during a wetting balance test. The numbers beside the solid curve correspond to the different stages in Figure 2.3. Varying degrees of wetting are shown.[5]

Figure 2.5. Wetting balance curve showing good wetting characteristics. The maximum wetting force can be measured as indicated. The plateau near the beginning of the test is related to the heat transfer of the coupon.

Figure 2.6. Wetting balance curve showing non-wetting characteristics.

Figure 2.7. Diagram illustrating the $\mathrm{Sn}-\mathrm{Pb}$ binary system. [8]

Figure 2.8. Diagram illustrating the $\mathrm{Cu}-\mathrm{Sn}$ binary system. [8]

Figure 5.1. Graph showing the maximum wetting force as a function of coating thickness and aging time for the Sn-rich (75Sn-25Pb), electroplated samples aged in argon.

Figure 5.2 Graph showing the maximum wetting force as a function of coating thickness and aging time for the Sn-rich (75Sn-25Pb), electroplated samples aged in air.

Figure 5.3. Graph showing the total time to $90 \%$ of the maximum wetting force as a function of coating thickness and aging time for the $\mathrm{Sn}$-rich $(75 \mathrm{Sn}-25 \mathrm{~Pb})$, electroplated samples aged in argon.

Figure 5.4. Graph showing the total time to $90 \%$ of the maximum wetting force as a function of coating thickness and aging time for the $\mathrm{Sn}$-rich $(75 \mathrm{Sn}-25 \mathrm{~Pb})$, electroplated samples aged in air.

Figure 5.5. Graph showing the net (excluding plateau) time to $90 \%$ of the maximum wetting force as a function of coating thickness and aging time for the Sn-rich (75Sn-25Pb), electroplated samples aged in argon. 
Figure 5.6. Graph showing the net (excluding plateau) time to $90 \%$ of the maximum wetting force as a function of coating thickness and aging time for the Sn-rich (75Sn-25Pb), electroplated samples aged in air.

Figure 5.7. Optical micrographs of the $30 \mu \mathrm{m}$ Sn-rich (75Sn-25Pb) electroplated specimens aged in air for a) 24 hours and b) 2 weeks at $170^{\circ} \mathrm{C}$.

Figure 5.8. SEM micrographs showing cross-sections of the $30 \mu \mathrm{m}$ Sn-rich $(75 \mathrm{Sn}-25 \mathrm{~Pb})$, electroplated specimen aged in air for 2 weeks at $170^{\circ} \mathrm{C}$.

a) Magnification $=2030 x$ and b) Magnification $=4100 x$

Figure 5.9. SEM micrograph showing a cross-section of the $3 \mu \mathrm{mi}$ Sn-rich $(75 \mathrm{Sn}-25 \mathrm{~Pb})$, electroplated specimens aged in air for 2 weeks at $170^{\circ} \mathrm{C}$. Only one intermetallic layer ( $\left.\mathrm{Cu}_{3} \mathrm{Sn}\right)$ is present.

a) Magnification $=2030 x$ and b) Magnification $=4100 x$

Figure 5.10. SEM micrograph showing the surface of the $3 \mu \mathrm{m}$ Sn-rich (75Sn-25Pb), electroplated, unaged specimen.

Figure 5.11. SEM micrographs showing the surfaces of the $3 \mu \mathrm{m}$ Sn-rich $(75 \mathrm{Sn}-25 \mathrm{~Pb})$, electroplated, specimens aged for 2 weeks at $170^{\circ} \mathrm{C}$ in a) argon, and b) air. In both samples, the residual $\mathrm{Pb}$ has withdrawn into irregularly shaped regions, leaving the $\mathrm{Cu}_{3} \mathrm{Sn}$ intermetallic exposed to the surface.

Figure 5.12. SEM micrographs showing the surface of the $10 \mu \mathrm{m}$ Sn-rich $(75 \mathrm{Sn}-25 \mathrm{~Pb})$, electroplated specimen aged for 2 weeks in air at $170^{\circ} \mathrm{C}$. The exposed intermetallic phase is $\mathrm{Cu}_{6} \mathrm{Sn} 5$.

Figure 5.13. SEM micrographs showing the surface of the $30 \mu \mathrm{m} \mathrm{Sn-rich}$ $(75 \mathrm{Sn}-25 \mathrm{~Pb})$, electroplated specimen aged for 2 weeks in air at $170^{\circ}$. Intermetallic exposed at the surface is $\mathrm{Cu}_{6} \mathrm{Sn}_{5}$.

Figure 5.14. SEM micrographs showing the surface of the $30 \mu \mathrm{m}$ Sn-rich $(75 \mathrm{Sn}-25 \mathrm{~Pb})$, electroplated specimen aged for 2 weeks in air at $170^{\circ}$. Intermetallic exposed at the surface is $\mathrm{Cu}_{6} \mathrm{Sn}_{5}$.

Figure 5.15. Graph showing the total time to $90 \%$ of the maximum wetting force as a function of coating thickness and aging time for the Sn-rich $(75 \mathrm{Sn}-25 \mathrm{~Pb})$, electroplated samples aged in argon. Intermetallics exposed at the surface are indicated.

Figure 5.16. Graph showing the total time to $90 \%$ of the maximum wetting force as a function of coating thickness and aging time for the Sn-rich $(75 \mathrm{Sn}-25 \mathrm{~Pb})$, electroplated samples aged in air. Intermetallics exposed at the surface are indicated. 
Figure 5.17. Auger depth profile showing chemical composition at the surface of the $10 \mu \mathrm{m}$ Sn-rich, electroplated sample which had been aged for 2 weeks at $170^{\circ} \mathrm{C}$ in air. $\mathrm{A} \mathrm{Sn}$ oxide is present on the $\mathrm{Cu}_{6} \mathrm{Sn}_{5}$ surface.

Figure 5.18. Auger depth profile showing chemical composition at the surface of the $3 \mu \mathrm{m}$ Sn-rich, electroplated sample which had been aged for 2 weeks at $170^{\circ} \mathrm{C}$ in air. A Cu oxide is present on the surface.

Figure 5.19. Graph showing the maximum wetting force as a function of coating thickness and aging time for the $\mathrm{Pb}$-rich $(8 \mathrm{Sn}-92 \mathrm{~Pb})$, electroplated samples aged in argon.

Figure 5.20. Graph showing the total time to $90 \%$ of the maximum wetting force as a function of coating thickness and aging time for the $\mathrm{Pb}$-rich $(8 \mathrm{Sn}-92 \mathrm{~Pb})$, electroplated samples aged in argon.

Figure 5.21. Graph showing the net (excluding plateau) time to $90 \%$ of the maximum wetting force as a function of coating thickness and aging time for the $\mathrm{Pb}$-rich (8Sn-92Pb), electroplated samples aged in argon.

Figure 5.22. SEM backscattered image showing the cross-section of a $10 \mu \mathrm{m} \mathrm{Pb}$-rich $(8 \mathrm{Sn}-92 \mathrm{~Pb})$, electroplated specimen which was aged in argon for 2 weeks at $170^{\circ} \mathrm{C}$.

Figure 5.23. Graph showing the maximum wetting force as a function of coating thickness and aging time for the $\mathrm{Pb}$-rich $(5 \mathrm{Sn}-95 \mathrm{~Pb})$, hot-dipped samples aged in argon.

Figure 5.24. Graph showing the total time to $90 \%$ of the maximum wetting force as a function of coating thickness and aging time for the $\mathrm{Pb}$-rich (5Sn-95Pb), hot-dipped samples aged in argon.

Figure 5.25. Graph showing the net (excluding plateau) time to $90 \%$ of the maximum wetting force as a function of coating thickness and aging time for the $\mathrm{Pb}$-rich $(5 \mathrm{Sn}-95 \mathrm{~Pb})$, hot-dipped samples aged in argon.

Figure 5.26. SEM micrograph (backscattered image) showing cross-section of a $\mathrm{Pb}$-rich $(5 \mathrm{Sn}-95 \mathrm{~Pb})$, hot-dipped $\left(360^{\circ} \mathrm{C}\right)$ specimen which was aged in argon at $170^{\circ} \mathrm{C}$ for 2 weeks.

Figure 5.27. SEM micrograph (backscattered image) showing cross-section of a $\mathrm{Pb}$-rich $(5 \mathrm{Sn}-95 \mathrm{~Pb})$, hot-dipped $\left(360^{\circ} \mathrm{C}\right)$ specimen which was aged in argon at $170^{\circ} \mathrm{C}$ for 2 weeks. 


\section{INTRODUCTION}

Pretinning refers to a thin, protective coating being applied to a substrate material in order to maintain solderability of the part. In the electronics industry, pretinned coatings are usually $\mathrm{Sn}-\mathrm{Pb}$ solders and are often applied to $\mathrm{Cu}$ substrates using electroplating or hot dipping techniques. Pretinning is a common method of maintaining solderability of electronic components which are stored for long periods of time before being fully assembled and soldered. Also, some components need to be reworked after experiencing high processing temperatures. Solderability must also be maintained for successful re-working of electronic components.

It is well known, however, that the wettability of pretinned $\mathrm{Cu}$ often decreases after long aging times, causing many problems for the electronics industry. A method of accelerated aging of electronic components is necessary in order to efficiently study the effect of long-term aging on wetting characteristics. This work has been done in order to better understand the reason for this decrease in wettability due to long-term aging, by studying the effects of accelerated aging on $\mathrm{Cu}$ substrates pretinned with $\mathrm{Sn}-\mathrm{Pb}$ solders.

\section{BACKGROUND}

\subsection{Concepts of Wetting and Solderability}

The current study relates the effects of aging to the wetting characteristics of $\mathrm{Cu}$ pretinned with $\mathrm{Sn}-\mathrm{Pb}$ solders. The wettability of a molten solder on a substrate can be discussed in terms of thermodynamics and kinetics. The thermodynamic quantity known as surface tension must be understood before a discussion of wettability can take 
place. The concept of surface tension is illustrated in Figure 2.1. Figure 2.1a shows a molecule in the center of a liquid and Figure $2.1 \mathrm{~b}$ shows a molecule at the surface of a liquid. Molecules at the surface experience a net attraction toward the interior of the liquid because there is no attraction at the surface, whereas a molecule in the bulk experiences attractive forces in all directions which cancel each other out. The surface tension is equal to the energy required to produce a net increase in the surface area of a phase, and the interfacial tension is the energy required to produce a net increase in the interfacial area between two phases. Surface tension has units of energy per unit area $\left(\mathrm{J} / \mathrm{m}^{2}\right)$ or force per unit length $(\mathrm{N} / \mathrm{m})$. According to the Gibbs' Relation, in the absence of chemical interactions, any spontaneous change that occurs at an interface between two phases must lower the interfacial tension $(\sigma)$.

$$
\Delta \sigma \leq 0
$$

The physics of wetting involves the surface tensions between the solid-liquid, solidvapor, and liquid-vapor interfaces and can be described by the Young-Dupre Equation which is. shown below:

$$
\sigma_{S V}=\sigma_{S L}+\sigma_{L V}(\cos \theta)
$$

(Young described the physics of wetting qualitatively in 1805 and Dupre described the physics of wetting mathematically in 1869 [3].) In the Young-Dupre equation, $\sigma_{S V}$, $\sigma_{\mathrm{SL}}$, and $\sigma_{\mathrm{LV}}$ represent the surface tensions of the solid-vapor, solid-liquid, and liquidvapor interfaces, respectively. The contact angle, $\theta$, is shown in Figure 2.2. The smaller the contact angle, the higher the degree of wetting. Ideal wetting conditions exist when the contact angle is zero and the liquid spreads across the substrate in a thin, continuous film. This condition is referred to as "fully wet" or complete wetting. In general, adequate wetting is achieved when the contact angle is $0<\theta<90^{\circ}$. This condition is referred to as "partially wet". If the contact angle is greater than $90^{\circ}$ then poor wetting or de-wetting conditions exist. Wetting is promoted when $\sigma_{\mathrm{SV}}$ is large 
and, $\sigma_{\mathrm{SL}}$ and $\sigma_{\mathrm{LV}}$ are small. In most soldering processes, the vapor phase is replaced by the flux, so that $\sigma_{\mathrm{SV}}$ and $\sigma_{\mathrm{LV}}$ would be replaced by $\sigma_{\mathrm{SF}}$ and $\sigma_{\mathrm{LF}}$. The flux acts to remove oxides from the surface of the solid and therefore, promotes wetting. The flux also acts to protect the substrate from re-oxidation during the soldering process and enhances heat transfer from the heating source to the solder and substrate [3]. In addition, wetting can be promoted by choosing a substrate material and solder alloy which will react spontaneously (i.e. in the formation of intermetallic phases) and effectively lower $\sigma_{\mathrm{SL}}$. A chemical reaction between the substrate material and the liquid solder will change the free energy of the system. [4] Yost and Romig [4] have calculated the change in free energy $(\Delta \mathrm{G})$ associated with the formation of a Cu-Sn ( $\mathrm{Cu}_{6} \mathrm{Sn}_{5}$ ) intermetallic from a molten $\mathrm{Sn}$ bath on a $\mathrm{Cu}$ substrate to be $\Delta \mathrm{G}=465-3.09 \mathrm{~T}$ $\mathrm{cal} / \mathrm{mol}$ which is "approximately two orders of magnitude" larger than the change in free energy associated with the Young-Dupre equation and the surface energy balance. In this case, the dominant thermodynamic driving force for wetting is the change in free energy which results from the formation of the $\mathrm{Cu}-\mathrm{Sn}$ intermetallic. The kinetics of the system must be such that the formation of intermetallics or the balance of surface tensions, and therefore wetting, takes place in the short time provided by manufacturing processes.

The phenomena of dewetting must also be considered when discussing wettability. Dewetting occurs when molten solder withdraws from a surface which was previously wet. The resulting surface often consists of irregular shaped solder droplets with thin layers of solder in between [5]. Dewetting reduces the size of solder joints on printed circuit boards and therefore, affects the joint quality. There are several proposed causes for the phenomena of dewetting: a) dissolution of a wettable coating on a non-wettable substrate, b) non-wettable spots on a wettable surface, and c)contamination of the solder. The relative importance of these causes is still being debated, however, and published literature on the phenomena of dewetting is limited. 
Solderability is a broader term which refers to the suitability of a component to be soldered by a given method [3] or the degree to which a good bond is formed [2]. Solderability of a component involves three factors: thermal demand, resistance to soldering heat, and wettability. The thermal conductivity of a component must be such that the component can be heated to the soldering temperature with practical methods used in industry. The component must be able to withstand this heating, however, and not be damagec by thermal stresses. The wetting characteristics of a component must be such that the molten solder wets and spreads over the surfaces to be joined in the amount of time allotted by the manufacturing process. Solderabilty is a complex issue involving many processing parameters which will not be discussed in this paper. For the remainder of this report, therefore, the terms solderability and wettability will be used interchangeably but the author would like to note that there is, indeed, a distinction between the two terms. 


\section{EIGURES}

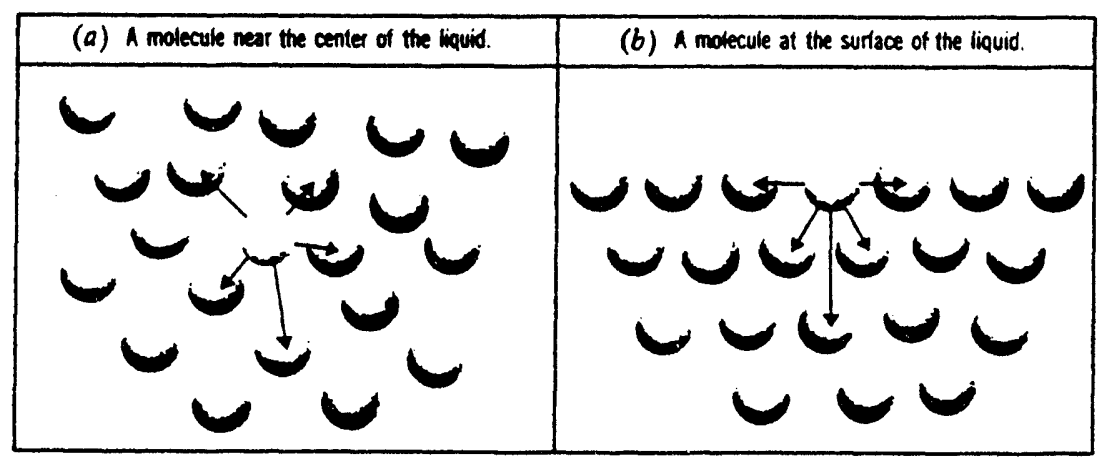

Figure 2.1. Illustration of the concept of surface tension of a liquid: a) A molecule near the center of the liquid; b) A molecule at the surface of the liquid. [1]

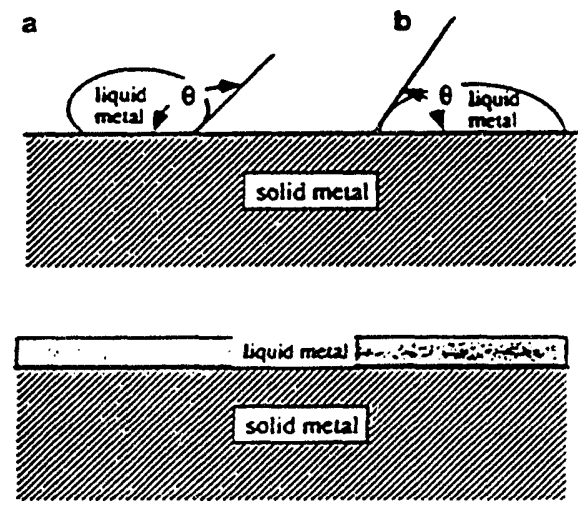

c

Figure 2.2. Illustration of typical contact angle: a) $\theta>90^{\circ}$, non-wetting or de-wetting; b) $0<\theta<90^{\circ}$, adequate wetting; c) $\theta=0^{\circ}$, complete wetting. [2] 


\subsection{Methods of Wettability Testing}

Methods for measuring the wettability of a certain system include the globule method, the parallel plates method, the sessile drop test method, the rotary dip method, the edge dip method, and the wetting balance method.

\subsubsection{Globule Method}

The globule test is the oldest, established method for wettability evaluation [5]. The globule method consists of a fluxed wire being lowered horizontally onto a molten solder droplet on a heated surface. The wire momentarily bisects the droplet of molten solder. The time required for the solder droplet to surround the wire is known as the "globule time" and can be used as a measure of wettability.

\subsubsection{The Parallel Plate Method}

The parallel plate test is simply a technique where the meniscus rise of molten solder between two parallel plates is measured. Correlation to solderability in manufacturing is poor [3].

\subsubsection{The Sessile Drop Method}

The sessile drop technique consists of uniform volumes of solder being placed on flat, substrate surfaces. The configuration is then heated above the liquidus temperature of the solder and held for a designated period of time. The area of spread, contact angle, or solder height can be measured for a quantitative comparison of wettability. The sessile drop test is also referred to as the area-of-spread test. 


\subsubsection{The Rotary Dip and Edge Dip Methods}

The rotary dip method is used for testing flat surfaces. The specimen rotates around a horizontal axis and just makes contact with a molten solder bath in its clockwise movement. The edge dip test of consists of coupons or components which are prefluxed, pre-heated and dipped into a constant temperature solder bath. The test coupons are immersed and withdrawn at a known rates. The rotary dip test and the edge dip test are based on visual observation. These tests are very subjective. Tested coupons are often ranked on a scale of $1-10$, with 10 indicating "good" wetting and 1 indicating no wetting or de-wetting.

\subsubsection{The Wetting Balance Method}

The wetting balance test is a quantitative technique which measures the wetting force as a function of time. Components or coupons to be tested are suspended from a sensitive balance. The coupons are immersed into a molten solder bath at a specified rate and to a predetermined depth. The temperature of the solder bath is held constant. The coupon is held in the molten solder bath for a given time and then removed as the solder bath is lowered. The coupon experiences forces due to buoyancy and surface tension. The net force on the coupon is detected by a transducer and converted to an electrical signal which can be continuously recorded. Five stages of the wetting balance test are illustrated in Figure 2.3.[5] The points corresponding to these stages are indicated on the trace of the resulting force in Figure 2.4. Stage 1 shows the coupon before immersion. Stage 2 shows the coupon immediately after immersion. In stage 3, the wetting forces are such that the vertical force due to surface tension is zero and the only force acting on the coupon is the buoyancy force. The correction for this buoyancy force is shown in Figure 2.4. Stage 4 illustrates the coupon experiencing a vertical force due to the surface tension. The coupon is withdrawn in Stage 5. The solid curve in Figure 2.4 illustrates a condition of excellent wetting. Conditions of moderate 
wetting, poor wetting, and non-wetting are also shown in Figure 2.4. Figures 2.5 and 2.6 show examples of actual data from a wetting balance test. The software used to create these curves has already made a correction for the buoyancy force. Figure 2.5 illustrates a sample exhibiting good wetting while Figure 2.6 illustrates a sample exhibiting non-wetting. Two types of meaningful data can be obtained from the wetting balance curves. The maximum wetting force can be determined as shown in Figure 2.5 and is taken as the absolute value of the greatest negative force. In order for wetting to occur, the trace of the wetting force must cross the zero force line. The time taken to reach the maximum wetting force is also a used as a comparative measure of wetting. According to MIL-STD-883C [6], the criteria for acceptable solderability during the evaluation of the wetting balance curves are:

1.) That the recorded signal trace crosses the zero balance point at or before 0.59 seconds of the test time.

and

2.) That the recorded signal trace reaches two-thirds of its maximum absolute value in 1 second or less of test time.

The wetting balance test is more quantitative than the rotary dip test, the edge dip test, or the parallel plate test and provides more versatility for sample geometry than the globuie test or the sessile drop test. 


\section{HIGURES}

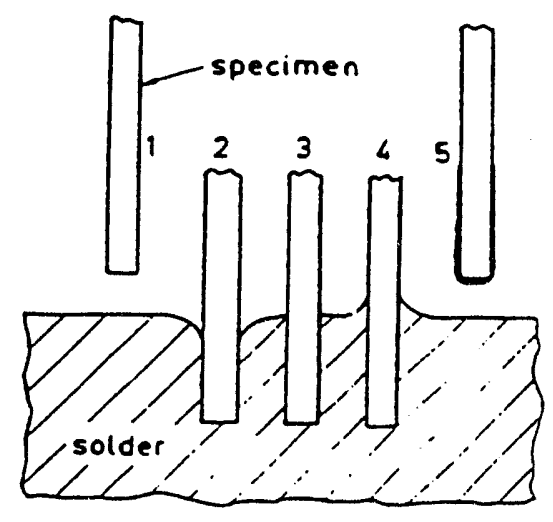

Figure 2.3. Schematic illustration of the five stages of a wetting balance test.[5]

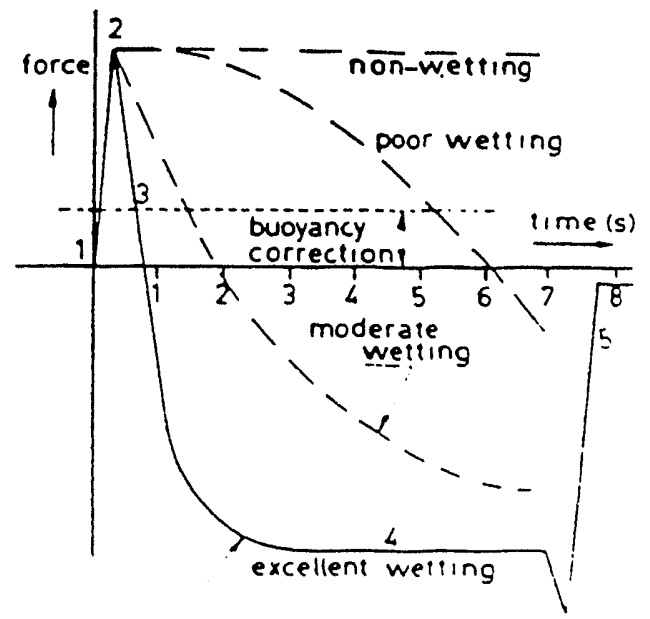

Figure 2.4. Forces exerted on a specimen during a wetting balance test. The numbers beside the solid curve correspond to the different stages in Figure 2.3. Varying degrees of wetting are shown.[5] 


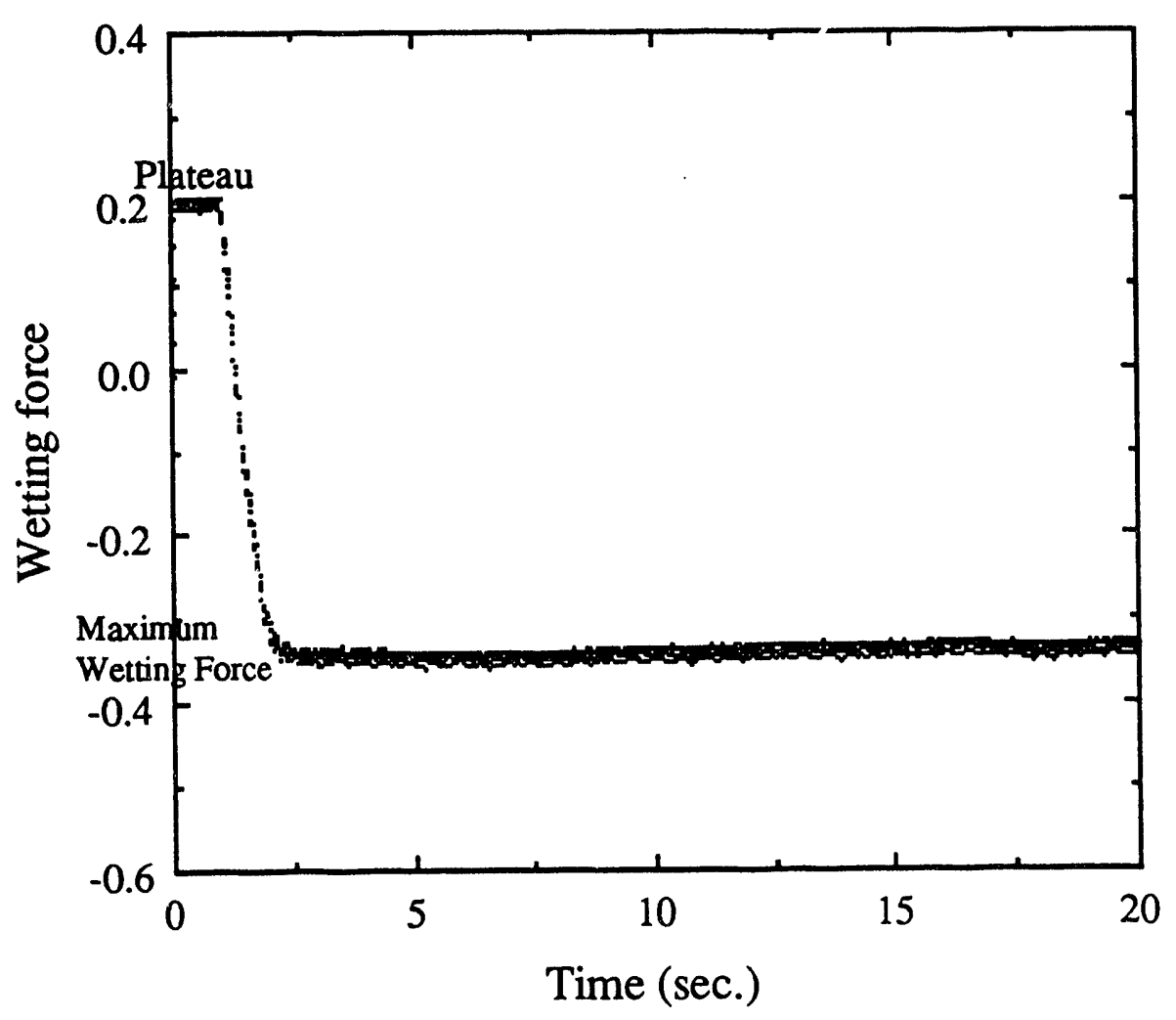

Figure 2.5. Wetting balance curve showing good wetting characteristics. The maximum wetting force can be measured as indicated. The plateau near the beginning of the test is related to the heat transfer of the coupon. 


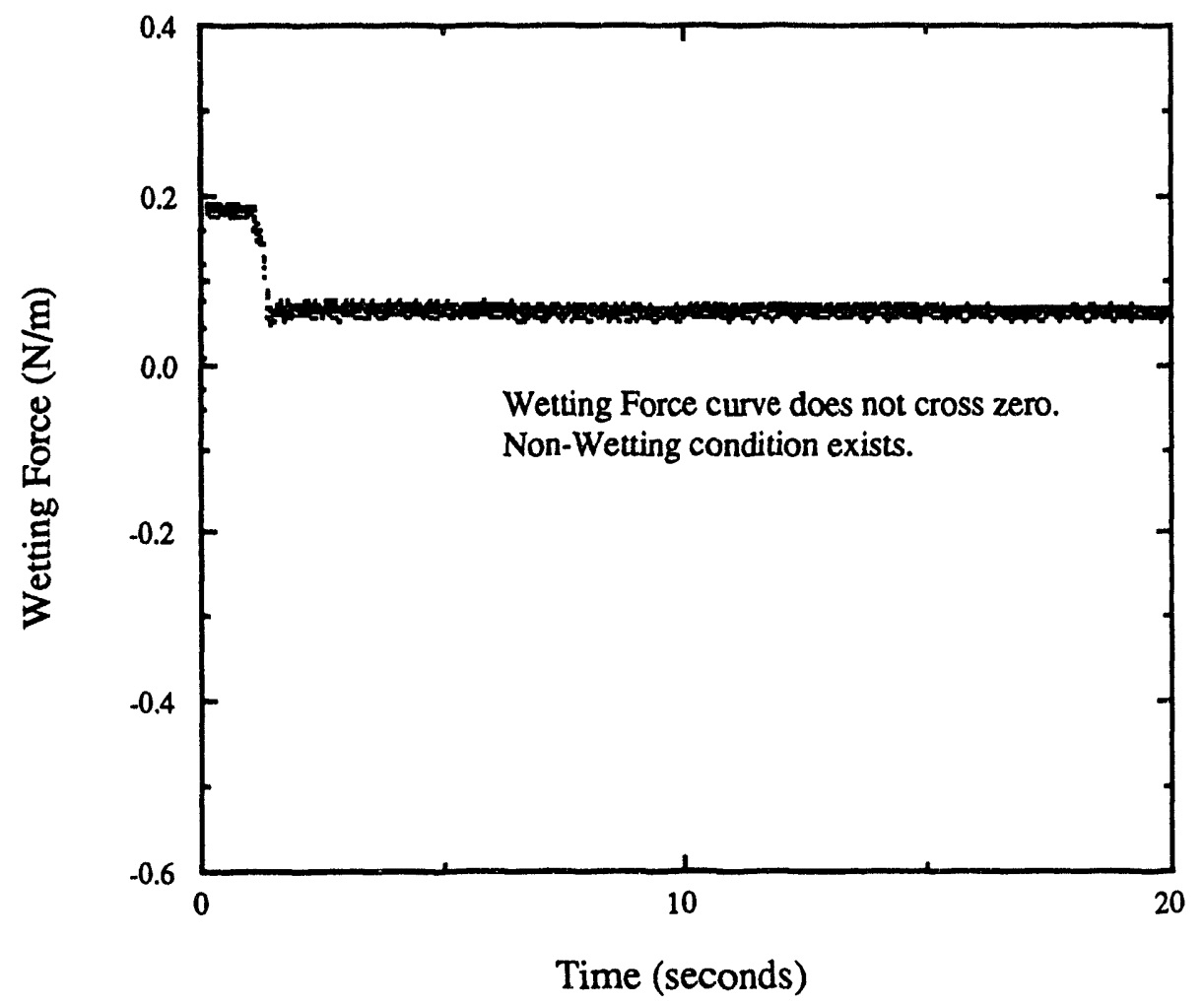

Figure 2.6. Wetting balance curve showing non-wetting characteristics. 


\subsection{Cu-Sn Intermetallic Phases}

As discussed above in Section 2.1, a chemical reaction between the substrate. material and the liquid solder will clange the free energy of the system. [4] The solder alloys used in this study contain $\mathrm{Sn}$ and $\mathrm{Pb}$. Figure 2.7 shows the binary alloy phase diagram for the $\mathrm{Sn}-\mathrm{Pb}$ system. The $\mathrm{Sn}$ reacts with the $\mathrm{Cu}$ substrate to form $\mathrm{Cu}-\mathrm{Sn}$ intermetallics. Lead forms no known intermetallics with $\mathrm{Cu}$ [7] and has a very low solubility. The Cu-Sn binary phase diagram can be useful in the interpretation of the intermetallic phase formation at the $\mathrm{Cu}$ substrate/ $\mathrm{Sn}-\mathrm{Pb}$ solder interface. This phase diagram is shown in Figure 2.8. The low-temperature intermetallic phases are $\mathrm{Cu}_{6} \mathrm{Sn}_{5}$ ( $\eta$-phase and $\eta^{\prime}$-phase) and $\mathrm{Cu}_{3} \mathrm{Sn}(\varepsilon$-phase). The crystallography of these phases has been recently reviewed by Sunwoo [7]. "The $\eta$-phase $\left(\mathrm{Cu}_{6} \mathrm{Sn}_{5}\right)$ has an ordered, hexagonal structure of the NiAs type. The stacking sequence is a modified closepacked sequence of the type .ABACABAC., in which $\mathrm{Sn}$ atoms have a hexagonal, close-packed (hcp) pattern on the $\mathrm{B}$ and $\mathrm{C}$ sites, while $\mathrm{Cu}$ atoms fill the octahedral (A) interstitial sites in the close-packed array." An extra $\mathrm{Cu}$ atom occupies one tenth of the tetrahedral interstitial sites in the hexagonal $\mathrm{Sn}$ lattice in order to achieve the proper stoichiometry for the $\mathrm{Cu}_{6} \mathrm{Sn} 5$ phase. The $\eta$-phase goes through a second-order phase transition (thermodynamic mutation) to the $\eta^{\prime}$-phase at $186^{\circ} \mathrm{C}$. The $\eta^{\prime}$-phase is a long period superlattice that results from periodic antiphase shifts in the $\eta$ structure. "The $\varepsilon$ phase $\left(\mathrm{Cu}_{3} \mathrm{Sn}\right)$ is a long-period antiphase domain structure that is based on the orthorhombic $\mathrm{Cu}_{3} \mathrm{Ti}$ structure." (Cu3 $\mathrm{Ti}$ is the hexagonal analog of the face-centered cubic-based structure of $\mathrm{Cu}_{3} \mathrm{Au}$.) 


\section{FIGURES}

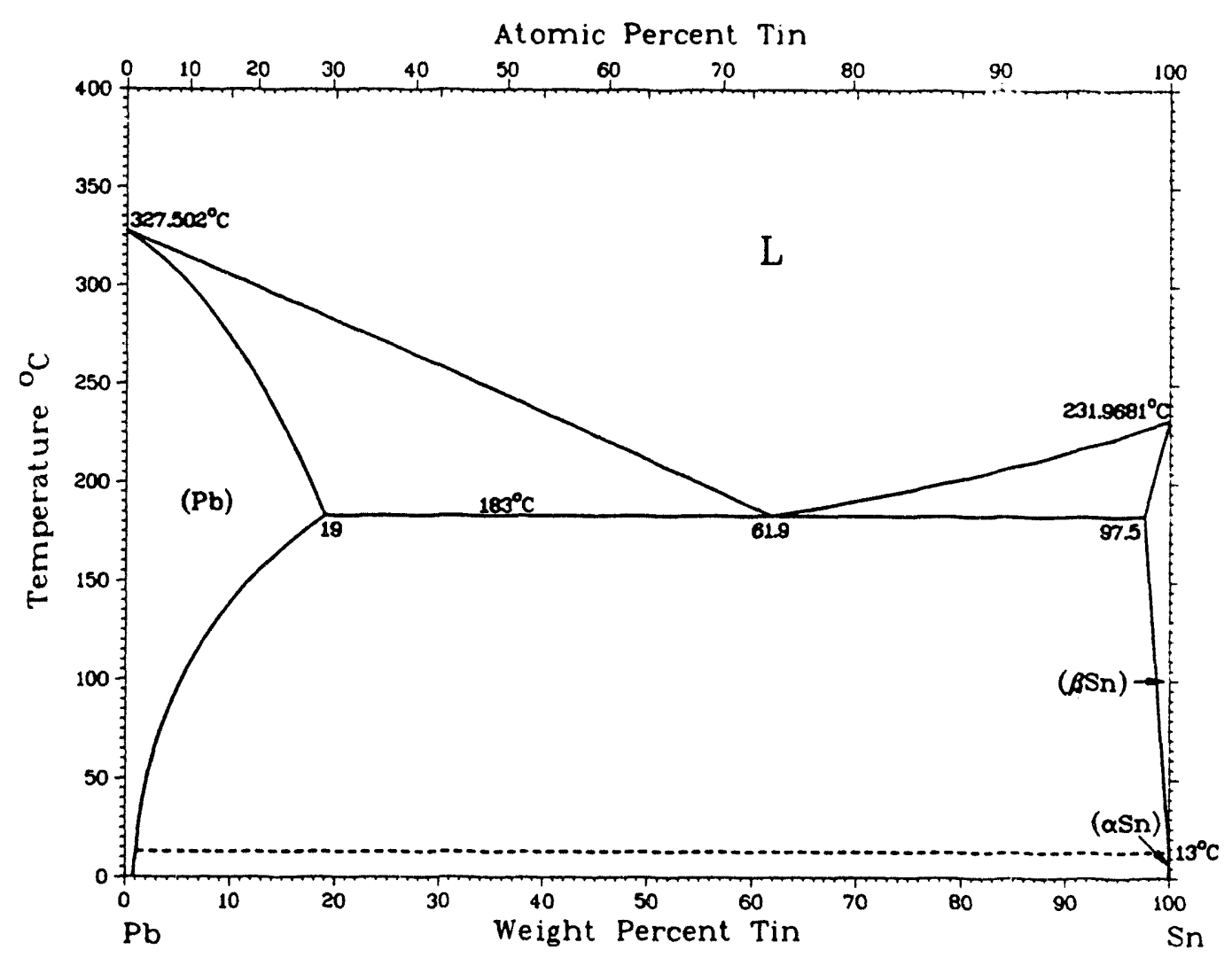

Figure 2.7. Diagram illustrating the $\mathrm{Sn}-\mathrm{Pb}$ binary system. [8] 


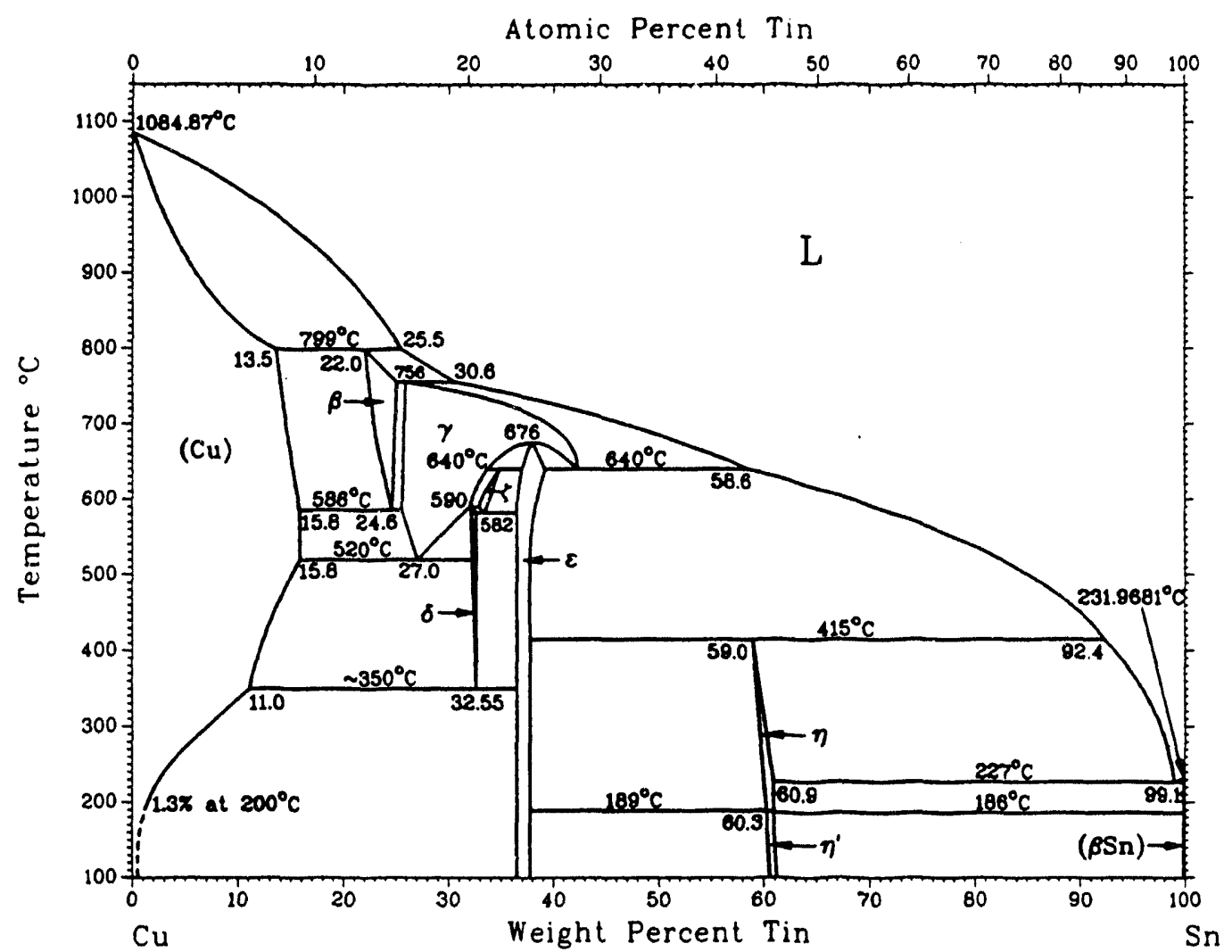

Figure 2.8. Diagram illustrating the Cu-Sn binary system. [8] 


\section{LITERATURE REVIEW}

\subsection{Accelerated Aging Methods}

Solderability testing plays an important role in quality control procedures in the electronics industry. Natural aging of electronic parts takes place due to delays between receipt, preparation and assembly of components. Accelerated aging methods have been developed in an attempt to predict the effect that natural aging has on the solderability of electronic components. The degradation of solderability is related to changes in surface characteristics via diffusion, oxidation and corrosion, and formation of intermetallic compounds. These chemical and metallurgical reactions occur at different rates for different coating and substrate materials.[9] A general aging method, therefore, does not exist which will accelerate the aging of all materials at the same rate relative to natural aging. Materials can be grouped, however, and acceptable aging methods can be found for selected groups of materials. Thwaites [10] conducted aging studies on $\mathrm{Cu}$ substrates coated with pure $\mathrm{Sn}$ and $\mathrm{Sn}-\mathrm{Pb}$ alloys. (The results of these tests will be discussed in more detail later in the Literature Review.) The results of Thwaites' study suggest that it is not possible to simulate natural storage by steam aging or by long term damp heat tests.[11] Stoneman and MacKay [9], however, investigated the decrease in solderability of $\mathrm{Sn}$ and $\mathrm{Sn}-\mathrm{Pb}$ plated wires over a 4 year natural storage period and observed similar solderability degradation patterns to those of specimens which were aged for shorter times in steam environments. In 1964, the Electronic Engineering Association (EEA) published the "EEA Guide for a Method of Measuring the Solderability of Round Wires and Component Termination Wires".[11] In preparing this guide, four accelerated aging methods were evaluated:

(1) A dry heat test; 16 hours at $155^{\circ} \mathrm{C}$

(2) A climatic test; $55^{\circ} \mathrm{C}$ and $95 \% \mathrm{RH}$ 
(3) A long term damp heat test; 21 days and 56 days at $40^{\circ} \mathrm{C}$ and $93 \% \mathrm{RH}$

(4) A steam aging test; 24 hours.

The EEA Guide recommended the dry heat test at $155^{\circ} \mathrm{C}$ for 16 hours as an accelerated aging procedure. Work by Leonhard Ochs[9] showed that the degradation in solderability which begins during and after 3 years natural storage can be approximated by only 4 hours in a dry environment at $155^{\circ} \mathrm{C}$. Humidity, however, can strongly influence the effects of aging as was demonstrated by Fidos and Piekarski who reported a significant increase in the oxidation rate of $\mathrm{Sn}$ coated wires at $98 \% \mathrm{RH}$ compared to the rate in dry air.[11] The Institute for Interconnecting and Packaging Electronic Circuits (IPC) formed a task force in 1979 to study and review existing methods of accelerated aging fo: the purposes of solderability testing.[9] Based on their study, which was published in 1983, the IPC Task Force recommended the following accelerated aging method for $\mathrm{Sn}$ and $\mathrm{Sn}-\mathrm{Pb}$ alloy coatings on $\mathrm{Cu}$ substrates as a simulation of one year natural storage: Components should be steam aged for 20 to 24 hours in a saturated steam zone above vigorously boiling-distilled water held to within $6^{\circ} \mathrm{C}$ of the local boiling point. The amount of oxygen present in the steam appears to significantly influence the rate of solderability degradation.[11] As can be seen from the varied test results and conclusions drawn from the investigations listed above, there is not a standard accelerated aging method which corresponds directly to natural aging.

\subsection{Previous Aging Studies}

\subsubsection{Intermetallic Formation and Growth}

A study of the growth of intermetallic compounds on various substrate materials coated with $\mathrm{Sn}$ and $\mathrm{Sn}-\mathrm{Pb}$ alloys for aging temperatures ranging from $20^{\circ} \mathrm{C}$ to $170^{\circ} \mathrm{C}$ was published by Kay and MacKay in 1976[12]. Both cold-worked $\mathrm{Cu}$ and annealed $\mathrm{Cu}$ were used as substrate materials coated with $\mathrm{Sn}-\mathrm{Pb}$ solders with compositions of $\mathrm{Sn}$ ranging from $10 \%$ to $60 \%$ by weight. The resulting intermetallic layer was observed to 
be duplex in nature with $\mathrm{Cu}_{3} \mathrm{Sn}$ in contact with the $\mathrm{Cu}$ substrate and $\mathrm{Cu}_{6} \mathrm{Sn}_{5}$ in contact with the remaining solder layer. $\mathrm{Cu}_{3} \mathrm{Sn}$ is only produced by solid-state diffusion at the interface between $\mathrm{Cu}$ and $\mathrm{Cu}_{6} \mathrm{Sn}_{5}$. This same sequence of intermetallic formation is noted in subsequent references $[7,13,14,15]$. Curves showing the growth rate of the duplex intermetallic layer were determined experimentally for storage times greater than 4 years [12]. The influence of the substrate material condition on the intermetallic growth rate was more significant at lower storage temperatures. At $20^{\circ} \mathrm{C}$ the intermetallic growth rate was faster on the cold-worked $\mathrm{Cu}$ substrate than on the annealed $\mathrm{Cu}$ substrate. At higher storage temperatures, (i.e. $170^{\circ} \mathrm{C}$ ) the intermetallic growth rates on the two substrate materials were similar. After the initial intermetallic layer had been established, growth of the intermetallics seemed to be the same for the as-electroplated and reflowed $\mathrm{Sn}$ and $\mathrm{Sn}-\mathrm{Pb}$ coatings.[14]

According to Ohriner[15], the thickness of the intermetallic layer is proportional to the square root of the exposure time. "The growth of the intermetallic layer follows parabolic kinetics and depends on the base metal composition, solder composition, and exposure temperature."

Yiyu, et. al [16] reports that the $\mathrm{Pb}$ content of the pretinned coating can either increase or decrease the $\mathrm{Cu}-\mathrm{Sn}$ intermetallic growth rate depending on the aging temperature. At low temperature and high $\mathrm{Pb}$ content, the intermetallic growth rate will be faster than at high temperature and low $\mathrm{Pb}$ content.

\subsubsection{Effects of Solder Thickness}

In 1959, Thwaites [10] compared the solderability of pure $\mathrm{Sn}$ ard $50 \mathrm{Sn}-50 \mathrm{~Pb}$ alloy electroplated coatings on $\mathrm{Cu}$ substrates. Solderability was measured prior to aging and after the samples had been aged at $25^{\circ} \mathrm{C}$ and $50^{\circ} \mathrm{C}$ for up to two years. The solderability was measured using area-of-spread tests. Initial solderability was "excellent" and the 
retention of solderability after aging was "excellent" as long as the coating thickness was a minimum of $8 \mu \mathrm{m}$.

Davis, Warwick, and Kay [13] reported that the solderability of $\mathrm{Cu}$ electroplated with $\mathrm{Sn}-\mathrm{Pb}$ solder and then aged, decreased significantly when the total intermetallic layer reaches a thickness of 2 to $4 \mu \mathrm{m}$. According to this 1982 study, the "thickness of the unreacted coating has a less pronounced effect on solderability". A similar report [14] which studied the effects of aging on the solderability of $\mathrm{Cu}$ substrates with reflowed $\mathrm{Sn}-\mathrm{Pb}$ coatings suggests a greater significance of the amount of unreact! 1 coating on the solderability. Contrasting with the earlier report, this 1983 study suggests that the unreacted solder thicknesses plays an important role in the solderability of aged samples. The role of solder thickness is related to the development of intermerallic compounds. In order to preserve solderabilty in the most severe thermal aging environments, a minimum pretinned thickness of $8-10 \mu \mathrm{m}$ is required.

Military specifications have required that circuit boards have a minimum solder coating thickness of $0.3 \mathrm{mil}(7.62 \mu \mathrm{m})$ in specifications such as MIL P-55110C, MILSTD-2750, MIL-F-14072B, and MIL-P-81728A. There has been some discussion of reducing this specification to $0.1 \mathrm{mil}(2.54 \mu \mathrm{m})$ but studies indicate that this will not provide sufficient protection against the degradation of solderability.

\subsubsection{Effects of Solder Alloy}

Bader and Baker [17] investigated the solderability of $\mathrm{Cu}$ electroplated with $\mathrm{Sn}$ and $50 \mathrm{Sn}-50 \mathrm{~Pb}$ after extended storage and found that the retention of solderability was better for the $\mathrm{Sn}-\mathrm{Pb}$ alloy plated specimen than the pure $\mathrm{Sr}$. Other references [18], however, suggest that there is a minimum $\mathrm{Sn}$ content required for thin $(<7 \mu \mathrm{m})$ pretinned coatings, in order obtain this retention of solderability. According to Hagge and Davis [18], the degradation of solderability of thin-coated parts is strongly 
influenced by low Sn content of the solder. "Since all circuit boards will have some areas with thin coatings (i.e., edges of traces, knees of plated-through-holes, etc.) an alloy range of 58 to 75 percent $\mathrm{Sn}$ is recommended to provide an additional solderability margin." Pretinned coatings of the eutectic (62Sn-38Pb) composition and near-eutectic (60Sn-40Pb) compositions of $\mathrm{Sn}-\mathrm{Pb}$ alloys, are reported to have good shelf life. Pretinned coatings of non-eutectic and particularly the $\mathrm{Pb}$-rich compositions are reported to show a significant loss of solderability after only a few months storage.[18] This position is also supported by Yiyu, et. al [16] whose work indicates that the retention of solderability decreases with deviations from the $\mathrm{Sn}-\mathrm{Pb}$ eutectic composition.

\subsubsection{Mechanisms of Solderability Degradation}

Processes related to the decrease of solderability include intermetallic formation, oxidation, corrosion, diffusion, particulate contamination, and film contamination. The formation and growth of $\mathrm{Cu}-\mathrm{Sn}$ intermetallics play a significant role in the decrease in solderability.[18] Growth of the intermetallic compound layer consumes Sn atoms from the pretinned solder layer which decreases the thickness of the unreacted layer and reduces the alloy content.

There are several proposed mechanisms for the decrease in solderability of a pretinned layer as a function of aging. The first proposed mechanism is that intermetallics grow through the $\mathrm{Sn}-\mathrm{Pb}$ solder layer and are exposed to oxidizing environments. According to Boettinger, Handwerker, and Kattner[19], Klein-Wassnik reports a strong increase in wetting times when the intermetallic surface is covered with as little as $1.5 \mathrm{~nm}$ of oxide. Klein-Wassnik is further quoted to say that the wettability is reduced "to a level unacceptable in practice." Kay and MacKay[12] report that when an active flux is used, both $\mathrm{Cu}_{6} \mathrm{Sn}_{5}$ and $\mathrm{Cu}_{3} \mathrm{Sn}$ are "readily wetted". No supportive data are included. Boettinger, Handwerker, and Smith [20] investigated the wetting 
characteristics of single phase $\mathrm{Cu}_{6} \mathrm{Sn}_{5}$ and $\mathrm{Cu}_{3} \mathrm{Sn}$ specimens which were prepared by hot isostatic pressure (HIP) consolidation of atomized powder. Near eutectic (60Sn$40 \mathrm{~Pb})$ solder was used for the area-of-spread wettability testing. The wetting behavior of $\mathrm{Cu}_{6} \mathrm{Sn} 5$ and $\mathrm{Cu}_{3} \mathrm{Sn}$ was much worse than the wetting behavior of pure $\mathrm{Cu}$. The wetting characteristics of the intermetallics were strongly influenced by the activity of the flux used. When using the same flux, the wettability of $\mathrm{Cu}_{6} \mathrm{Sn}_{5}$ and $\mathrm{Cu}_{3} \mathrm{Sn}$ was similar with $\mathrm{Cu}_{6} \mathrm{Sn}_{5}$ demonstrating slightly poorer wetting characteristics. Area-ofspread measurements and contact angles were given. The oxidation of intermetallic phases may also play a role in the phenomenon of dewetting by acting as non-wettable spots on a wettable surface.

The second proposed mechanism for solderability degradation is supported by Geist and Kottke [21] who conclude that the primary cause of solder ability degradation is an internal mechanism. The Geist and Kottke study consists of OFHC Cu coupons which were pretinned with $\mathrm{Sn}$ or $\mathrm{Sn}-\mathrm{Pb}$ solders and aged at $85^{\circ} \mathrm{C}$ in $85 \% \mathrm{RH}$ for 100 days and at $190^{\circ} \mathrm{C}$ in an air environment for 10 hours. Samples were pretinned with one of the following three coatings: 1)Pure Sn, hot-dipped at $300^{\circ} \mathrm{C}, 2$ ) Pure Sn, electroplated with a $10 \mu \mathrm{m}$ nominal coating, or 3$)$ Near-eutectic $(60 \mathrm{Sn}-40 \mathrm{~Pb})$, hot-dipped at $300^{\circ} \mathrm{C}$. Solderability was measured using an edge dip method. Prior to solderability testing, some of the aged samples were ion-milled in order to remove the surface oxides. The effect of the surface oxide on the solderability of the aged specimens was determined by the difference in solderability of the milled and unmilled samples. The solderability degradation due to an internal mechanism was determined by the difference between the unaged and ion-milled aged samples. According to Geist and Kottke, this internal mechanism could consist of either or both of the following: 1) internal oxidation of the intermetallic phases, and/or modification of the fusible solder coating below the depth studied with Auger profiling. The Geist and Kottke study did not differentiate between the two interior mechanisms although the summary states that the "likely 
degradation mechanism is oxidation at the internal surfaces, the intermetallic interfaces."[21] The present study found no evidence of internal oxidation as indicated by the Results and Discussion included in Section 5 .

\subsection{Oxidation of $\mathrm{Cu}-\mathrm{Sn}$ Intermetallic Compounds}

A sequential electrochemical reduction analysis (SERA) technique has been used to investigate oxide formation on $\mathrm{Cu}-\mathrm{Sn}$ intermetallics.[22-25] Electrochemical reduction of $\mathrm{Cu}_{3} \mathrm{Sn}$ was performed by Tench et al. [22] in an argon-saturated borate buffer. A constant current was applied and the electrode $(\mathrm{Pt})$ potential versus a reference electrode (saturated calomel electrode or SCE) was recorded as a function of time. The reduced surface was stable in the deaereated solution. The reduced surface was then exposed to air for 5 seconds and an overnight period of time. These exposed surfaces were electrochemically reduced again in order to determine the nature of the oxide layer which had formed. The potential curve showed a plateau at a voltage of approximately $-0.9 \mathrm{~V}$ which $\mathrm{r}$.s similar to a voltage observed previously for the reduction of $\mathrm{SnO}$. The thickness of the oxide layer was determined by the amount of charge passed. After a 5 second air exposure, the oxide was approximately 5 monolayers in thickness. Overnight air exposure produced an oxide layer which was greater than 10 monolayers in thickness. According to Tench et al. [23], oxides formed on $\mathrm{Cu}-\mathrm{Sn}$ intermetallics consist of "intimate" mixtures of $\mathrm{Cu}$ and $\mathrm{Sn}$ oxide species and often produce SERA curves which are distorted. SERA was developed primarily as a solderability test method rather than as a technique for quantitative analysis of surface oxides. SERA has been successfully used as a, non-destructive, solderability test method for production printed wiring boards.[24]

Bertocci et al. [26] used voltammetry, impedance spectroscopy, and chronocoulometry techniques to investigate the oxide layers formed by electrochemical and thermal oxidation of $\mathrm{Cu}_{6} \mathrm{Sn}_{5}$ and $\mathrm{Cu}_{3} \mathrm{Sn}$. Auger electron spectroscopy (AES) and 
X-ray photoelectron spectroscopy (XPS) were also used to study the thickness, composition, and structure of oxides on $\mathrm{Cu}_{6} \mathrm{Sn} 5$. The results obtained from electrochemical measurement and surface analysis techniques are in agreement that the oxides formed are only a few monolayers in thickness. According to this study, oxidation of the $\mathrm{Cu}-\mathrm{Sn}$ intermetallics in an air environment at $200^{\circ} \mathrm{C}$ for 20 minutes produced oxide layers of approximately 3-6 monolayers. The formation of $\mathrm{SnO}, \mathrm{Sn}_{2} \mathrm{O}$, $\mathrm{CuO}$, and $\mathrm{Cu}_{2} \mathrm{O}$ was observed within the oxide layer during electrochemical oxidation of $\mathrm{Cu}_{6} \mathrm{Sn}_{5}$ and $\mathrm{Cu}_{3} \mathrm{Sn}$. XPS results indicated the presence of both $\mathrm{SnO} / \mathrm{SnO}_{2}$ and $\mathrm{CuO}$ on the surface of $\mathrm{Cu}_{6} \mathrm{Sn} 5$. The $\mathrm{SnO}$ oxide, however, could not be distinguished from the $\mathrm{SnO}_{2}$ oxide, nor could elemental $\mathrm{Cu}$ be distinguished from $\mathrm{Cu}_{2} \mathrm{O}$ using XPS to analyze the $\mathrm{Cu}_{6} \mathrm{Sn} 5$ surface. Ion sputtering studies of the oxidized $\mathrm{Cu}_{6} \mathrm{Sn}_{5}$ revealed both $\mathrm{Cu}$ and $\mathrm{Sn}$ at the surface, "with $\mathrm{Sn}$ enrichment seen at the oxide/intermetallic interface."[26] Bertocci et al. did not conduct AES analysis, XPS analysis, or ion sputtering studies on $\mathrm{Cu}_{3} \mathrm{Sn}$. 


\section{EXPERIMENTAL PROCEDURES}

\subsection{General Procedures}

$\mathrm{Cu}$ was chosen as the substrate material because it is commonly used in industry. Oxygen-free, high conductivity (OFHC) $\mathrm{Cu}$ was used. $\mathrm{Cu}$ sheet of 30 mil thickness was cut into coupons which were 1 " $x$ 0.75 " in dimension. The coupons were ground on successively finer silicon carbide paper down to 600 grit and etched with a $50 \%$ $\mathrm{HNO}_{3}$ solution. Specimens were pretinned with electroplated and hot-dipped coatings of varying compositions of $\mathrm{Sn}-\mathrm{Pb}$ solders. As mentioned earlier, the $\mathrm{Sn}-\mathrm{Pb}$ eutectic composition is $63 \mathrm{Sn}-37 \mathrm{~Pb}$ by weight. This eutectic composition is typically used in industry for pretinning. The current study took an academic approach and investigated the aging effects using $\mathrm{Sn}$-rich and $\mathrm{Pb}$-rich off-eutectic coatings. Three sets of coupons were prepared: 1) Sn-rich electroplated, 2) $\mathrm{Pb}$-rich electroplated, and 3) $\mathrm{Pb}$-rich hotdipped. Electroplating procedures and guidelines written by M\&T Chemicals, Inc. [27] were followed. The compositions of the electroplated coatings were measured using energy dispersive X-ray spectroscopy (EDX) and converted to weight percent. The Snrich coating was measured to be $75 \mathrm{Sn}-25 \mathrm{~Pb}$. The $\mathrm{Pb}$-rich coating was measured to be $8 \mathrm{Sn}-92 \mathrm{~Pb}$. According to a survey of manufacturers conducted by an IPC Task Group in the early 1980 's, $\mathrm{Sn}$ or $\mathrm{Sn}-\mathrm{Pb}$ coatings are typically $7.5 \mu \mathrm{m}$ thick with $2.5 \mu \mathrm{m}$ being the minimum and $50 \mu \mathrm{m}$ the maximum for hot-dipped coatings.[9] Based on these ranges, electroplating times were calculated in order to achieve three different nominal thicknesses: $3 \mu \mathrm{m}, 10 \mu \mathrm{m}$, and $30 \mu \mathrm{m}$. The hot-dipped specimens were prepared using a $5 \mathrm{Sn}-95 \mathrm{~Pb}$ (weight \%) molten solder bath at a temperature of $360^{\circ} \mathrm{C}$. The hot-dipped coatings showed thickness variations from 3-15 $\mu \mathrm{m}$.

A dry heat accelerated aging method was chosen based on the fact that the concentration level of the oxygen in the aging environments could be measured and controlled. The specimens were separated based on coating type and aging time. 
Specimens were then encapsulated in Pyrex tubes and back-filled with argon gas. A number of the $\mathrm{Sn}$-rich (75Sn-25Pb) electroplated specimens were also encapsulated in Pyrex tubes with a "normal" (laboratory) air environment. Specimens were aged at 170 ${ }^{\circ} \mathrm{C}$ for 0 hours, 2 hours, 24 hours, and 2 weeks. The Pyrex tubes were broken and all of the specimens were allowed to equilibrate in air for an hour before wetting balance testing was performed. The solder bath used for the wetting balance tests was $63 \mathrm{Sn}$ $37 \mathrm{~Pb}$ and the temperature of the molten bath was $245^{\circ} \mathrm{C}$. Additional wetting balance test parameters are listed in Table 4.1. Microstructural changes, resulting from aging, were evaluated using $\mathrm{X}$-ray diffraction, energy dispersive $\mathrm{X}$-ray spectroscopy, Auger spectroscopy, Auger depth profiling, optical microscopy, and scanning electron microscopy.

\subsection{X-ray Diffraction Analysis Set Up and Sample Preparation}

Aged samples identical to those tested using the wetting balance were analyzed using X-ray diffraction. The analysis was conducted using a $\mathrm{CuK}_{\alpha}$ source which has a wavelength $(\lambda)=1.542 \AA$. Samples were placed in a holder and molding clay was used to insure that the surface was flat. Testing conditions were such that the analysis began at an angle of $2 \theta=25^{\circ}$ and rotated through an angle of $2 \theta=80^{\circ}$. Calculations to determine the X-ray penetration depth [28] through the pretinned coating are shown in Appendix A.

\subsection{Metallographic Sample Preparation}

Samples were cross-sectioned using a diamond blade cutting wheel and mounted in epoxy. Samples were mounted so that both "wetting balance tested" areas and "nonwetting balance tested" areas could be observed. All samples were ground on successively finer silicon carbide paper down to 600 grit and then polished sequentially with $6 \mu \mathrm{m}$ and $1 \mu \mathrm{m}$ diamond paste and oil on nylon polishing pads. Polishing of the 
solder coated copper coupons presented a problem due to the difference in hardness of the coating and the substrate. When a manual polishing method was used, the solder had a tendency to be polished away at a faster rate, creating a "scooped" or "dished" effect at the interface. In order to obtain a flat interface, the polishing steps were performed using a vibrating table. Each mounted sample was placed in an individual holder and allowed to rotate in a "bumper car" fashion on the polishing pad for a period of 2-4 hours depending on the particular sample. This method of polishing helped to improve the edge retention and create a flat interface between the $\mathrm{Cu}$ substrate, the intermetallic phases, and the remaining solder.

\subsection{Scanning Electron Microscopy Sample Preparation}

Scanning electron microscopy (SEM) images were made using the back-scatter electron detector. All SEM samples were sputter coated with carbon before observations were made. An accelerating voltage of $15 \mathrm{kV}$ was used. 


\section{TABLE 4.1}

\section{TABLE 4.1}

\section{WETTING BALANCE TEST PARAMETERS}

PARAMETER

Immersion Time

Immersion Depth

Immersion Speed

Specimen Width
VALUE

20 seconds

$4 \mathrm{~mm}$

$25 \mathrm{~mm} / \mathrm{sec}$

$25.4 \mathrm{~mm}$ 


\section{RESULTS and DISCUSSION}

\subsection{Sn-Rich (75Sn-25Pb) Electroplated Samples}

\subsubsection{Wetting Balance Test Results}

The Sn-rich, electroplated samples were aged at $170^{\circ} \mathrm{C}$ in both air and argon environments. The maximum wetting force $(\mathrm{N} / \mathrm{m})$ and time to $90 \%$ of the maximum wetting force (seconds) were obtained from the wetting balance curves. The maximum wetting force is plotted against coating thickness and aging time for the specimens aged in argon and air in Figures 5.1 and 5.2, respectively. (The maximum wetting force is positive because it is an absolute value.) The $3 \mu \mathrm{m}$ specimen aged for 2 weeks in air did not wet during the length of the wetting balance test, therefore, no maximum wetting force could be recorded. No significant trends are observed with regard to the maximum wetting force for either aging environment.

There is some ambiguity in determining the time to maximum wetting force due to the shape of the curve. The time to $90 \%$ of the maximum wetting force, therefore, was chosen as the comparison value. In support of this choice, military standards (MIISTD-883C [6]) use a minimum time (1 second or less) to a reach two-thirds of the maximum wetting force as a criterion for acceptable solderability. A number of the wetting balance curves show a plateau as indicated in Figure 2.5. This plateau in the wetting force vs. ime curve, is related to heat transfer in the coated sample and varies with the thickness of the specimen. Figures 5.3 and 5.4 show the total time (including plateau) to reach $90 \%$ of the maximum wetting force plotted against coating thickness and aging time for the two aging environments. Figures 5.5 and 5.6 show the net time (excluding plateau) to reach $90 \%$ of the maximum wetting force plotted against coating thickness and aging time for the two aging environments. The trends for the total time 
and net time are the same. The time to $90 \%$ of the maximum wetting force is not affected by aging time or coating thickness for specimens aged in argon. The specimens aged in air, however, show a significant increase in the time to $90 \%$ maximum wetting force as a function of aging time. Wettability decreases monotonically with aging time for the specimens aged in air. The specimen with an initial electroplated coating thickness of $3 \mu \mathrm{m}$ shows no wetting by the molten solder within the first 20 seconds of the wetting balance test. The effect of electroplated coating thickness on the wettability of the specimens aged in air is more significant for thin coatings. A more rapid decrease in wettability is observed for the specimens with a nominal coating of $3 \mu \mathrm{m}$ than is observed for the $10 \mu \mathrm{m}$ and $30 \mu \mathrm{m}$ coated specimens. Little difference is observed between the $10 \mu \mathrm{m}$ and $30 \mu \mathrm{m}$ coated specimens.

\section{5,1.2. Microstructural Changes}

Microstructural changes during aging must be investigated to more clearly understand effects of the coating thickness on the wetting characteristics.

\subsubsection{X-ray Diffraction Analysis}

Results of the X-ray diffraction (XRD) analysis are shown in Table 5.1. The argon aged samples analyzed by $\mathrm{X}$-ray diffraction were identical to the samples tested with the wetting balance, but had not been exposed to the excess solder from the wetting balance. All of the air aged samples, however, were exposed to the wetting balance test. The presence of excess solder on the surface of these samples made X-ray diffraction analysis difficult. Samples which were not analyzed using X-ray diffraction analysis are indicated. Analysis of the specimens coated with 10 and $30 \mu \mathrm{m}$ nominal thicknesses provided limited information since the remaining coating thickness was greater than or equal to the $X$-ray penetration depth. Analysis of the $3 \mu \mathrm{m}$ coated specimen showed the presence of $\mathrm{Cu}_{6} \mathrm{Sn}_{5}$ at 2 hours aging time. The $3 \mu \mathrm{m}$ specimens aged in air and argon showed the presence of $\mathrm{Cu}_{6} \mathrm{Sn}_{5}$ and $\mathrm{Cu}_{3} \mathrm{Sn}$ after 24 hours at 
$170^{\circ} \mathrm{C}$. It is significant to note that, according to the XRD analysis, for the $3 \mu \mathrm{m}$ specimens, the $\mathrm{Sn}$ in the pretinned solder coating is completely consumed by the $\mathrm{Cu}-\mathrm{Sn}$ intermetallic phases after 24 hours in both aging environments. After 2 weeks aging, the $\mathrm{Cu}_{6} \mathrm{Sn} 5$ appears to be completely transformed to $\mathrm{Cu}_{3} \mathrm{Sn}$.

The $\mathrm{Cu}_{6} \mathrm{Sn}_{5}$ phase which forms at the interface is $\eta^{\prime}$-phase rather than $\eta$-phase. The electroplating processes is performed at approximately room temperature and the aging temperature is $170^{\circ} \mathrm{C}$. Both of these temperatures are below the second-order phase transformation temperature $\left(186^{\circ} \mathrm{C}\right)$ for the $\eta / \eta^{\prime}$ thermodynamic mutation. The significance of the form of the $\mathrm{Cu}_{6} \mathrm{Sn} 5$ intermetallic compound with regard to wetting characteristics is unclear.

\subsubsection{Microscopy and EDX Analysis}

Optical and scanning electron microscopy and EDX analysis can be used to confirm and clarify the information obtained from $\mathrm{X}$-ray diffraction analysis. Samples were prepared as described above in Section 4.3. Figure 5.7 shows optical microscopy images of the $30 \mu \mathrm{m}$ coated samples aged in air for 24 hours and 2 weeks. SEM images shown in Figure 5.8 provide a higher magnification view of this same interface. EDX spectroscopy was used to determine the composition of the intermetallic layers. Initially, $\mathrm{Cu}_{6} \mathrm{Sn}_{5}$ forms and grows at the interface between the $\mathrm{Cu}$ substrate and the $\mathrm{Sn} / \mathrm{Pb}$ solder. $\mathrm{Cu}_{6} \mathrm{Sn} 5$ transforms to $\mathrm{Cu}_{3} \mathrm{Sn}$ as $\mathrm{Cu}$ diffuses toward the interface. This transformation occurs after aging for approximately 24 hours at $170^{\circ} \mathrm{C}$. This same sequence of intermetallic phase formation occurs in the $10 \mu \mathrm{m}$ and $3 \mu \mathrm{m}$ aged specimens as well. Transformation of $\mathrm{Cu}_{6} \mathrm{Sn}_{5}$ to $\mathrm{Cu}_{3} \mathrm{Sn}$ is complete after 2 weeks aging at $170^{\circ} \mathrm{C}$ for the specimen with a $3 \mu \mathrm{m}$ coating thickness as illustrated in Figure 5.9. This complete transformation from $\mathrm{Cu}_{6} \mathrm{Sn}_{5}$ to $\mathrm{Cu}_{3} \mathrm{Sn}$ is due to the fact there is an insufficient supply of $\mathrm{Sn}$ to maintain the $\eta$ '- phase. The microstructural changes appear to be the same regardless of the aging environment. 


\subsubsection{Surface Characteristics}

SEM was also used to examine the surfaces of the aged samples. The initial $3 \mu \mathrm{m}$ electroplated surface is shown in Figure 5.10. At 0 hours aging there are no intermetallics exposed at the surface of the specimens. After 2 hours aging at $170^{\circ} \mathrm{C}$, however, the $\mathrm{Cu}_{6} \mathrm{Sn}_{5}$ intermetallic phase is exposed at the surface. Figure 5.11 shows the surfaces of samples aged for 2 weeks in argon and air. The Sn has been totally consumed in the formation of the $\mathrm{Cu}-\mathrm{Sn}$ intermetallics, as confirmed with XRD analysis. The residual $\mathrm{Pb}$ has withdrawn into irregularly shaped regions which appear as "bumps" on the surface. The underlying intermetallic phase is then exposed. The transformation of $\mathrm{Cu}_{6} \mathrm{Sn}_{5}$ to $\mathrm{Cu}_{3} \mathrm{Sn}$ is complete. The intermetallic phase exposed in Figures 5.11a and 5.11b is Cu3Sn which was determined by EDX spectroscopy. EDX was also used to analyze the composition of the irregularly shaped regions ("bumps")

on the surface. As expected, these regions contained mostly $\mathrm{Pb}$, however, a significant amount of $\mathrm{Cu}$ was also detected. Caution must be used when using EDX techniques for surface analysis. The above results were confirmed with Auger electron spectroscopy (AES) which has a depth resolution of approximately $5 \AA$ and a spatial resolution less

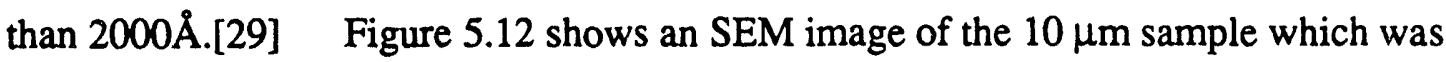
aged in air for 2 weeks. The appearance is similar to that of the $3 \mu \mathrm{m}$ samples, although the exposed intermetallic phase was determined to be $\mathrm{Cu}_{6} \mathrm{Sn} 5$, which is consistent with the observations made from the metallurgical cross-sections. Figures $5.13-5.14$ show SEM images of the $30 \mu \mathrm{m}$, air aged sample surface. The $\mathrm{Cu}_{6} \mathrm{Sn}_{5}$ is exposed at the surface. The specimens which were aged in argon show similar surface morphologies. Significant amounts of $\mathrm{Cu}$ were also observed in the $\mathrm{Pb}$-rich regions on the surface of the $10 \mu \mathrm{m}$ and $30 \mu \mathrm{m}$ samples aged in air and argon for 2 weeks.

Figures 5.15 and 5.16 show the previously included plots of the time to $90 \%$ wetting force as a function of aging time and coating thickness (identical to the plots shown in Figures 5.3 and 5.4) with the exposed intermetallic phases indicated. Different 
intermetallic phases exist, therefore, at specimen surfaces as a function of aging time and coating thickness. How does the presence of these different phases effect the solderability?

Auger electron spectroscopy (AES) and Auger depth profiling allow for a closer investigation of the surface and near surface characteristics of the specimens. These surface characteristics must be more clearly understood in order to explain the wetting behavior of the specimens. Auger depth profiling was performed with a $\mathrm{Ar}^{+}$ion beam. Figure 5.17 shows a depth profile for a $10 \mu \mathrm{m}$ Sn-rich electroplated sample which had been aged at $170^{\circ} \mathrm{C}$ in air for 2 weeks. The profile was conducted in an area where the $\mathrm{Cu}_{6} \mathrm{Sn}_{5}$ was exposed and indicates that the oxide present on the $\mathrm{Cu}_{6} \mathrm{Sn}_{5}$ surface is a $\mathrm{Sn}$ oxide. The dip in the profile at about 5 minutes sputtering time was due to an adventitious twist of the control knob during the sputtering process and chemical analysis. Figure 5.18 shows a depth profile for a $3 \mu \mathrm{m}$ Sn-rich electroplated sample which had been aged at $170^{\circ} \mathrm{C}$ in air for 2 weeks. This chemical depth profile analysis was conducted in an area where a $\mathrm{Cu}_{3} \mathrm{Sn}$ intermetallic existed underneath a $\mathrm{Pb}$-rich, irregularly shaped region. The profile indicates the presence of a $\mathrm{Cu}$ oxide on the surface of the residual $\mathrm{Pb}$ "bump". The profile further indicates that no oxide is present on the internal interface between the residual $\mathrm{Pb}$ (or remaining solder layer) and the unexposed intermetallic phase. Additional profiles conducted in the areas where $\mathrm{Cu}_{3} \mathrm{Sn}$ was exposed, indicate that the oxide present on the $\mathrm{Cu}_{3} \mathrm{Sn}$ surface is a $\mathrm{Cu}$ oxide. No evidence was found of internal oxidation of the intermetallic phases. 
TABLE 5.1

TABLE 5.1

Sn-Rich Electroplated Samples

Microstructural Phases Detected using X-ray Diffraction

$\sqrt{ }$ Denotes Phiases Detected writhin X-ray Penetration Depth

X Denotes Phase Not Detected

- Denotes Sample Not Analyzed

Aging Time (at $170^{\circ} \mathrm{C}$ )

2 hours
2 hours
2 hours
2 hours
2 hours
2 hours
2 hours
2 hours
2 hours
2 hours

24 hours

24 hours

24 hours

24 hours

24 hours

24 hours

24 hours

24 hours

24 hours

24 hours

2 weeks

2 weeks

2 weeks

2 weeks

2 weeks

2 weeks

2 weeks

2 weeks

2 weeks

2 weeks

\section{Plating Thickness}

$3 \mu \mathrm{m}$

$3 \mu \mathrm{m}$

$3 \mu \mathrm{m}$

$3 \mu \mathrm{m}$

$3 \mu \mathrm{m}$

$10 \mu \mathrm{m}$

$10 \mu \mathrm{m}$

$10 \mu \mathrm{m}$

$10 \mu \mathrm{m}$

$10 \mu \mathrm{m}$

$3 \mu \mathrm{m}$

$3 \mu \mathrm{m}$

$3 \mu \mathrm{m}$

$3 \mu \mathrm{m}$

$3 \mu \mathrm{m}$

$10 \mu \mathrm{m}$

$10 \mu \mathrm{m}$

$10 \mu \mathrm{m}$

$10 \mu \mathrm{m}$

$10 \mu \mathrm{m}$

$3 \mu \mathrm{m}$

$3 \mu \mathrm{m}$

$3 \mu \mathrm{m}$

$3 \mu \mathrm{m}$

$3 \mu \mathrm{m}$

$10 \mu \mathrm{m}$

$10 \mu \mathrm{m}$

$10 \mu \mathrm{m}$

$10 \mu \mathrm{m}$

$10 \mu \mathrm{m}$
Aging Environment

Phases

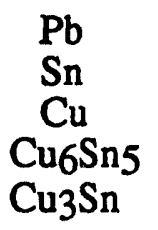

$\mathrm{Pb}$

$\mathrm{Sn}$

$\mathrm{Cu}_{6} \mathrm{Sn}_{5}$

Cu3Sn

$\begin{array}{ll}\mathrm{Pb} & \sqrt{ } \\ \mathrm{Sn} & \mathrm{X} \\ \mathrm{Cu} & \sqrt{ } \\ \mathrm{Cu} 6 \mathrm{Sn} 5 & \sqrt{ } \\ \text { Cu3Sn } & \sqrt{ }\end{array}$

$\mathrm{Pb}$
$\mathrm{Sn}$
$\mathrm{Cu}$
Cu6Sn5
Cu3Sn

$\mathrm{Pb}$
$\mathrm{Sn}$
$\mathrm{Cu}$
Cu6Sn5
Cu3Sn

$\mathrm{Pb}$
$\mathrm{Sn}$
$\mathrm{Cu}$
$\mathrm{Cu}_{6 \mathrm{Sn}} 5$
$\mathrm{Cu}_{3} \mathrm{Sn}$

$\sqrt{ }$
$X$
$\sqrt{ }$
$\sqrt{ }$

AIR

ARGON

$\sqrt{ }$
$\sqrt{ }$
$\sqrt{ }$
$x$

$\sqrt{ }$
$\sqrt{ }$
$\sqrt{x}$
$\mathrm{x}$

$\sqrt{ }$
$\sqrt{ }$
$X$
$X$
$X$ 


\section{FIGURES}

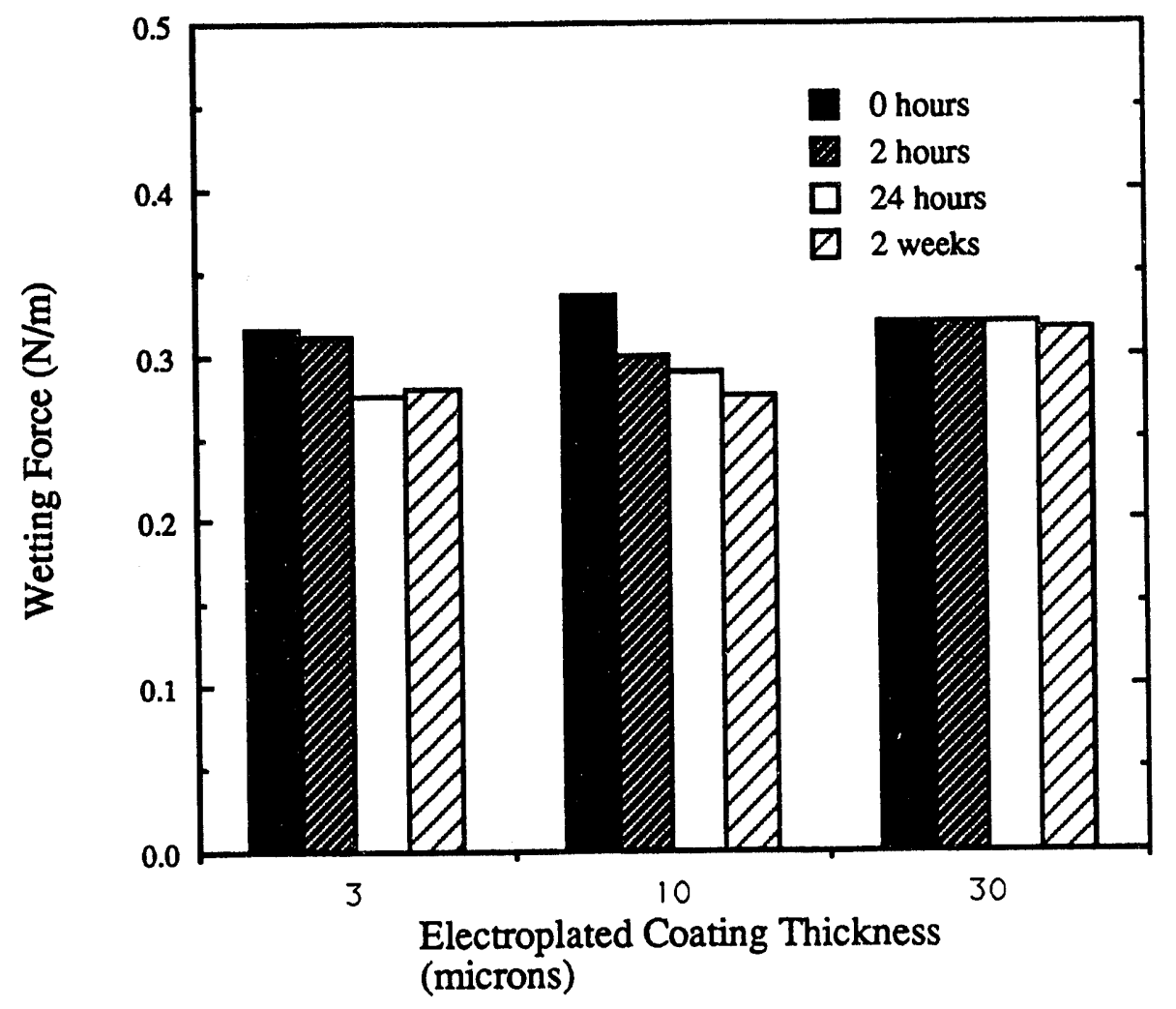

Figure 5.1. Graph showing the maximum wetting force as a function of coating thickness and aging time for the $\mathrm{Sn}$-rich (75Sn-25Pb), electroplated samples aged in argon. 


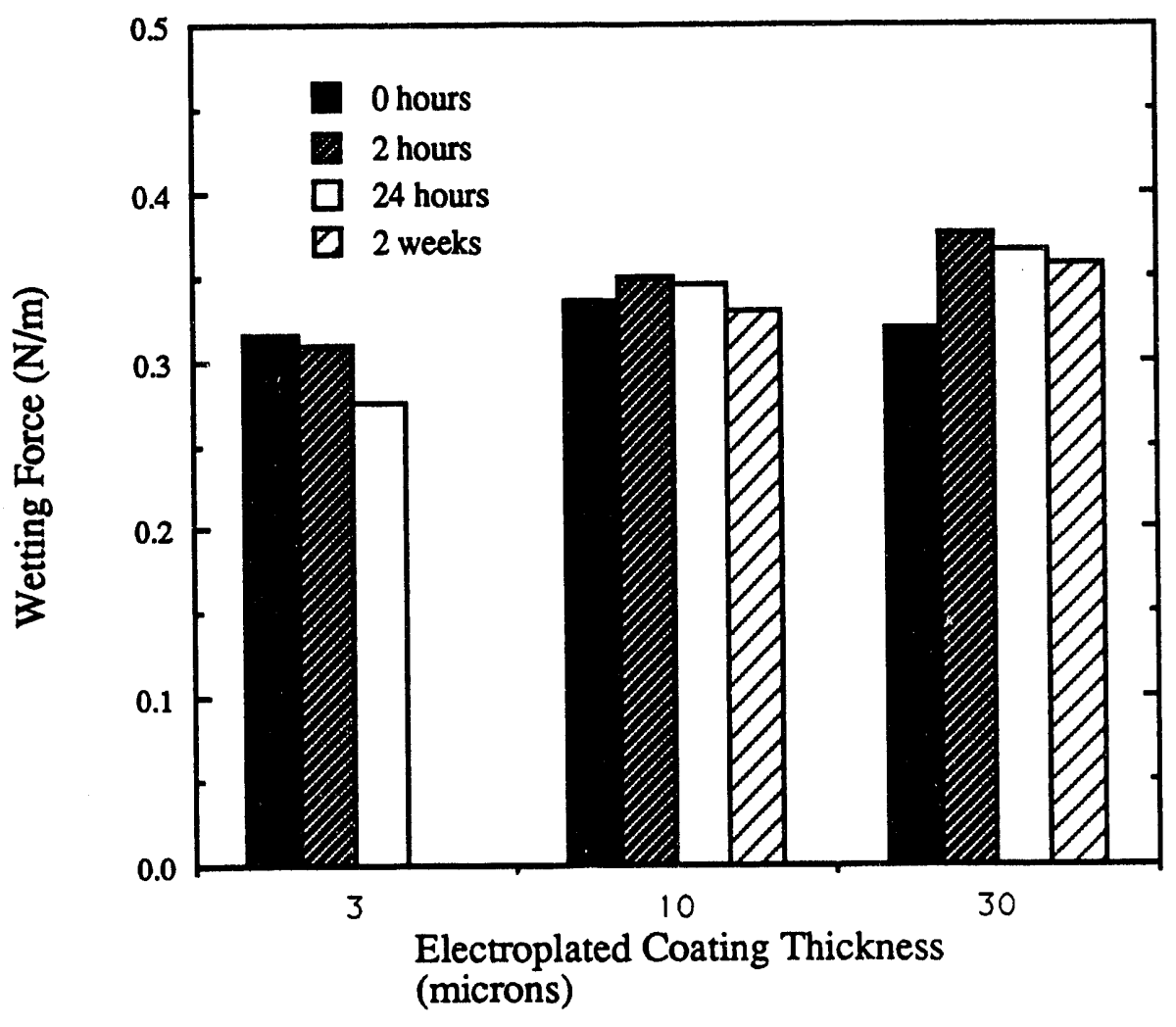

Figure 5.2 Graph showing the maximum wetting force as a function of coating thickness and aging time for the Sn-rich $(75 \mathrm{Sn}-25 \mathrm{~Pb})$, electroplated samples aged in air. 


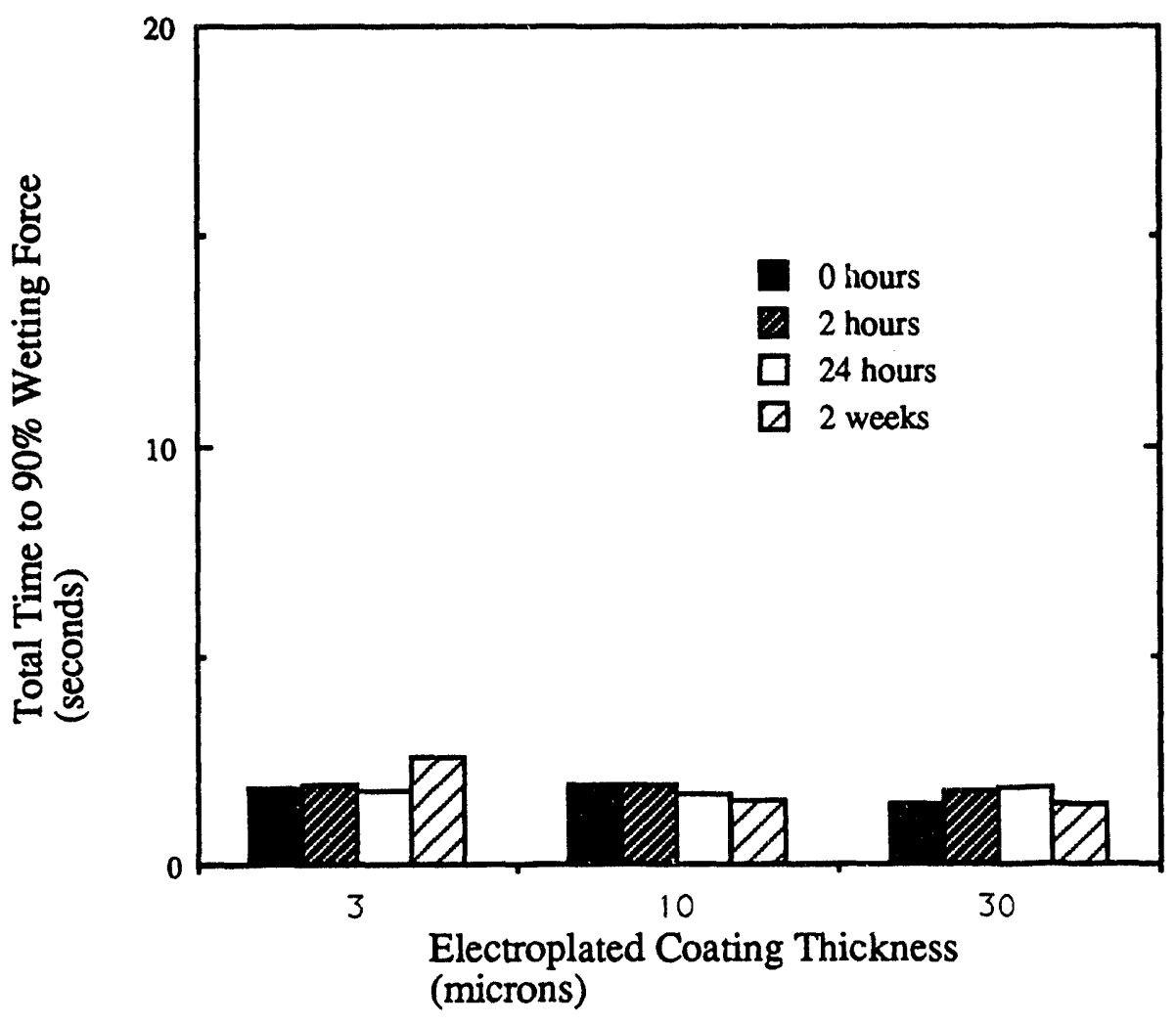

Figure 5.3. Graph showing the total time to $90 \%$ of the maximum wetting force as a function of coating thickness and aging time for the Sn-rich $(75 \mathrm{Sn}-25 \mathrm{~Pb})$, electroplated samples aged in argon. 


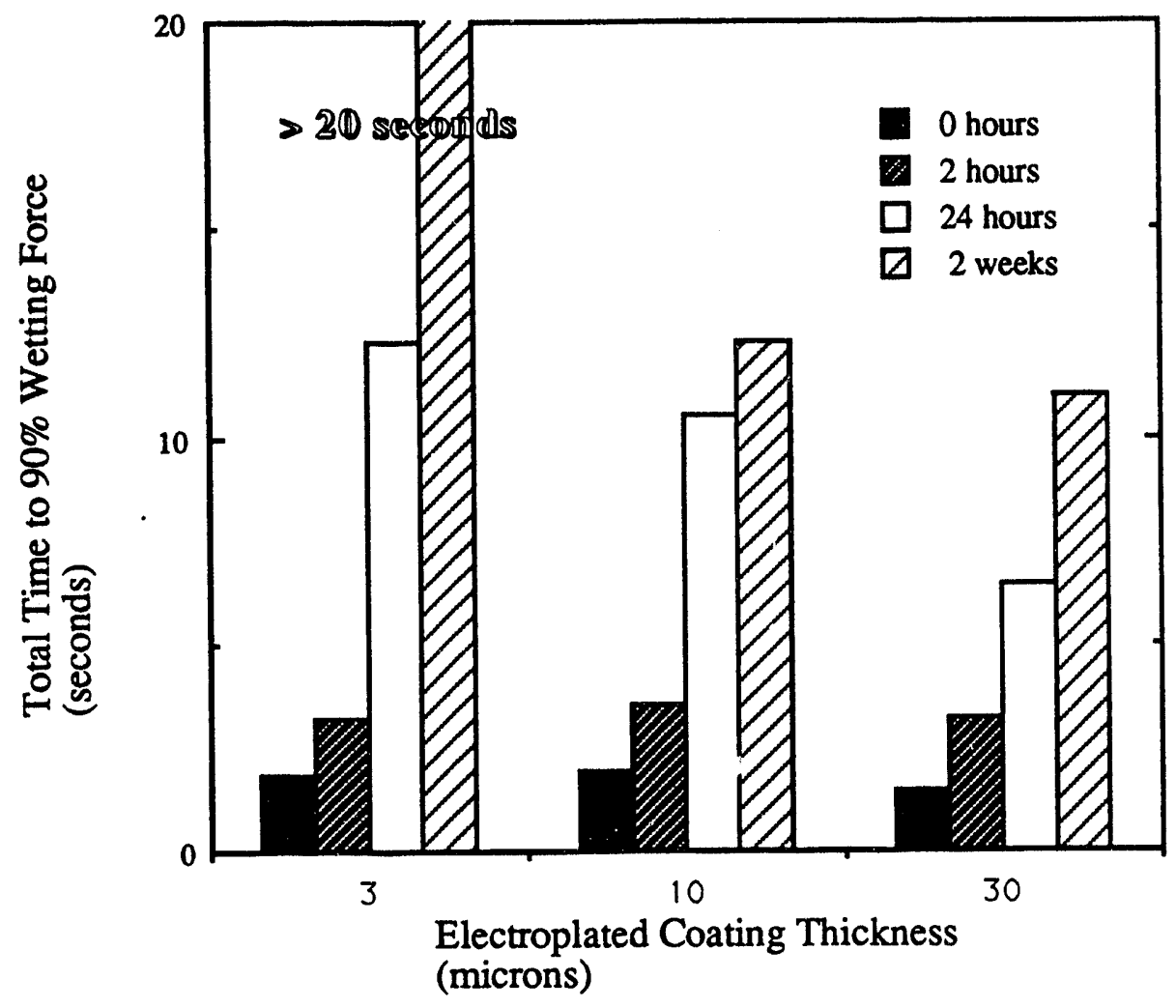

Figure 5.4. Graph showing the total time to $90 \%$ of the maximum wetting force as a function of coating thickness and aging time for the $\mathrm{Sn}$-rich (75Sn-25Pb), electroplated samples aged in air. 


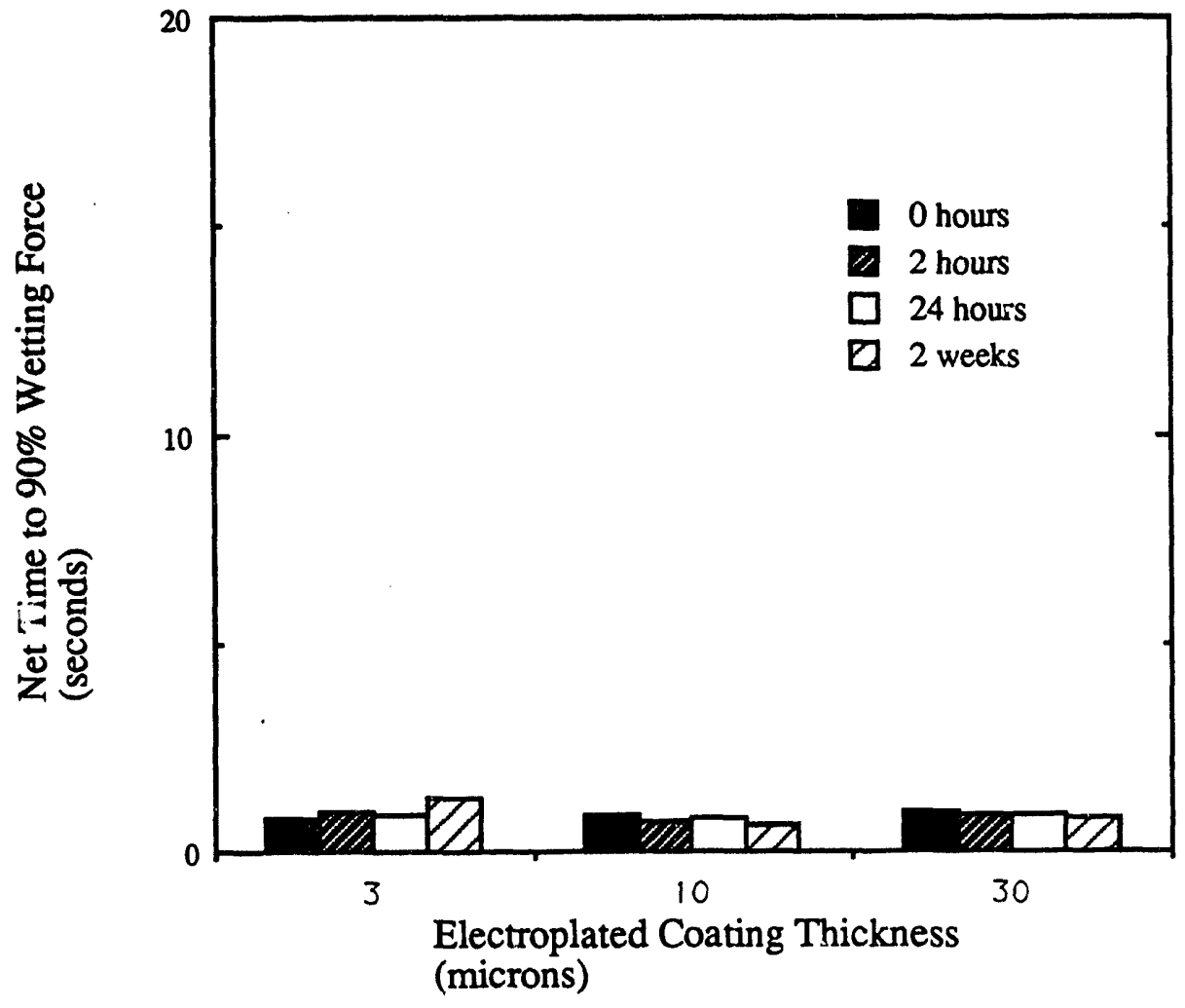

Figure 5.5. Graph showing the net (excluding plateau) time to $90 \%$ of the maximum wetting force as a function of coating thickness and aging time for the Sn-rich (75Sn-25Pb), electroplated samples aged in argon. 


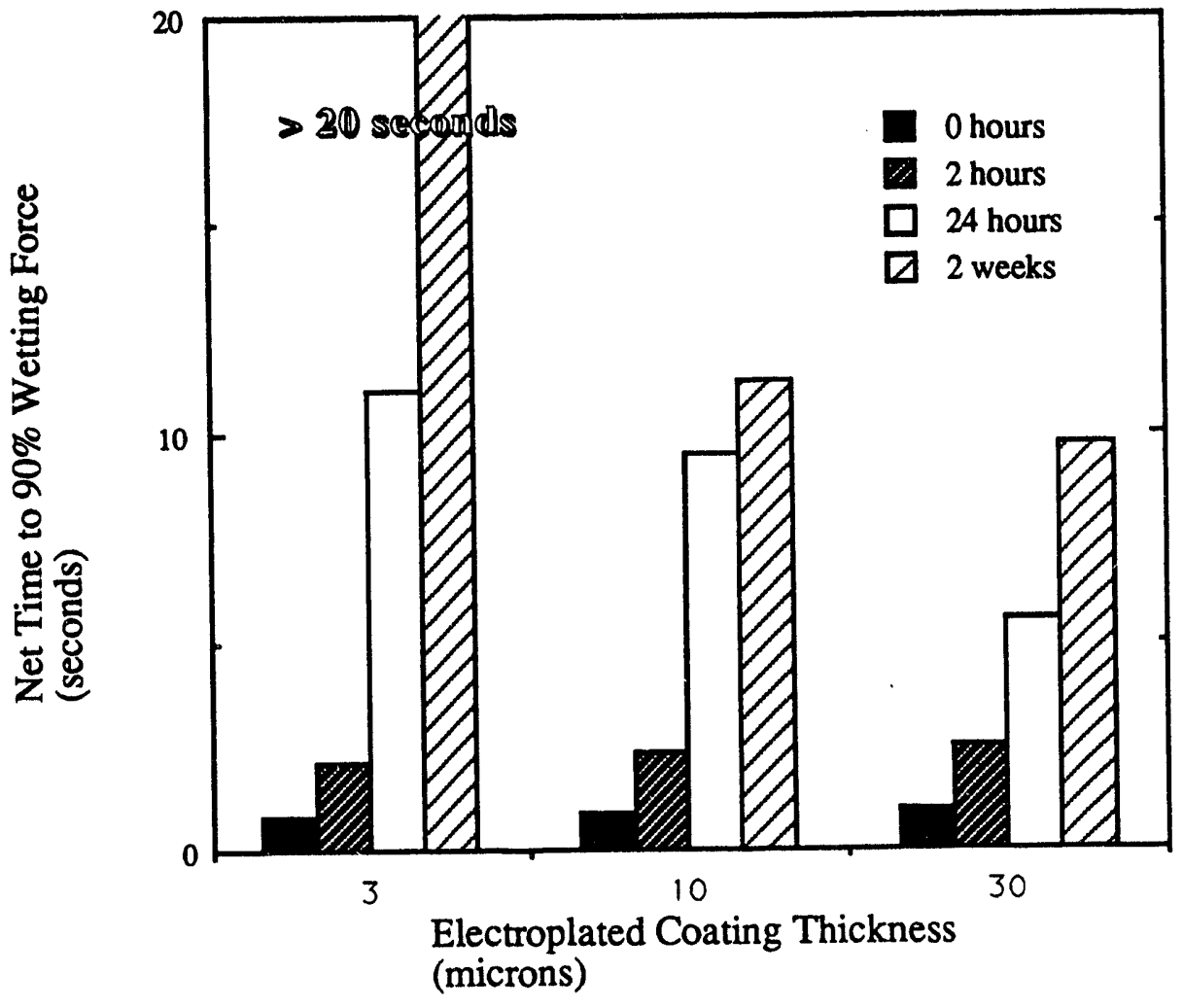

Figure 5.6. Graph showing the net (excluding plateau) time to $90 \%$ of the maximum wetting force as a function of coating thickness and aging time for the $\mathrm{Sn}$-rich $(75 \mathrm{Sn}-25 \mathrm{~Pb})$, electroplated samples aged in air. 


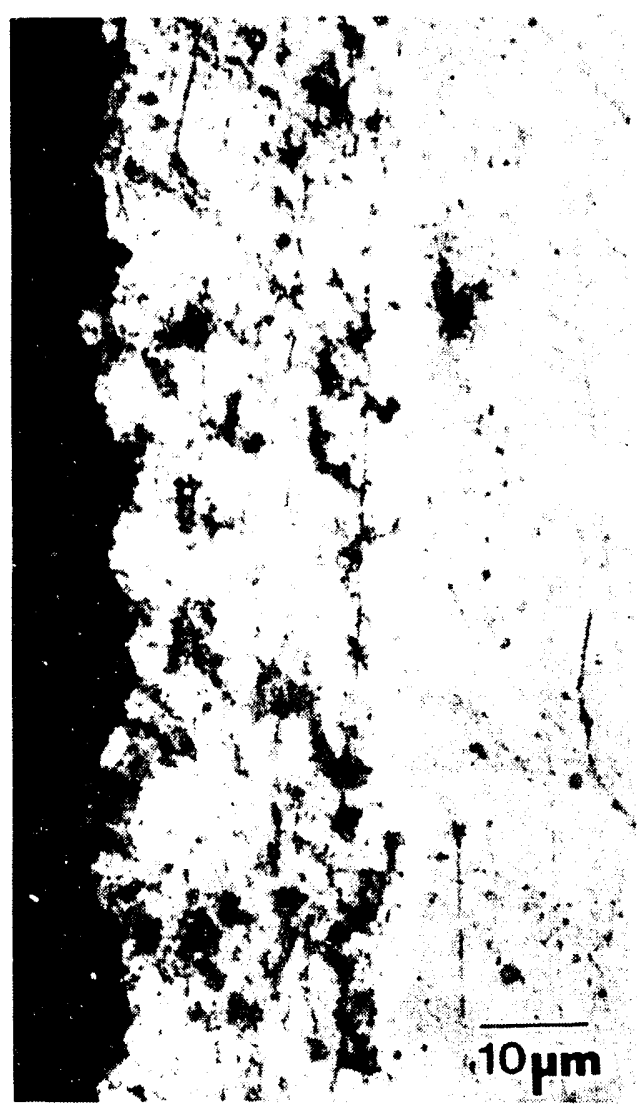

(a)

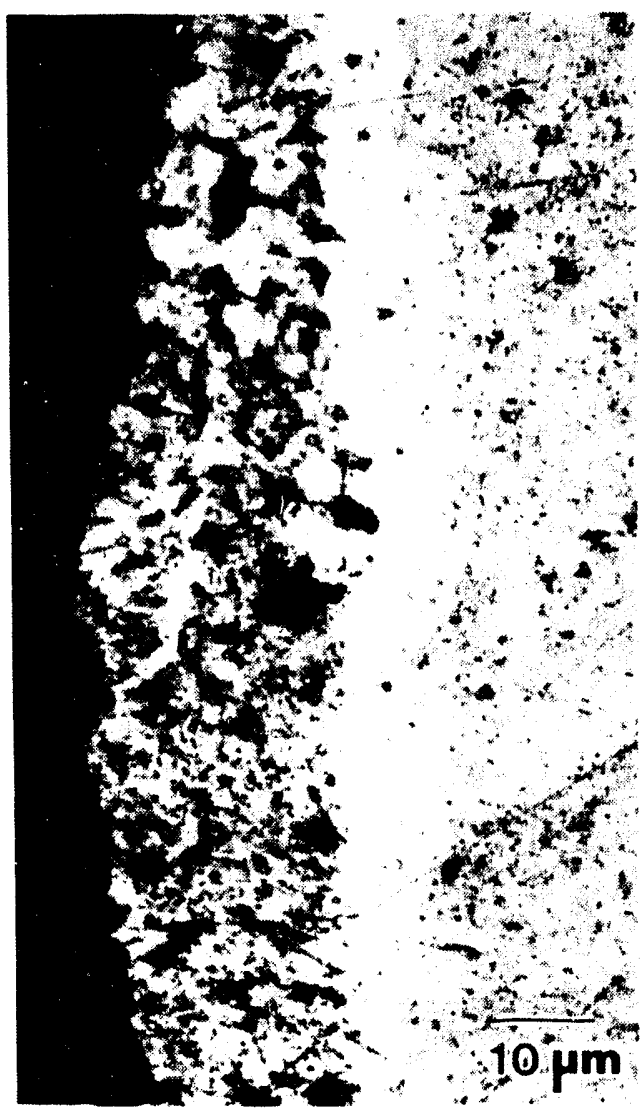

(b)

Figure 5.7. Optical micrographs of the $30 \mu \mathrm{m} \mathrm{Sn-rich} \mathrm{(75Sn-25Pb)} \mathrm{electroplated}$ specimens aged in air for a) 24 hours and b) 2 weeks at $170^{\circ} \mathrm{C}$. 


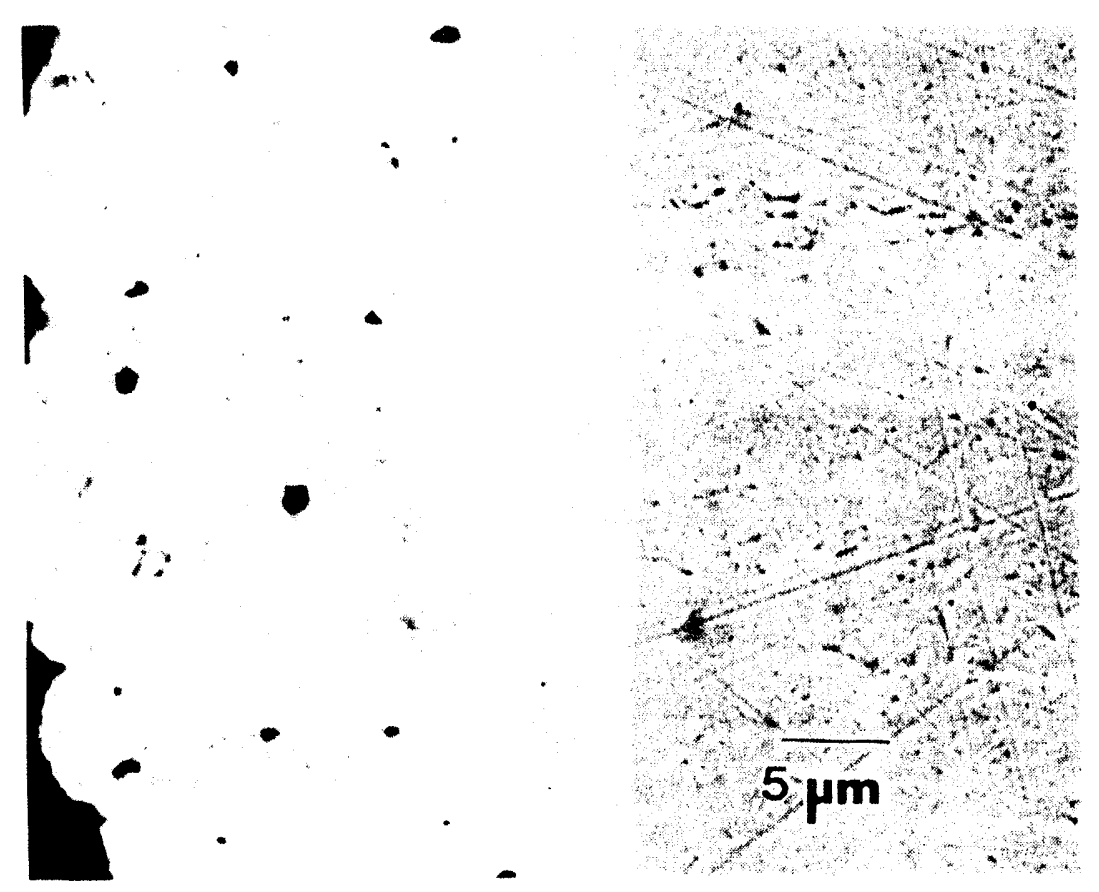

(a)

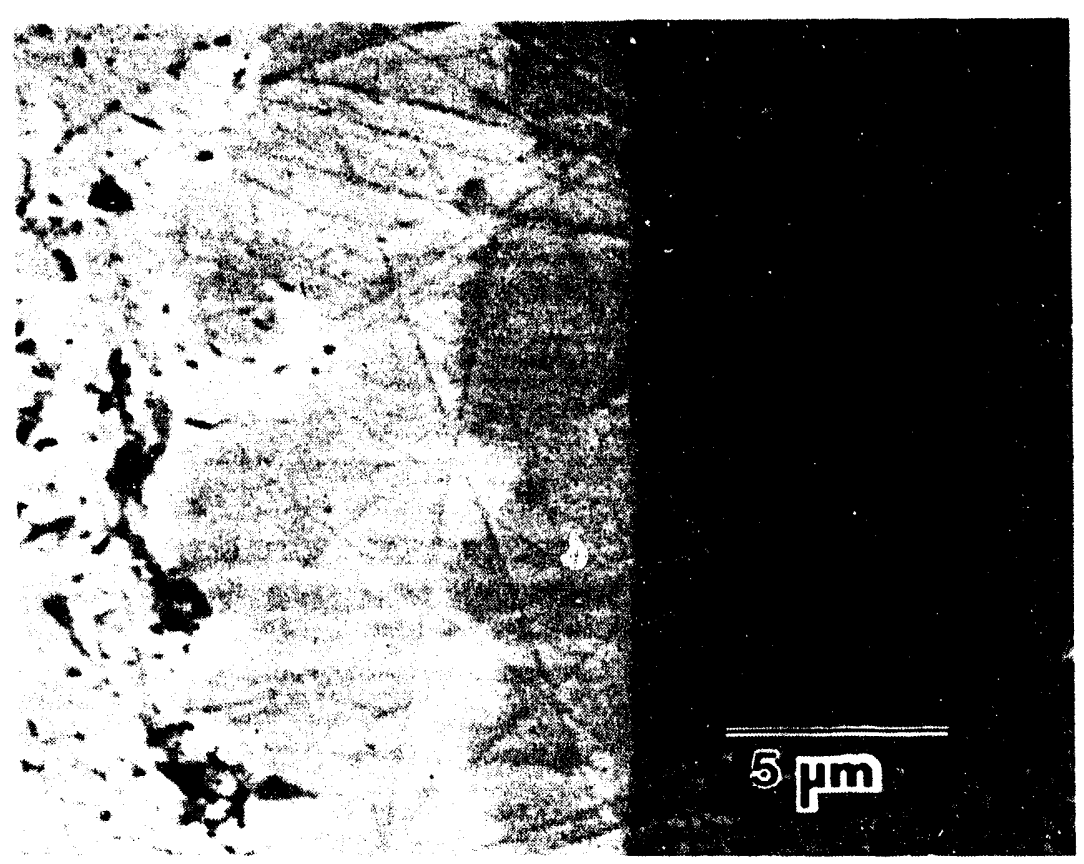

(b)

Figure 5.8. SEM micrographs showing cross-sections of the $30 \mu \mathrm{m} \mathrm{Sn-rich}$ (75Sn-25Pb), electroplated specimen aged in air for 2 weeks at $170^{\circ} \mathrm{C}$. a) Magnification $=2030 \mathrm{x}$ and $\mathrm{b}$ ) Magnification $=4100 \mathrm{x}$ 


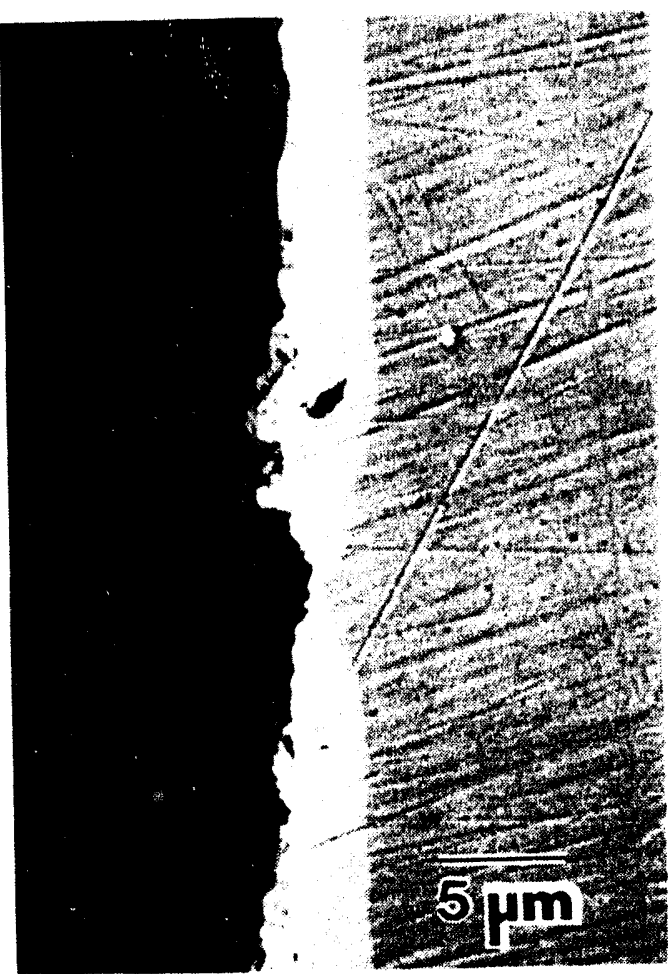

(a)

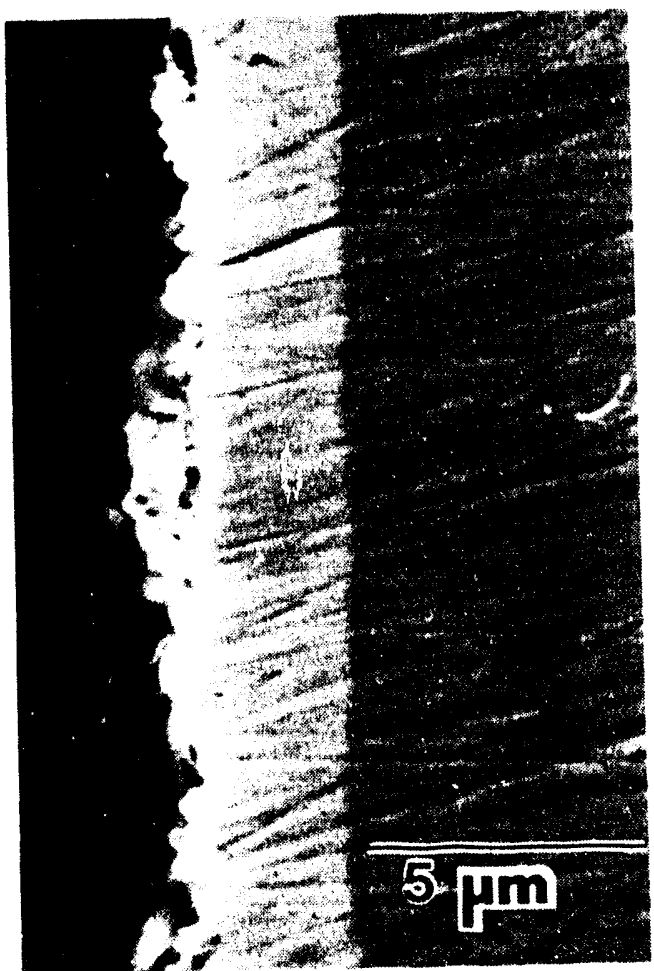

(b)

Figure 5.9. SEM micrograph showing a cross-section of the $3 \mu \mathrm{m}$ Sn-rich $(75 \mathrm{Sn}-25 \mathrm{~Pb})$, electroplated specimens aged in air for 2 weeks at $170^{\circ} \mathrm{C}$. Only one intermetallic layer ( $\mathrm{Cu}_{3} \mathrm{Sn}$ ) is present.

a) Magnification $=2030 \mathrm{x}$ and b) Magnification $=4100 \mathrm{x}$ 


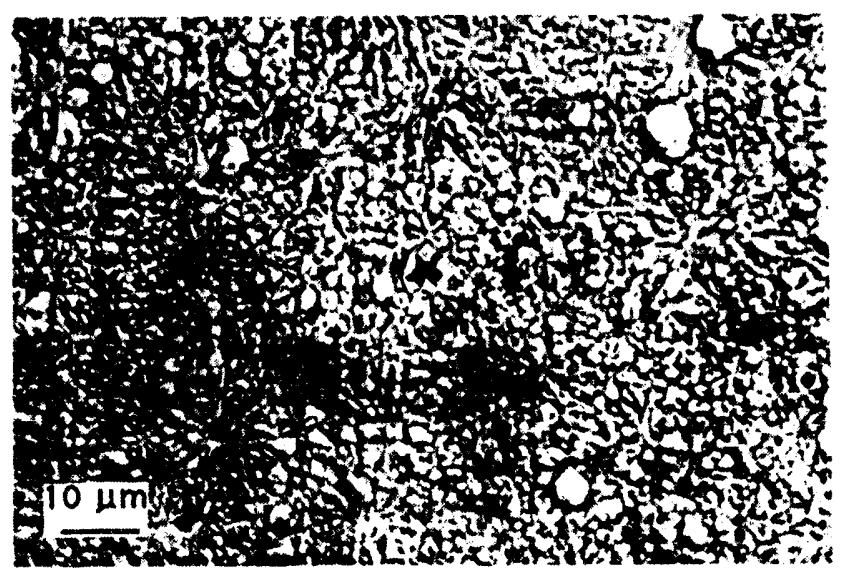

Figure 5.10. SEM micrograph showing the surface of the $3 \mu \mathrm{m}$ Sn-rich (75Sn-25Pb), electroplated, unaged specimen. 


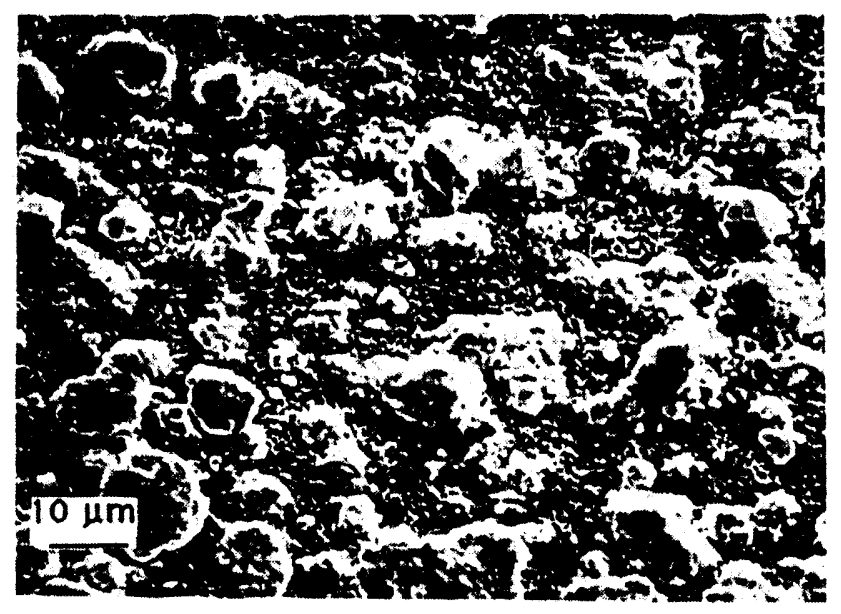

(a)

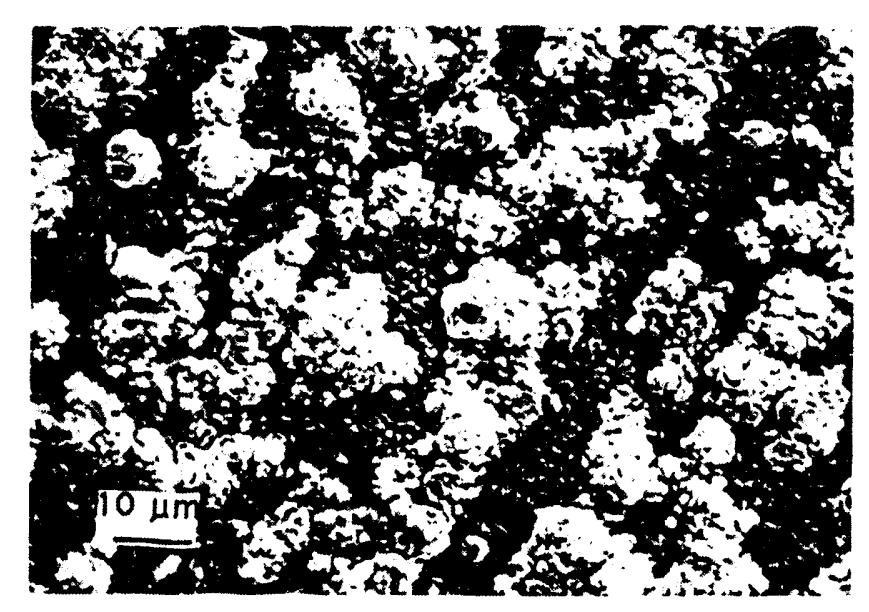

(b)

Figure 5.11. SEM micrographs showing the surfaces of the $3 \mu \mathrm{m}$ Sn-rich $(75 \mathrm{Sn}-25 \mathrm{~Pb})$, electroplated, specimens aged for 2 weeks at $170^{\circ} \mathrm{C}$ in a) argon, and b) air. In both samples, the residual $\mathrm{Pb}$ has withdrawn into irregularly shaped regions, leaving the $\mathrm{Cu}_{3} \mathrm{Sn}$ intermetallic exposed to the surface. 

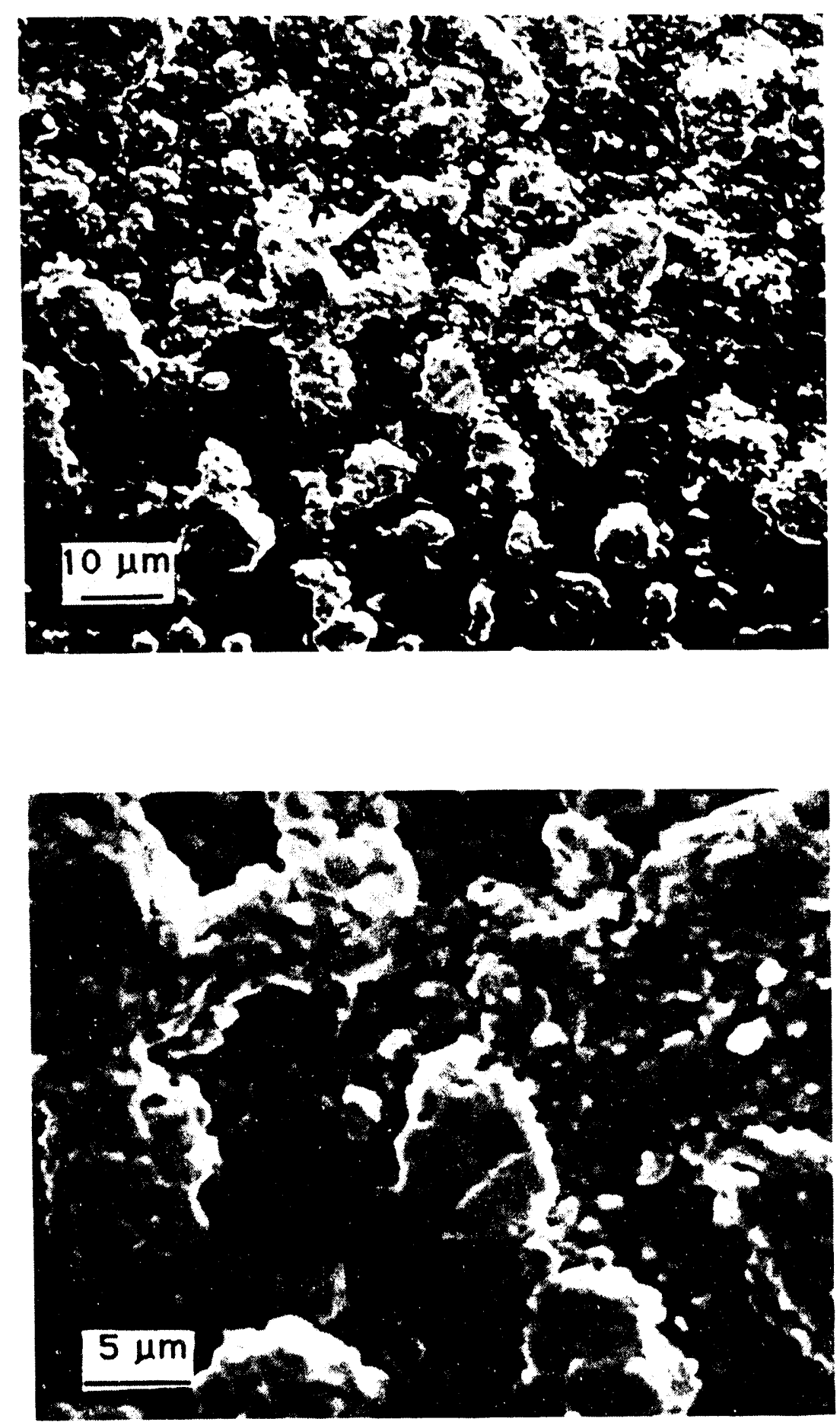

Figure 5.12. SEM micrographs showing the surface of the $10 \mu \mathrm{m}$ Sn-rich $(75 \mathrm{Sn}-25 \mathrm{~Pb})$, electroplated specimen aged for 2 weeks in air at $170^{\circ} \mathrm{C}$. The exposed intermetallic phase is $\mathrm{Cu}_{6} \mathrm{Sn} 5$. 

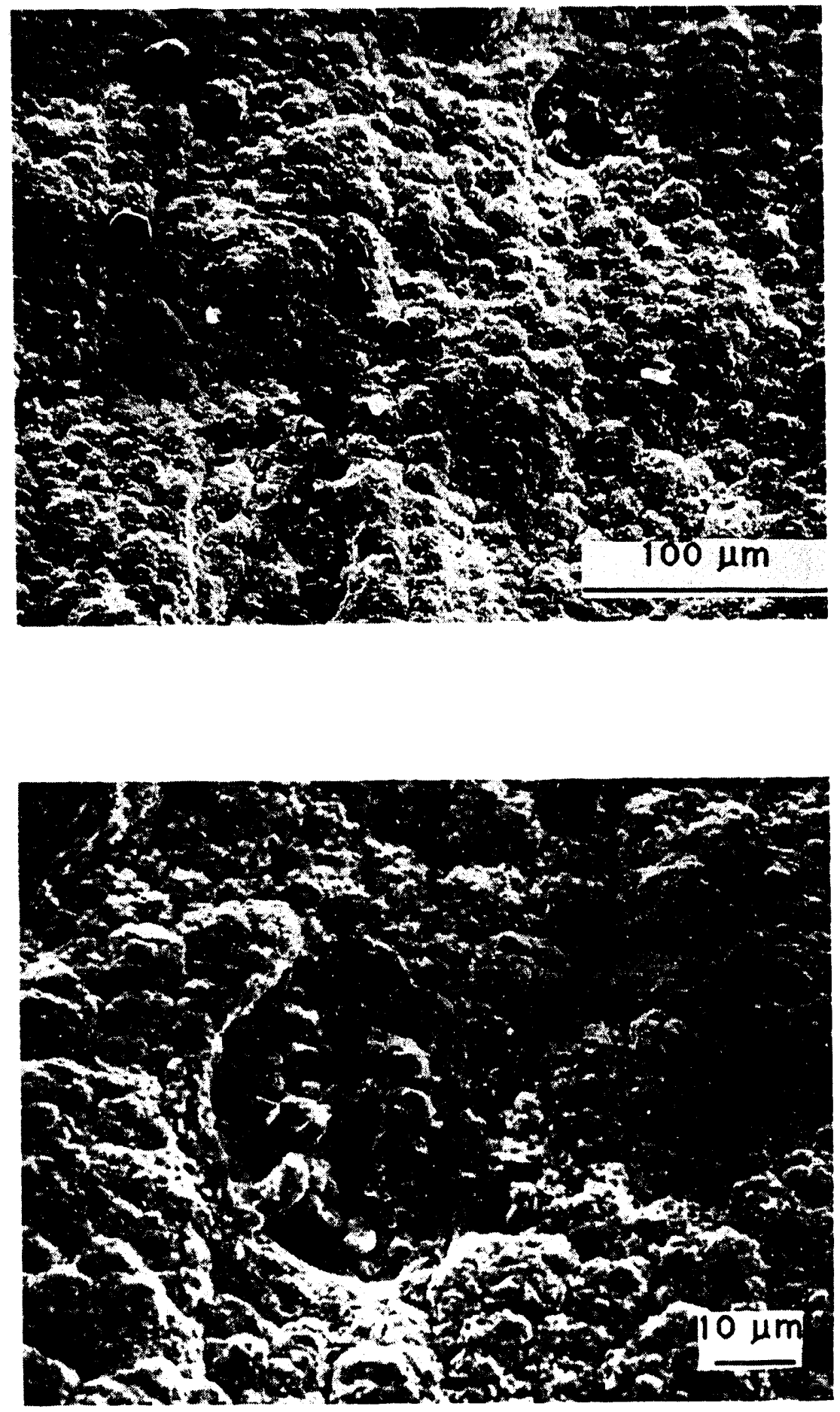

Figure 5.13. SEM micrographs showing the surface of the $30 \mu \mathrm{m}$ Sn-rich $(75 \mathrm{Sn}-25 \mathrm{~Pb})$, electroplated specimen aged for 2 weeks in air at $170^{\circ}$. Intermetallic exposed at the surface is $\mathrm{Cu}_{6} \mathrm{Sn} 5$. 

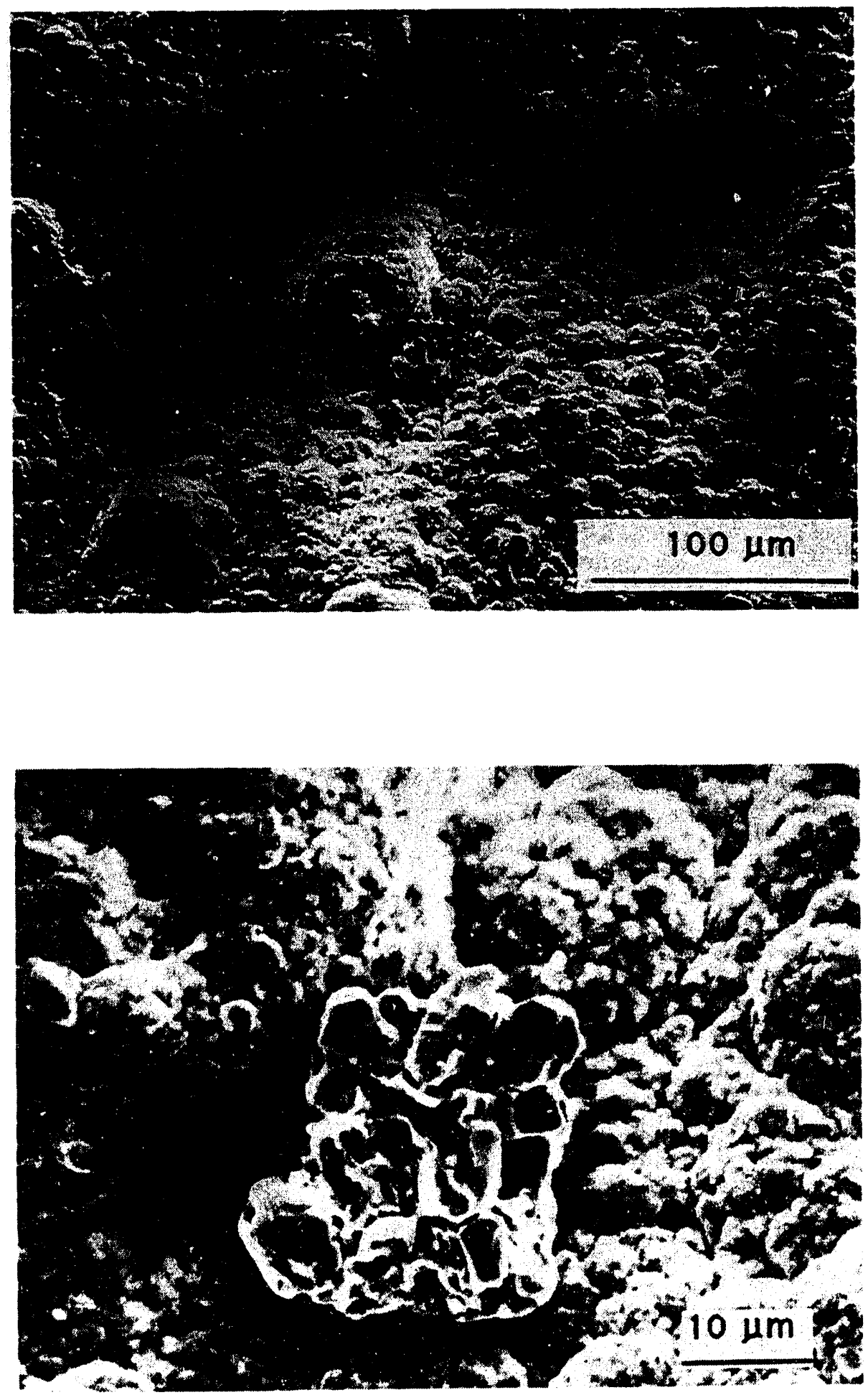

Figure 5.14. SEM micrograph showing the surface of the $30 \mu \mathrm{m}$ Sn-rich $(75 \mathrm{Sn}-25 \mathrm{~Pb})$, electroplated specimen aged for 2 weeks in air at $170^{\circ}$. Intermetallic exposed at the surface is $\mathrm{Cu}_{6} \mathrm{Sn}_{5}$. 


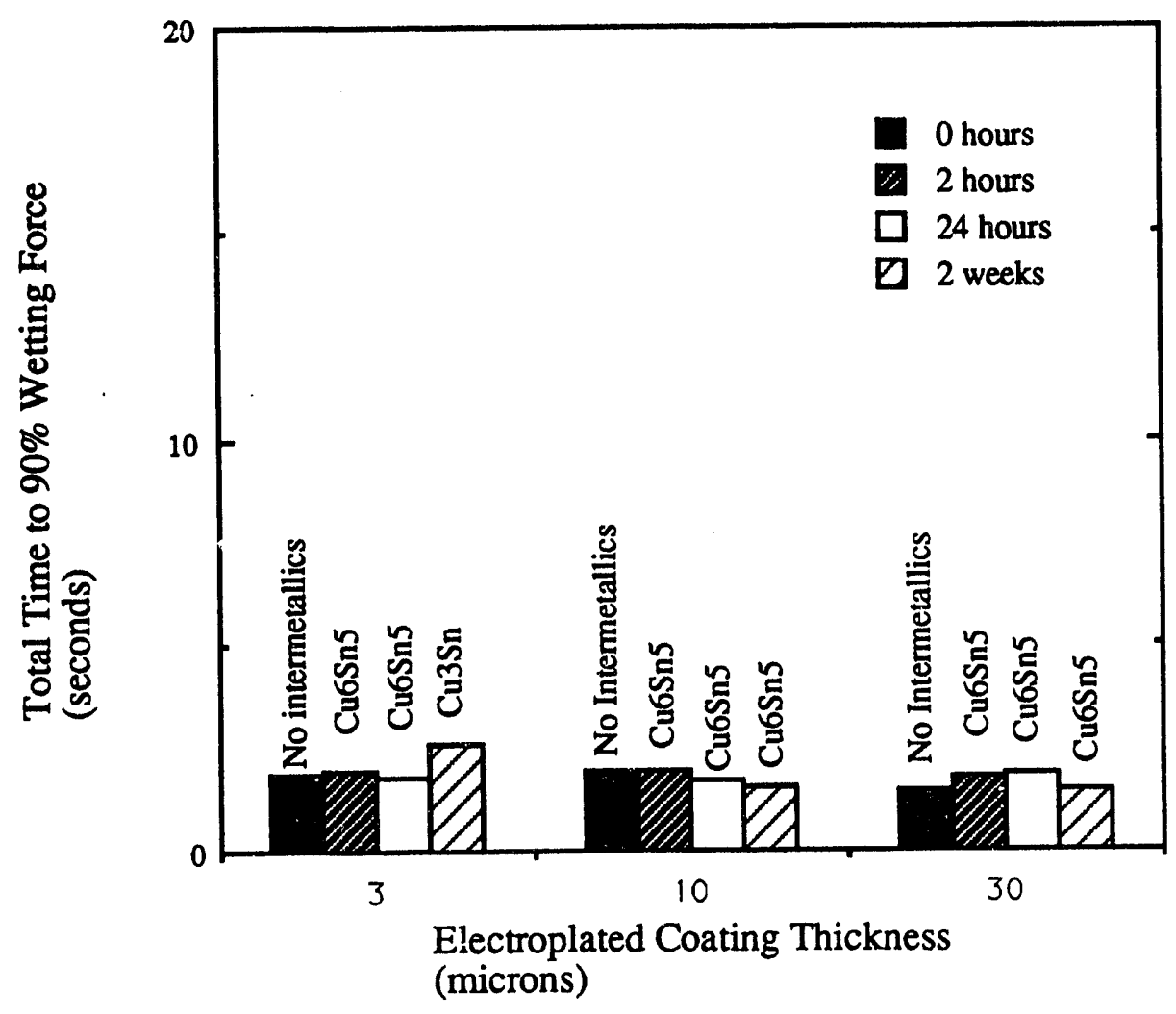

Figure 5.15. Graph showing the total time to $90 \%$ of the maximum wetting force as a function of coating thickness and aging time for the Sn-rich (75Sn-25Pb), electroplated samples aged in argon. Intermetallics exposed at the surface are indicated. 


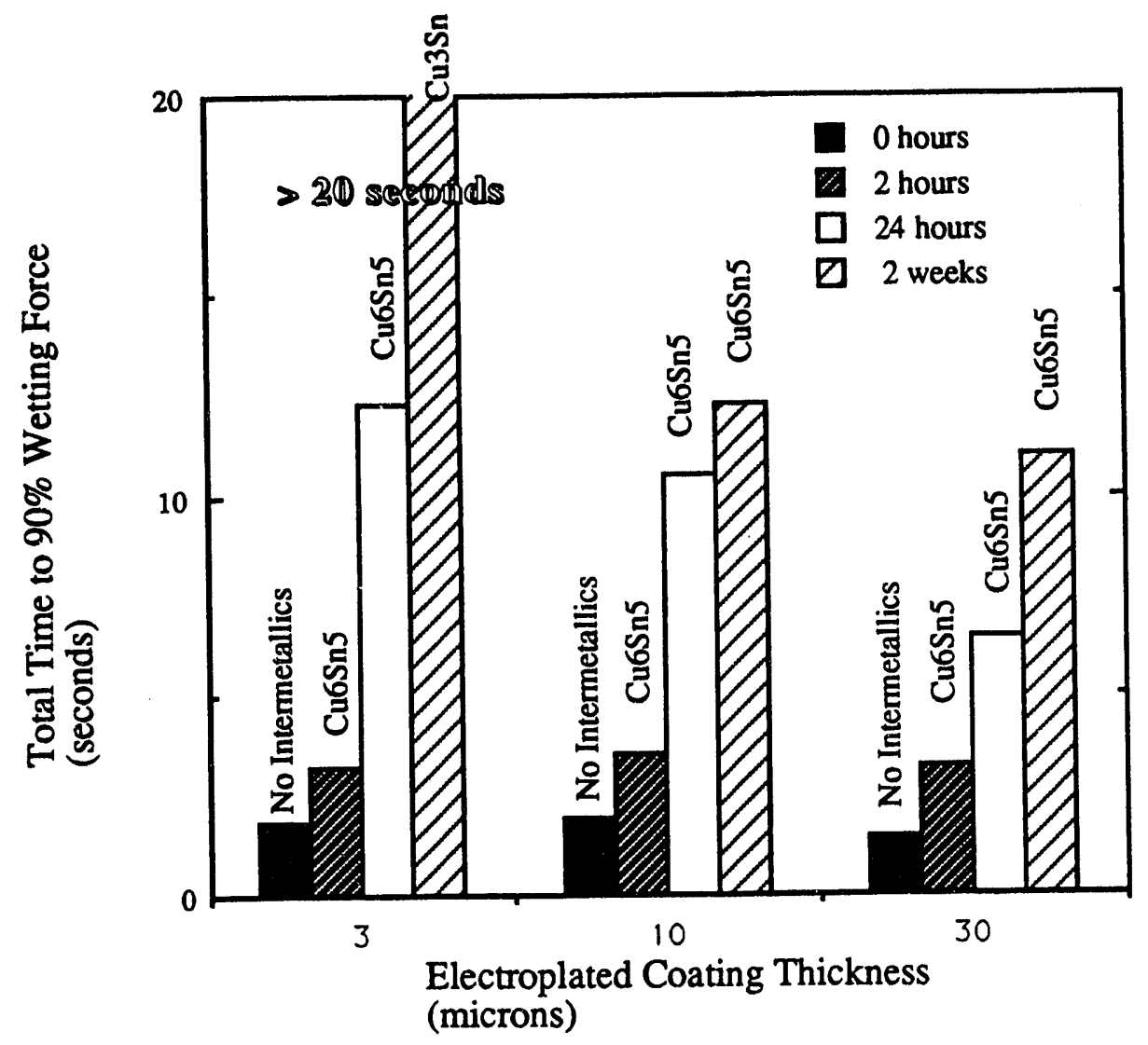

Figure 5.16. Graph showing the total time to $90 \%$ of the maximum wetting force as a function of coating thickness and aging time for the Sn-rich (75Sn-25Pb), electroplated samples aged in air. Intermetallics exposed at the surface are indicated. 


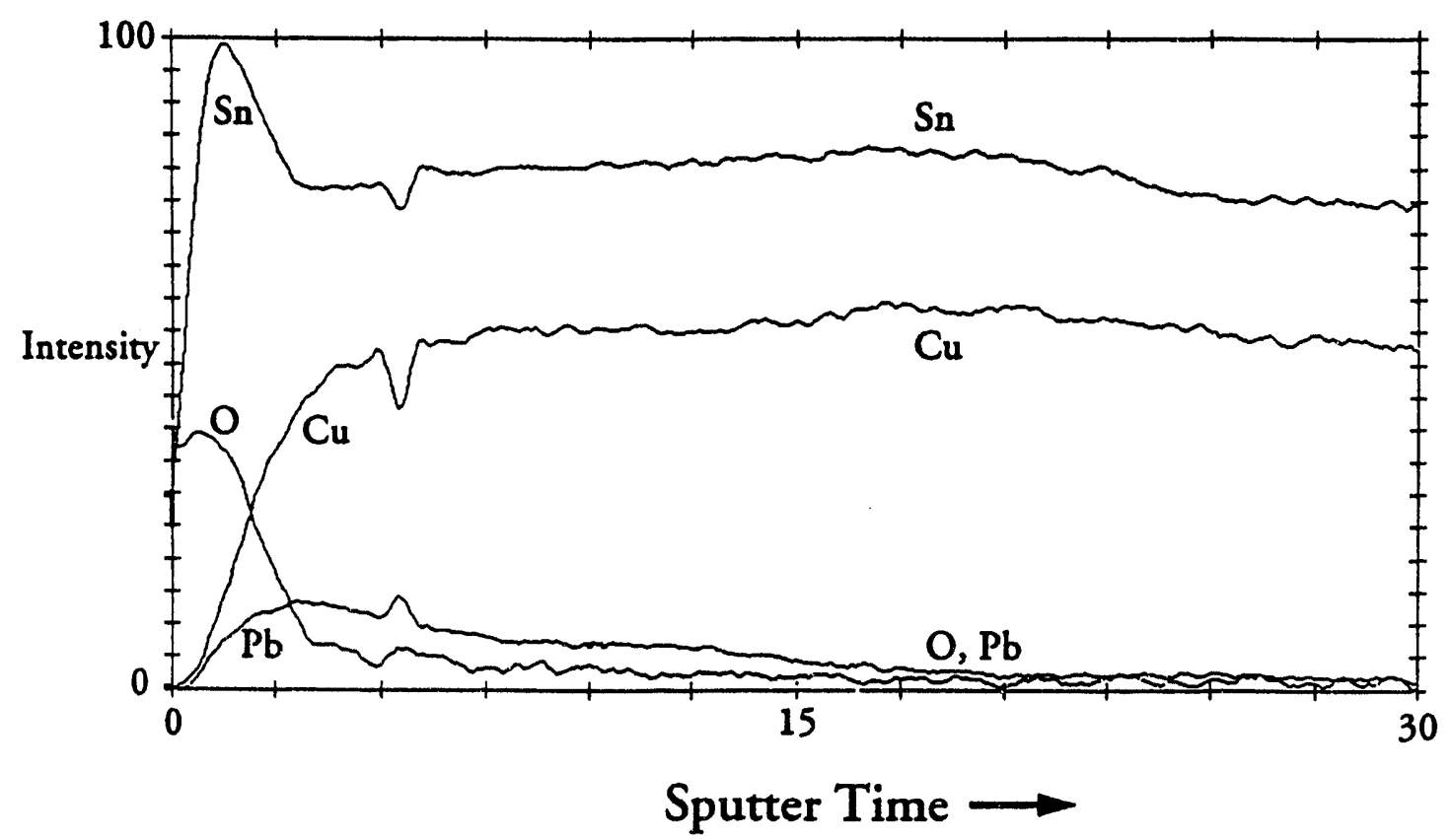

Figure 5.17. Auger depth profile showing chemical composition at the surface of the $10 \mu \mathrm{m} \mathrm{Sn-rich,} \mathrm{electroplated} \mathrm{sample} \mathrm{which} \mathrm{had} \mathrm{been} \mathrm{aged} \mathrm{for} 2$ weeks at $170^{\circ} \mathrm{C}$ in air. A Sn oxide is present on the $\mathrm{Cu}_{6} \mathrm{Sn} 5$ surface. 


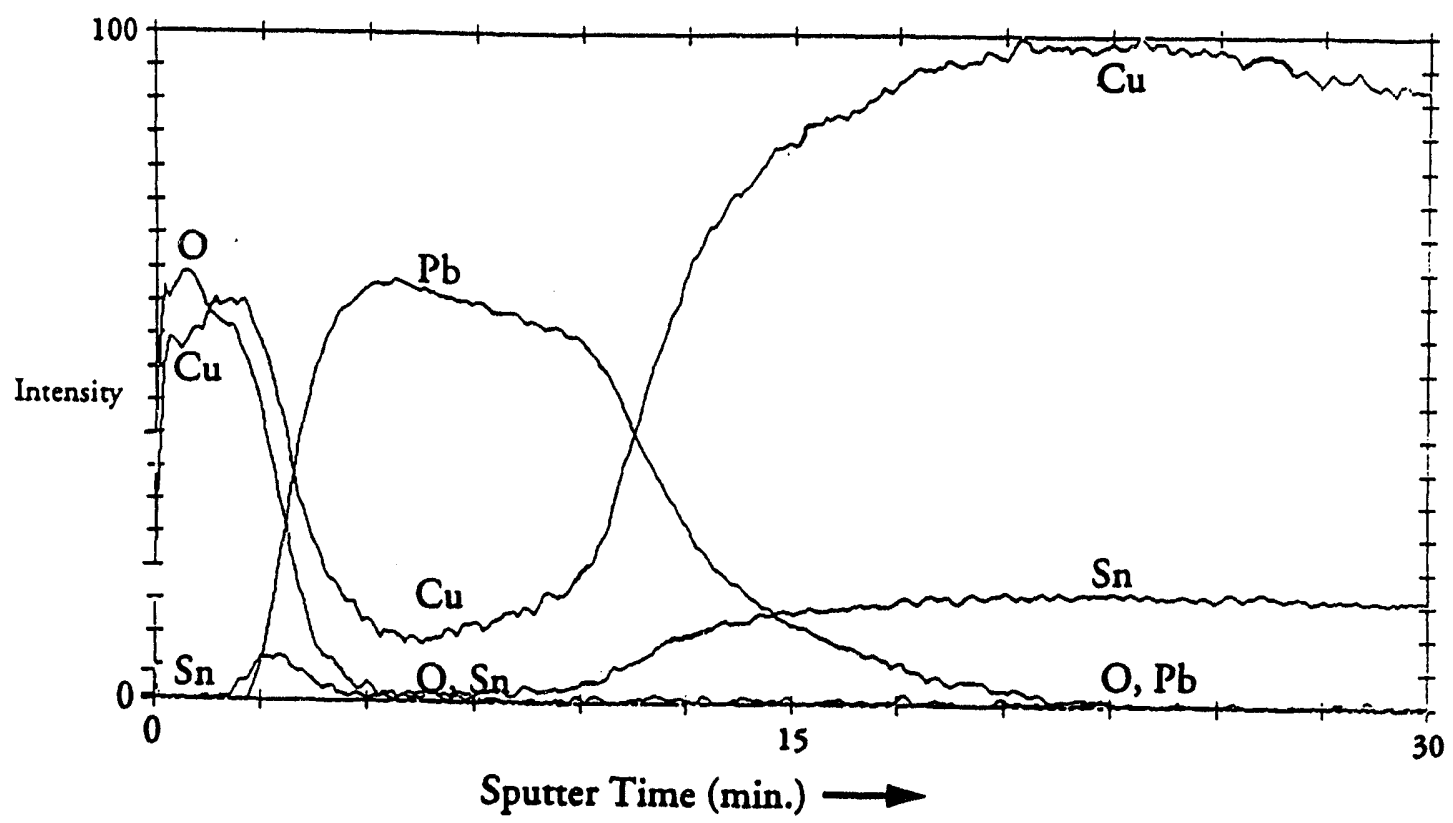

Figure 5.18. Auger depth profile showing chemical composition at the surface of the $3 \mu \mathrm{m}$ Sn-rich, electroplated sample which had been aged for 2 weeks at $170^{\circ} \mathrm{C}$ in air. $\mathrm{A}$ Cu oxide is present on the surface. 


\subsection{Pb-Rich (8Sn-92Pb) Electroplated Samples}

\subsubsection{Wetting Balance Test Results}

The $\mathrm{Pb}$-rich, electroplated samples were aged at $170^{\circ} \mathrm{C}$ in an argon environment. The maximum wetting force $(\mathrm{N} / \mathrm{m})$ and time to $90 \%$ of the maximum wetting force (seconds) were obtained from the wetting balance curves. The maximum wetting force is plotted against coating thickness and aging time in Figure 5.19. For the $3 \mu \mathrm{m}$ and $10 \mu \mathrm{m}$ coated samples, the maximum wetting force decreases for the samples aged for 24 hours. This decrease in maximum wetting force indicates a decrease in wettability. Samples with the same nominal coating thicknesses $(3 \mu \mathrm{m}$ and $10 \mu \mathrm{m})$ which were aged for 2 weeks showed a higher maximum wetting force.

Figures 5.20 and 5.21 show the total time (including plateau) and net time (excluding plateau) to reach $90 \%$ of the maximum wetting force plotted against coating thickness and aging time. The trends for the total time and net time are again similar. The $\mathrm{Pb}$-rich electroplated specimens aged in argon show a significant increase and then decrease in the time to $90 \%$ maximum wetting force as a function of aging time. The coating thickness seems to have a less significant effect on the time to $90 \%$ maximum wetting force.

\subsubsection{Microstructural Changes}

\subsubsection{X-ray Diffraction Analysis}

Results of the X-ray diffraction (XRD) analysis are shown in Table 5.2 The analyzed samples had not been exposed to the excess solder from the wetting balance. The $\mathrm{X}$-ray penetration depth through pure $\mathrm{Pb}$ is calculated to be up to approximately 5 $\mu \mathrm{m}$ depending on the angle of incidence. (See Appendix A.) Despite this calculation, even the data collected for the $3 \mu \mathrm{m} \mathrm{Pb}$-rich electroplated sample provide no 
information about the formation and growth of intermetallic phases at the interface between the $\mathrm{Cu}$ substrate and the $8 \mathrm{Sn}-92 \mathrm{~Pb}$ pretinned solder coating. The XRD data collected on the $30 \mu \mathrm{m}$ samples are not included in Table 5.2.

\subsubsection{Microscopy and EDX Analysis}

Figure 5.22 shows an SEM backscattered image of a $\mathrm{Pb}$-rich (8Sn-92Pb) electroplated specimen cross section. A single phase intermetallic layer is observed. The composition of the intermetallic phase was determined to be $\mathrm{Cu}_{3} \mathrm{Sn}$ ( $\varepsilon$-phase) using EDX. The $\mathrm{Cu}_{3} \mathrm{Sn}$ intermetallic forms at the interface between the $\mathrm{Cu}$ substrate and the $8 \mathrm{Sn}-92 \mathrm{~Pb}$ electroplated coating. Thermodynamically, the formation of $\mathrm{Cu}_{3} \mathrm{Sn}$ at this interface is reasonable. 
TABLE 5.2

TABLE 5.2

$\mathrm{Pb}$-Rich Electroplated Samples

Microstructural Phases Detected using X-ray Diffraction

\section{$\checkmark$ Denotes Phases Detected within X-ray Penetration Depth $X$ Denotes Phase Not Detected}

Aging Time (at $\left.170^{\circ} \mathrm{C}\right)$

0 hours

0 hours

0 hours

0 hours

0 hours

2 hours

2 hours

2 hours

2 hours

2 hours

24 hours

24 hours

24 hours

24 hours

24 hours

2 weeks

2 weeks

2 weeks

2 weeks

2 weeks

2 weeks

2 weeks

2 weeks

2 weeks

2 weeks

\section{Plating Thickness}

$3 \mu \mathrm{m}$

$3 \mu \mathrm{m}$

$3 \mu \mathrm{m}$

$3 \mu \mathrm{m}$

$3 \mu \mathrm{m}$

$3 \mu \mathrm{m}$

$3 \mu \mathrm{m}$

$3 \mu \mathrm{m}$

$3 \mu \mathrm{m}$

$3 \mu \mathrm{m}$

$3 \mu \mathrm{m}$

$3 \mu \mathrm{m}$

$3 \mu \mathrm{m}$

$3 \mu \mathrm{m}$

$3 \mu \mathrm{m}$

$3 \mu \mathrm{m}$

$3 \mu \mathrm{m}$

$3 \mu \mathrm{m}$

$3 \mu \mathrm{m}$

$3 \mu \mathrm{m}$

$10 \mu \mathrm{m}$

$10 \mu \mathrm{m}$

$10 \mu \mathrm{m}$

$10 \mu \mathrm{m}$

$10 \mu \mathrm{m}$
Phases

$\mathrm{Pb}$
$\mathrm{Sn}$
$\mathrm{Cu}$
$\mathrm{Cu}_{6 \mathrm{Sn}} 5$
$\mathrm{Cu} 3 \mathrm{Sn}$

$\mathrm{Pb}$

$\mathrm{Sn}$

$\mathrm{Cu}$

$\mathrm{Cu}_{6} \mathrm{Sn} 5$

$\mathrm{Cu} 3 \mathrm{Sn}$
Aging Environment ARGON

$\sqrt{ }$
$X$
$\sqrt{ }$
$X$
$X$

$\sqrt{ }$
$X$
$y$
$X$
$X$

$\sqrt{ }$
$X$
$y$
$X$
$X$
$\mathrm{Pb}$

$\mathrm{Sn}$

$\mathrm{Cu}$

$\mathrm{Cu}_{6} \mathrm{Sn}_{5}$

$\mathrm{Cu}_{3} \mathrm{Sn}$

\section{$\mathrm{Pb}$ \\ $\mathrm{Sn}$ \\ $\mathrm{Cu}$}

Cu6Sn5

Cu3Sn

$\mathrm{Pb}$
$\mathrm{Sn}$
$\mathrm{Cu}$
$\mathrm{Cu}_{6} \mathrm{Sn}_{5}$
Cu3Sn

$\sqrt{ }$
$X$
$\sqrt{ }$
$X$
$X$

V
$X$
$X$
$X$
$X$ 


\section{EIGURES}

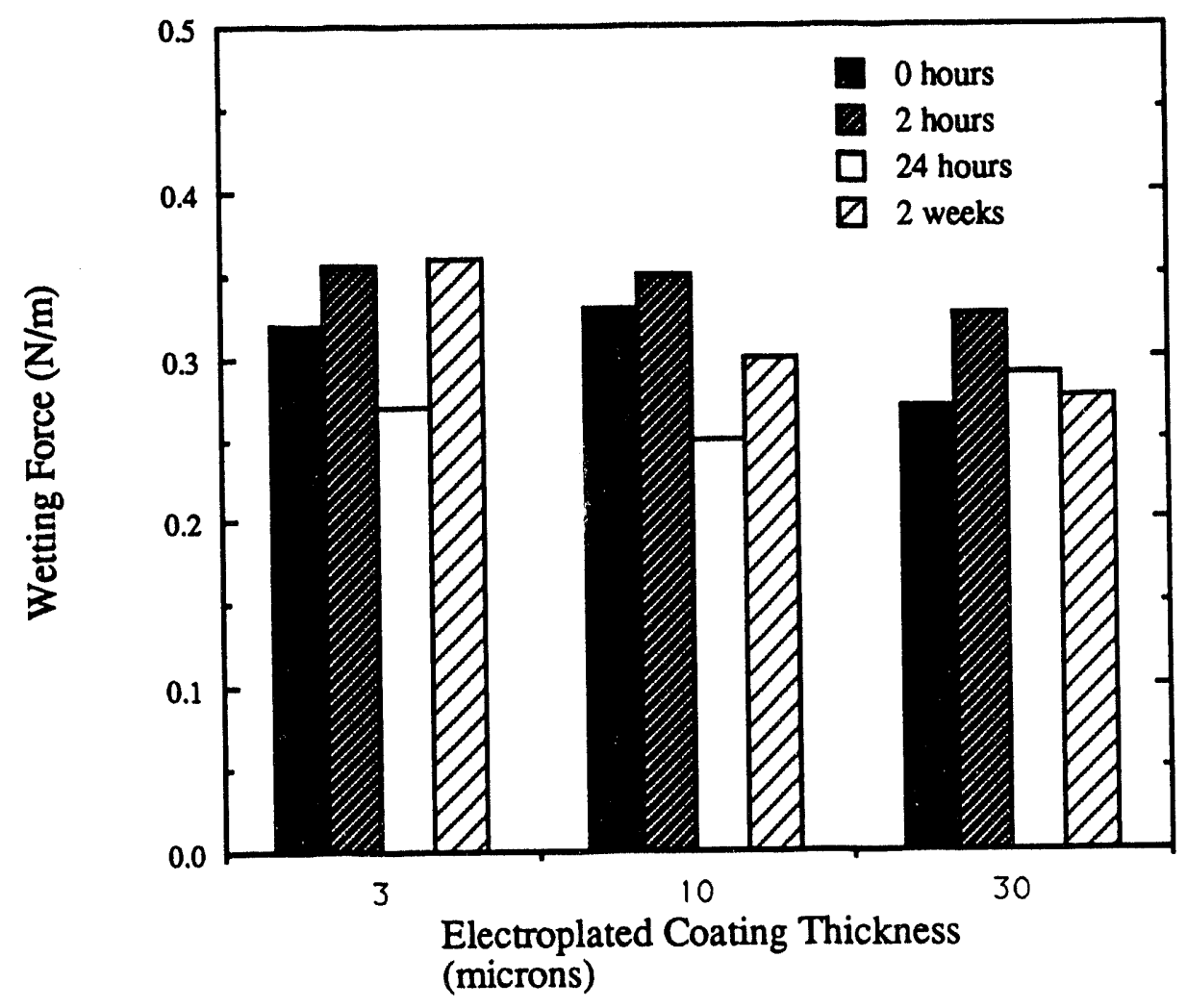

Figure 5.19. Graph showing the maximum wetting force as a function of coating thickness and aging time for the $\mathrm{Pb}$-rich $(8 \mathrm{Sn}-92 \mathrm{~Pb})$, electroplated samples aged in argon. 


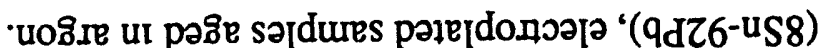

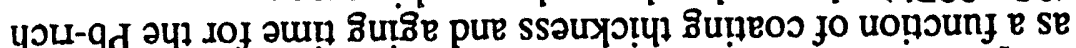

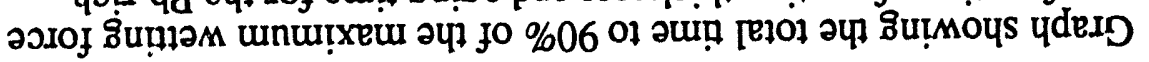

oZ'

(suosoriu)

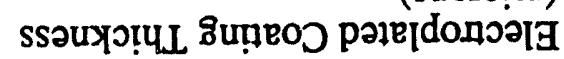

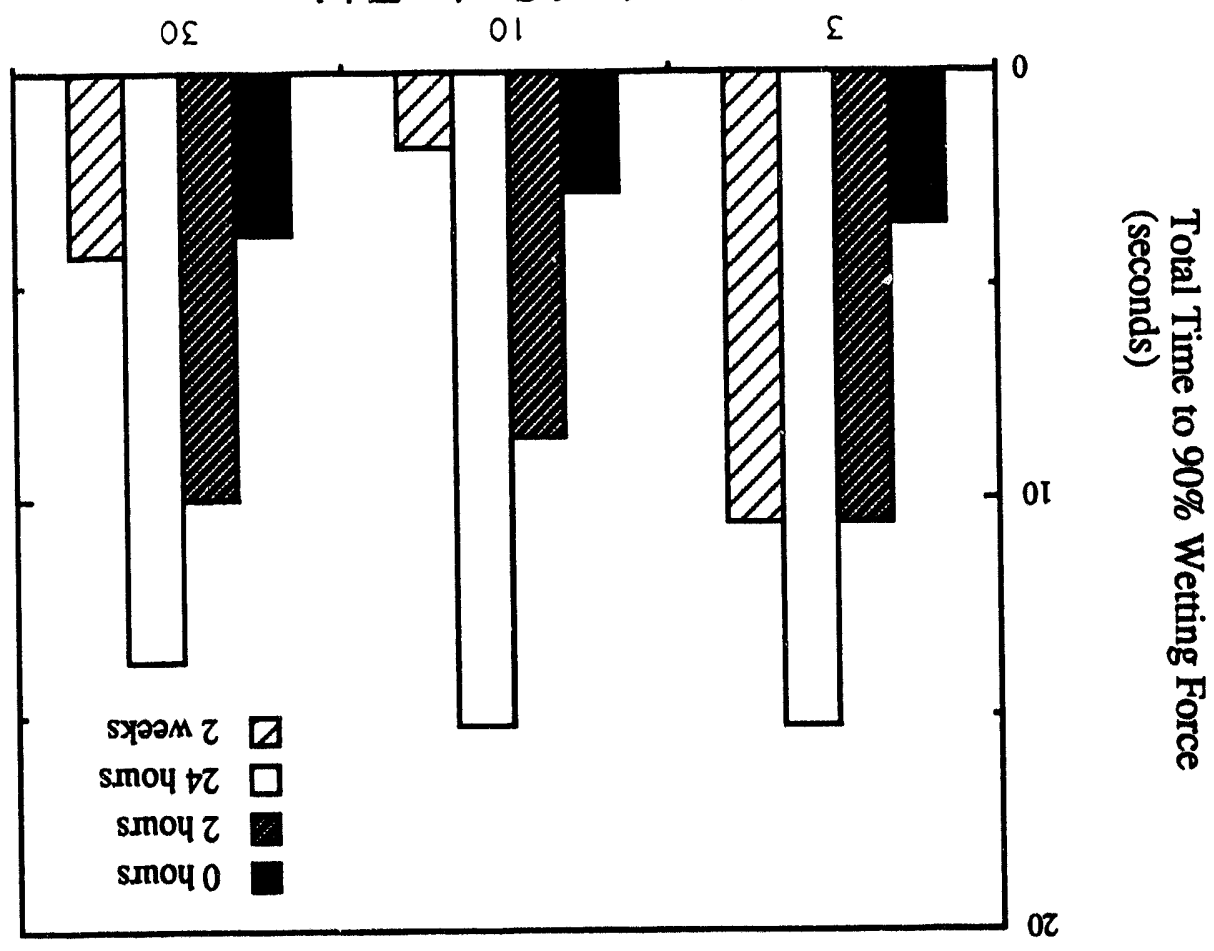




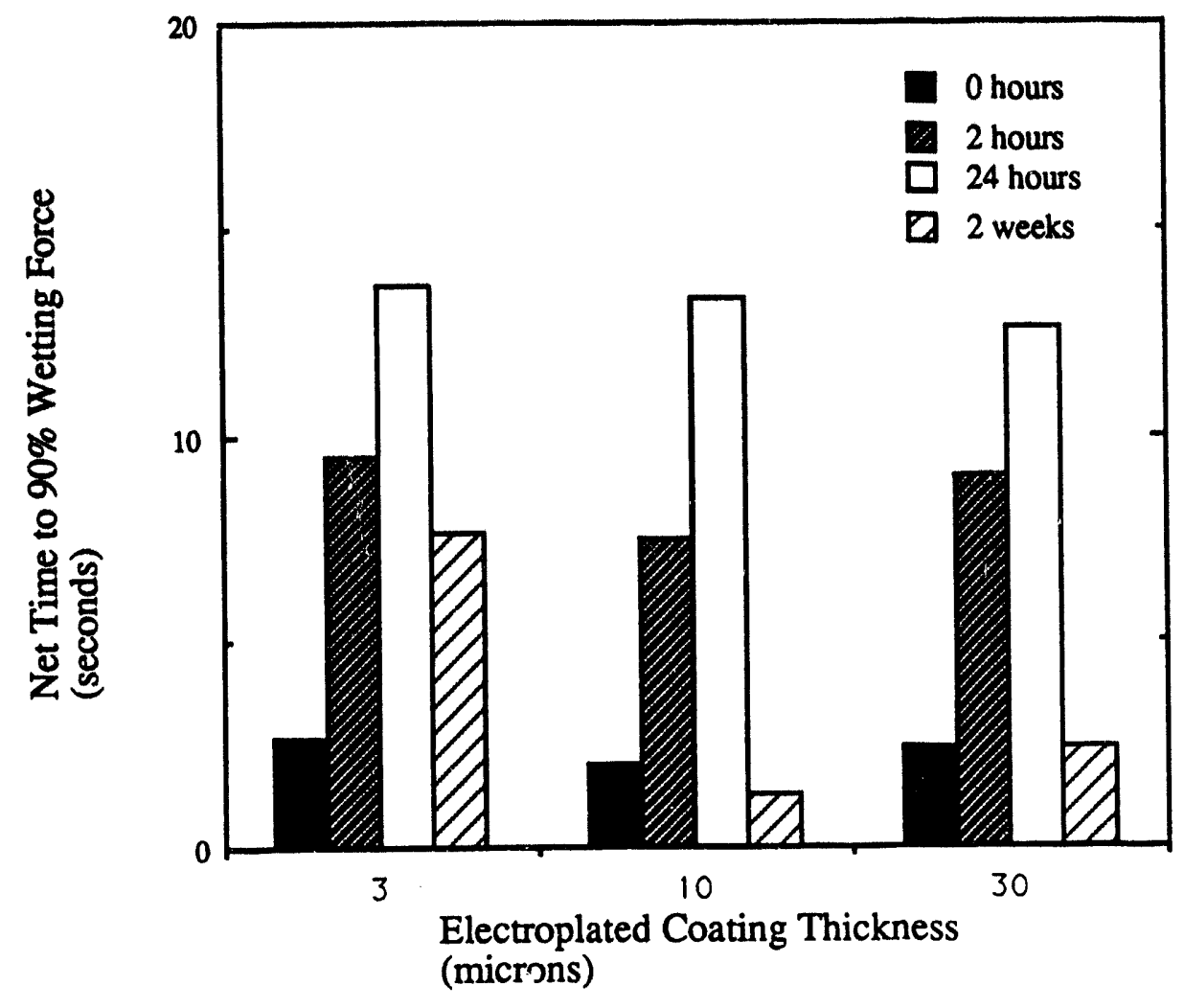

Figure 5.21. Graph showing the net (excluding plateau) time to $90 \%$ of the maximum wetting force as a function of coating thickness and aging time for the $\mathrm{Pb}$-rich $(8 \mathrm{Sn}-92 \mathrm{~Pb})$, electroplated samples aged in argon. 


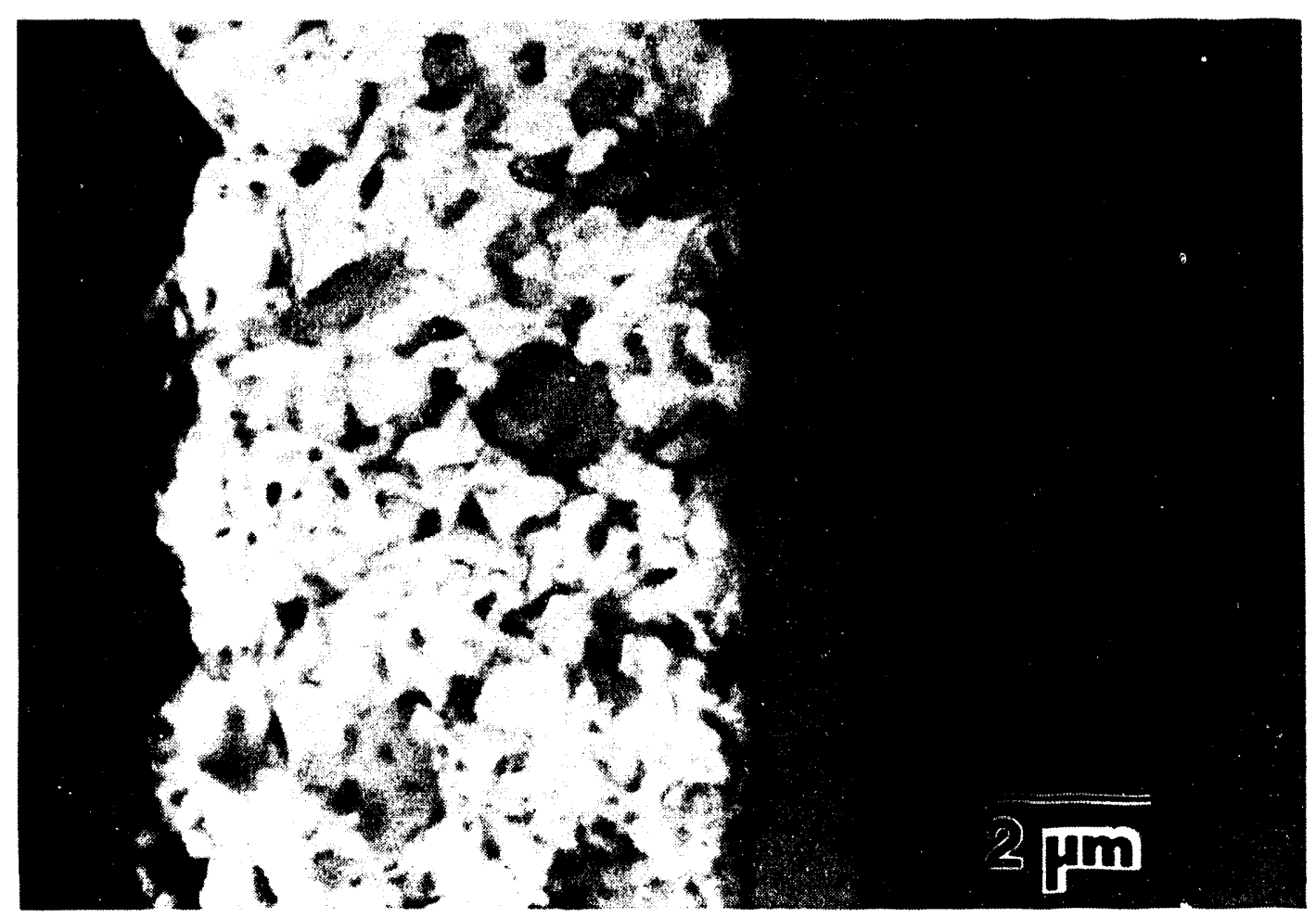

Figure 5.22. SEM backscattered image showing the cross-section of a $10 \mu \mathrm{m} \mathrm{Pb}$-rich $(8 \mathrm{Sn}-92 \mathrm{~Pb})$, electroplated specimen which was aged in argon for 2 weeks at $170^{\circ} \mathrm{C}$. 


\subsection{Pb-Rich (5Sn-95Pb) Hot-Dipped Samples}

\subsubsection{Wetting Balance Test Results}

The $\mathrm{Pb}$-rich (5Sn-95Pb), hot-dipped samples were aged at $170^{\circ} \mathrm{C}$ an argon environment. The maximum wetting force $(\mathrm{N} / \mathrm{m})$ and time to $90 \%$ of the maximum wetting force (seconds) were obtained from the wetting balance curves. The maximum wetting force is plotted as a function of aging time in Figure 5.23. The aging time has little effect on the maximum wetting force. The total time to $90 \%$ of the maximum wetting fore and the net time to $90 \%$ maximum wetting force are shown in Figures 5.24 and 5.25. The specimens show an increase in the wetting time up to 24 hours of aging and a decrease in the wetting time after 2 weeks aging. This same trend was observed for the $\mathrm{Pb}$-rich $(8 \mathrm{Sn}-92 \mathrm{~Pb})$ electroplated specimens aged in argon.

\subsubsection{Microstructural Changes}

\subsubsection{X-ray Diffraction Analysis}

The results of the XRD analysis are given in Table 5.3. As with the Pb-rich, electroplated specimens, the data collected provides little information about the formation and growth of intermetallic phases during aging. Other methods of observation and analysis are required in order to understand the microstructural changes which take place during aging in argon at $170^{\circ} \mathrm{C}$.

\subsubsection{Microscopy and EDX Analysis}

Figures 5.26 and 5.27 show SEM backscattered images of the interface for the $\mathrm{Pb}$ rich (5Sn-95Pb) hot-dipped specimens aged for 2 weeks in argon. A single phase intermetallic layer is observed, similar to that observed in the $\mathrm{Pb}$-rich electroplated samples discussed in Section 5.2. The composition of the intermetallic phase was 
determined to be $\mathrm{Cu}_{3} \mathrm{Sn}$ by EDX. This result is in agreement with previous studies that investigated $\mathrm{Pb}$-rich (5Sn-95Pb), hot-dipped coatings on Cu substrates.[30] Figure 5.27 shows intermetallic spikes (or whiskers as they are often called) growing into the remaining solder layer. EDX analysis of these spikes has given ambiguous results up to the present time. The results are inconclusive between $\mathrm{Cu}_{6} \mathrm{Sn}_{5}$ and $\mathrm{Cu}_{3} \mathrm{Sn}$. The whisker morphology, however, is characteristic of the $\mathrm{Cu}_{6} \mathrm{Sn} 5$ ( $\eta$-phase).[31] 
TABLE 5.3

$\mathrm{Pb}-\mathrm{Rich}$ (5Sn-95Pb) Hot-Dipped Samples Microstructural Phases Detected using X-ray Diffraction

$\sqrt{ }$ Denotes Phases Detected within X-ray Penetration Depth $X$ Denotes Phase Not Detected

- Denotes Sample Not Analyzed

Aging Time (at $170^{\circ} \mathrm{C}$ )

$\frac{\text { Plating Thickness }}{(3-15 \mu \mathrm{m})}$

0 hours

0 hours

0 hours

0 hours

0 hours

2 hours

2 hours

2 hours

2 hours

2 hours

24 hours

24 hours

24 hours

24 hours

24 hours

2 weeks

2 weeks

2 weeks

2 weeks

2 weeks
HD

HD

HD

HD

HD

HD

HD

HD

HD

HD

HD

HD

HD

HD

HD

HD

HD

HD

HD

HD
Phases

Aging Environment ARGON

$\sqrt{ }$
$X$
$\sqrt{ }$
$X$
$X$

Cu6sns

$\mathrm{Cu}_{3} \mathrm{Sn}$

$\mathrm{Pb}$
$\mathrm{Sn}$
$\mathrm{Cu}$
$\mathrm{Cu}_{6 \mathrm{Sn}} 5$
$\mathrm{Cu}_{3} \mathrm{Sn}$

$\sqrt{ }$
$X$
$\sqrt{ }$
$X$
$X$

$\mathrm{Pb}$

$\mathrm{Sn}$

$\mathrm{Cu}$

$\mathrm{Cu}_{6} \mathrm{Sn} 5$

Cu3Sn

$\mathrm{Pb}$
$\mathrm{Sn}$
$\mathrm{Cu}$
$\mathrm{Cu}_{6 \mathrm{Sn} 5}$
Cu3Sn

V
$\mathbf{X}$
$\mathbf{X}$
$\mathbf{X}$
$\mathbf{X}$

V
$\mathbf{X}$
$\mathbf{X}$
$\mathbf{X}$
$\mathbf{X}$ 


\section{EIGURES}

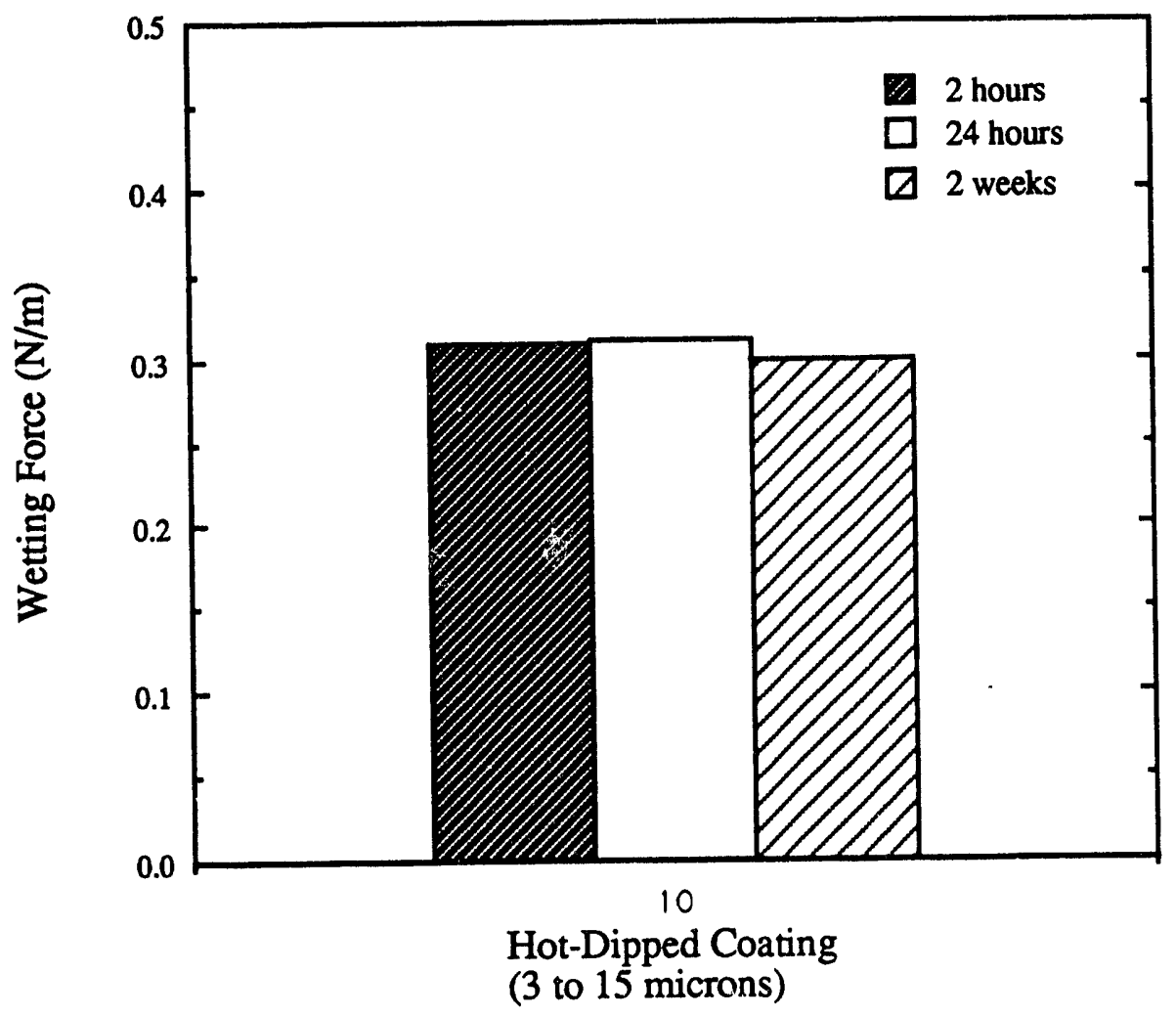

Figure 5.23. Graph showing the maximum wetting force as a function of coating thickness and aging time for the $\mathrm{Pb}$-rich (5Sn-95Pb), hot-dipped samples aged in argon. 


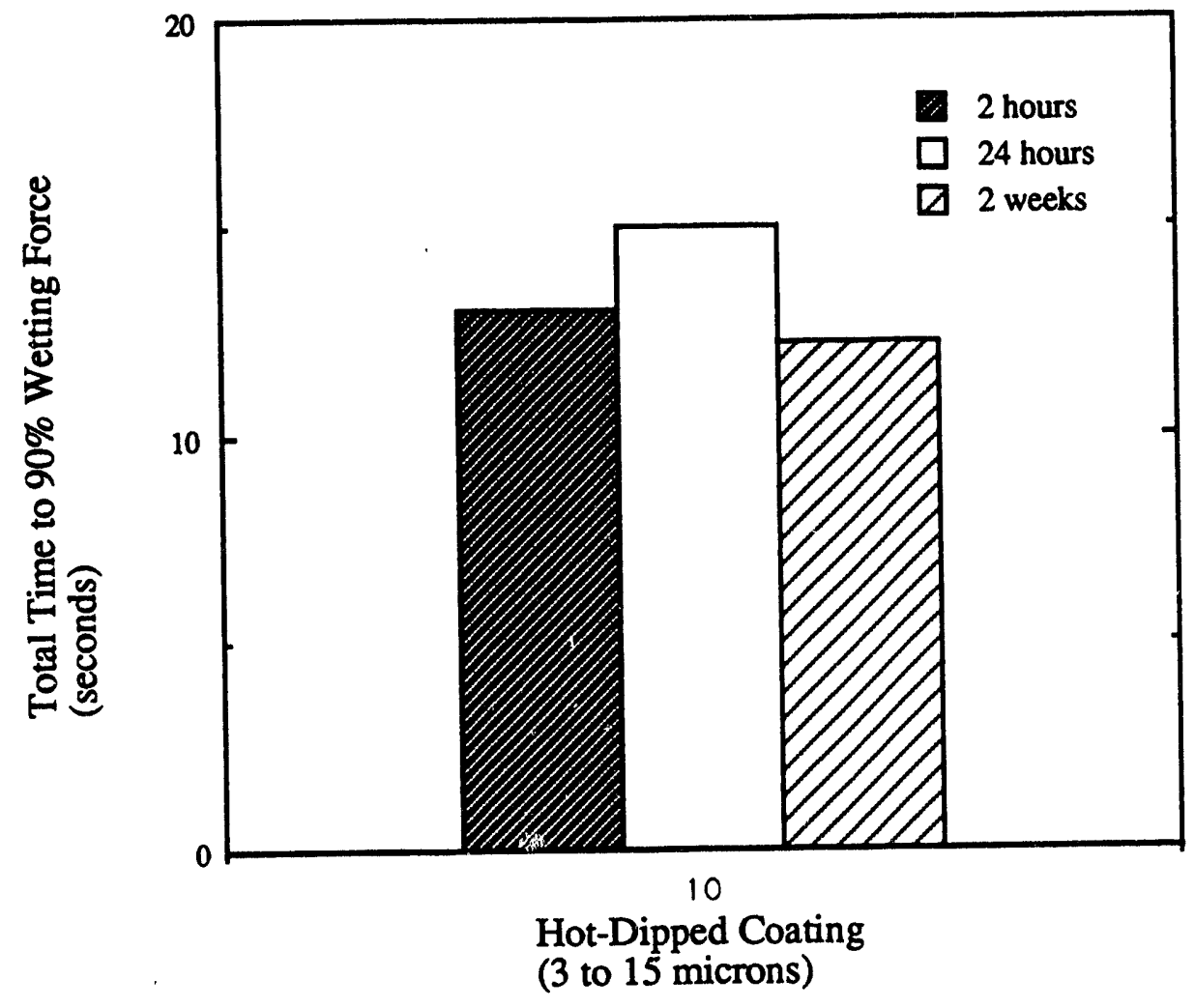

Figure 5.24. Graph showing the total time to $90 \%$ of the maximum wetting force as a function of coating thickness and aging time for the $\mathrm{Pb}$-rich (5Sn-95Pb), hot-dipped samples aged in argon. 


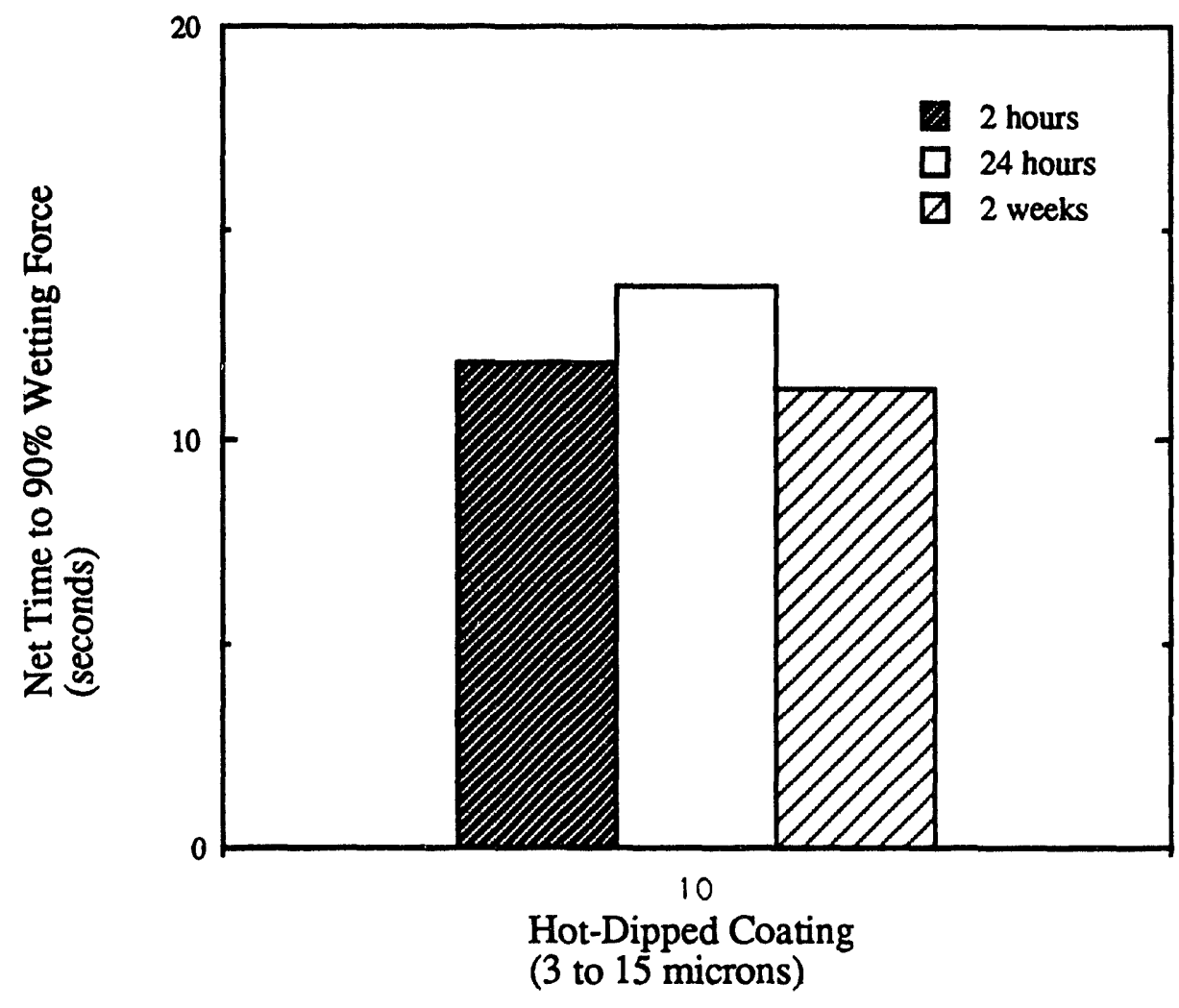

Figure 5.25. Graph showing the net (excluding plateau) time to $90 \%$ of the maximum wetting force as a function of coating thickness and aging time for the $\mathrm{Pb}$-rich (5Sn-95Pb), hot-dipped samples aged in argon. 


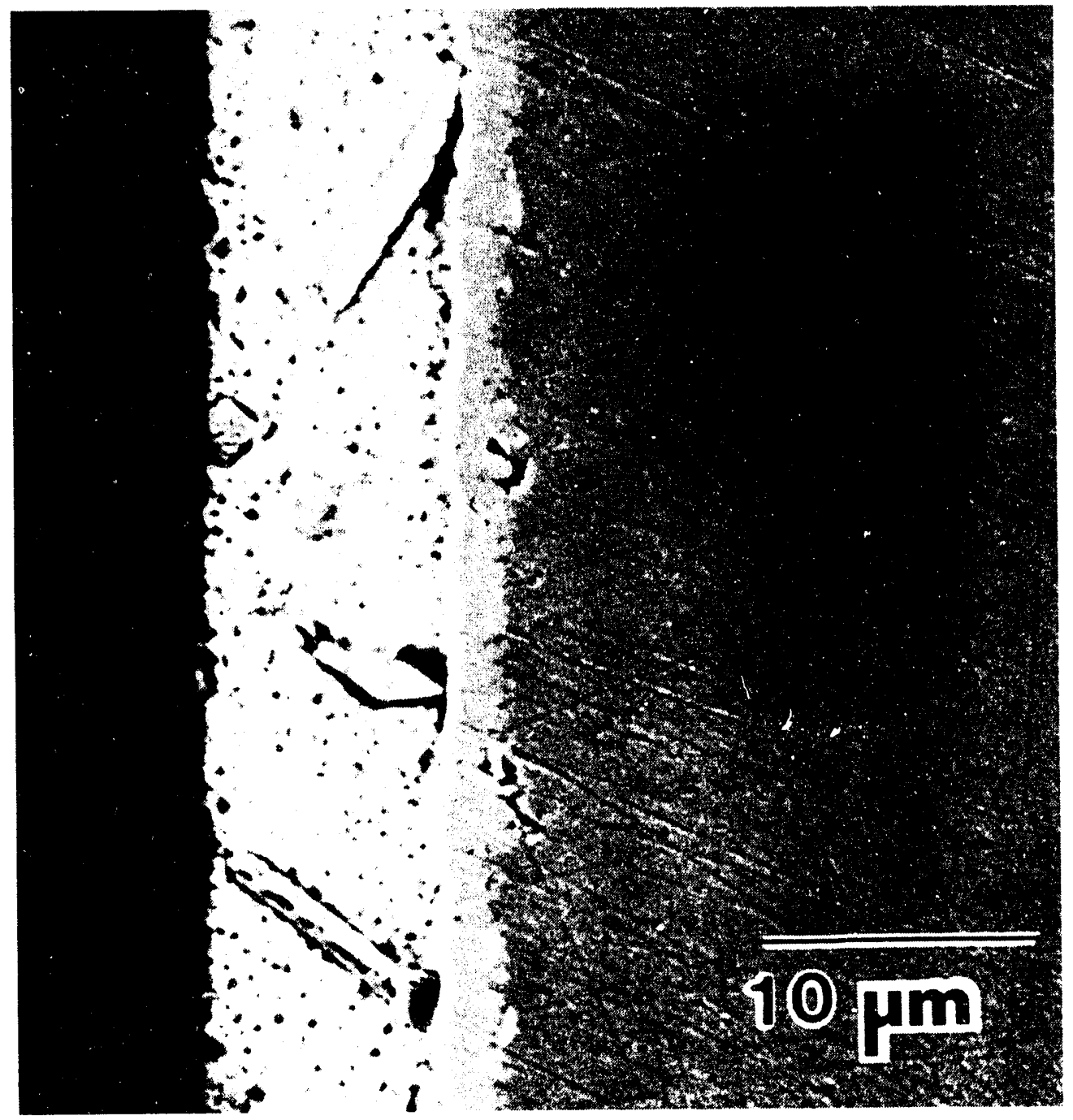

Figure 5.26. SEM micrograph (backscattered image) showing cross-section of a $\mathrm{Pb}$-rich (5Sn-95Pb), hot-dipped $\left(360^{\circ} \mathrm{C}\right)$ specimen which was aged in argon at $170^{\circ} \mathrm{C}$ for 2 weeks. 


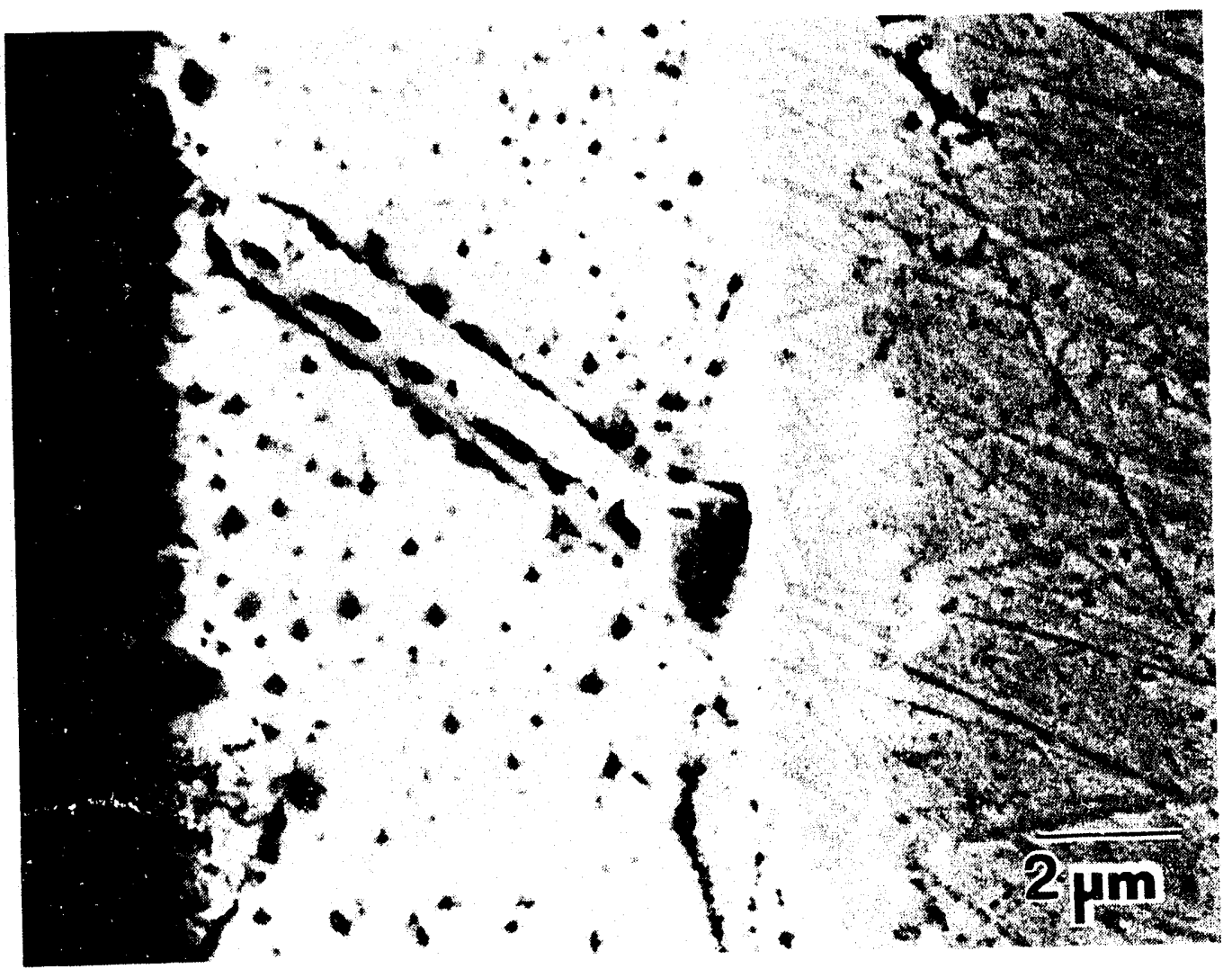

Figure 5.27. SEM micrograph (backscattered image) showing cross-section of a $\mathrm{Pb}$-rich $(5 \mathrm{Sn}-95 \mathrm{~Pb})$, hot-dipped $\left(360^{\circ} \mathrm{C}\right)$ specimen which was aged in argon at $170^{\circ} \mathrm{C}$ for 2 weeks. 


\subsection{Discussion}

\subsubsection{Determination of Accelerated Aging Method}

As discussed in Section 3.1, there is not a standard accelerated aging method which corresponds directly to natural aging. The amount of oxygen present in the steam appears to significantly influence the rate of solderability degradation. A dry heat accelerated aging method was chosen for the current study based on the fact that the concentration level of the oxygen in the aging environments could be measured and controlled. In addition, previous work done in this laboratory was performed using a dry heat accelerated aging method. A means of comparison was provided with the present study since an identical accelerated aging method was used.

\subsubsection{Analysis of Pb-Rich Specimens}

No surface analysis was performed on the $\mathrm{Pb}$-rich electroplated or hot-dipped specimens. Surface analysis, as well as further chemical analysis would be helpful in identifying the intermetallic spikes growing into the solder for the hot-dipped specimens. The improved solderability for the 2 week aged samples seems to be consistent regardless of processing conditions. The reason for this improved solderability is not understood at the present time.

\subsubsection{Internal Mechanisms for Solderability Degradation}

Geist and Kottke [21] conclude that an internal mechanism is the primary cause of solderability degradation and that the most likely degradation mechanism is oxidation of the intermetallic interfaces. Auger depth profiling, performed in the current study however, showed no evidence of internal oxidation of the intermetallic phases. Figure 5.18 shows an Auger profile through the residual solder to the intermetallic interface. Geist and Kottke did not sputter down to the intermetallic layer. Additionally, in the Geist study, solderabilty was measured using the edge dip method which is not as quantitative as the wetting balance method. 


\subsubsection{Intermetallic Phases Ahead of Planar Interface}

The majority of previous research published on the aging and solderability of $\mathrm{Sn}-\mathrm{Pb}-$ $\mathrm{Cu}$ systems has been concerned with the thickness of the resulting intermetallic layer. Sunwoo et al.[7] discuss the subject of intermetallic phases forming ahead of the planar interface in the bulk solder, although little else has been published on the subject. The results of this study seem to support this idea. For $\mathrm{Cu}$ coupons pretinned with $\mathrm{Sn}-\mathrm{Pb}$ solders and then aged, it is proposed that $\mathrm{Cu}$ diffuses rapidly into the solder layer and reacts to form $\mathrm{Cu}-\mathrm{Sn}$ intermetallics ahead of the growing interface. Surface analysis of the $3 \mu \mathrm{m} \mathrm{Sn-rich,} \mathrm{electroplated} \mathrm{specimens} \mathrm{which} \mathrm{had} \mathrm{been} \mathrm{aged} \mathrm{for} 2$ weeks, revealed the presence of $\mathrm{Cu}$ in $\mathrm{Pb}$-rich regions in the absence of $\mathrm{Sn}$. In addition, intermetallic phases are present in the bulk solder of both the electroplated and hot-dipped, aged, $\mathrm{Pb}$ rich coated samples as illustrated in Figures 5.22, 5.26, and 5.27. The possibility of intermetallics forming ahead of the interface helps to explain the existence of intermetallic phases exposed at the surface of even the thick-coated $(30 \mu \mathrm{m})$ samples. Unfortunately, however, the supposition of a minimum coating thickness for solderability preservation will need to be re-evaluated. 


\section{SUMMARY and CONCLUSIONS}

\subsection{Aging Effects of Cu Pretinned with Sn-rich Solder (75Sn-25Pb)}

Based on wetting balance test results (specifically, the time to $90 \%$ of the maximum wetting force), $\mathrm{Cu}$ coupons electroplated with $75 \mathrm{Sn}-25 \mathrm{~Pb}$ solder show no effects due to aging time or coating thickness when aged in argon at $170^{\circ} \mathrm{C}$. Similar $\mathrm{Cu}$ coupons aged in air at $170^{\circ} \mathrm{C}$, show a monotonic decrease in wettability with aging time. The effect of coating thickness on the wettability of samples aged in air is significant for very thin coatings but less significant as the electroplated coating thickness is increased above $10 \mu \mathrm{m}$.

Initially, $\mathrm{Cu}_{6} \mathrm{Sn} 5$ forms and grows at the interface of the $\mathrm{Cu}$ substrate and the $75 \mathrm{Sn}$ $25 \mathrm{~Pb}$ solder. The $\mathrm{Cu}_{6} \mathrm{Sn} 5$ transtorms to $\mathrm{Cu}_{3} \mathrm{Sn}$ as $\mathrm{Cu}$ diffuses toward the interface. Transformation of $\mathrm{Cu}_{6} \mathrm{Sn} 5$ to $\mathrm{Cu}_{3} \mathrm{Sn}$ is complete after 2 weeks aging for thin $(3 \mu \mathrm{m})$ electroplated specimens due to the fact there is an insufficient amount of $\mathrm{Sn}$ to maintain the existence of the $\mathrm{Cu}_{6} \mathrm{Sn}_{5}$ phase. The microstructural changes appear to be the same for specimens aged in argon and air.

The surfaces of the specimens aged in argon and air also appear to have the same morphology. The $\mathrm{Sn}$ is consumed in the formation of the $\mathrm{Cu}-\mathrm{Sn}$ intermetallics, and for the thinner coated samples $(3 \mu \mathrm{m}$ and $10 \mu \mathrm{m})$, the residual $\mathrm{Pb}$ withdraws into irregularly shaped "bumps" on the surface, exposing the intermetallic phase underneath. Unoxidized $\mathrm{Cu}_{3} \mathrm{Sn}$ and $\mathrm{Cu}_{6} \mathrm{Sn}_{5}$ have no effect on the wetting characteristics, while oxidized $\mathrm{Cu}_{3} \mathrm{Sn}$ and $\mathrm{Cu}_{6} \mathrm{Sn} 5$ significantly decrease the wettability. Oxidized $\mathrm{Cu}_{3} \mathrm{Sn}$ exhibits poorer wetting characteristics than oxidized $\mathrm{Cu}_{6} \mathrm{Sn} 5$. This could be largely influenced by the different oxides which form on the different intermetallic phases. The current study indicates the formation of a $\mathrm{Sn}$ oxide on the $\mathrm{Cu}_{6} \mathrm{Sn}_{5}$ intermetallic and a $\mathrm{Cu}$ oxide on the $\mathrm{Cu}_{3} \mathrm{Sn}$ intermetallic. No evidence of internal oxidation was found, 
which implies that wetting characteristics of pretinned $\mathrm{Cu}$ are determined by the surface.

\subsection{Aging Effects of $\mathrm{Cu}$ Pretinned with $\mathrm{Pb}-\mathrm{Rich}$ Solders (8Sn-92Pb and 5Sn-95Pb)}

Wetting balance test results for $\mathrm{Pb}$-rich electroplated and hot-dipped coatings indicate a decrease in wettability as a function of aging time up to 24 hours in argon at $170^{\circ} \mathrm{C}$. Improved wettability is observed for all thickness' of the electroplated specimens and the hot-dipped specimens after further aging ( 2 weeks) under the same conditions. The reason for this behavior in not currently understood.

$\mathrm{A} \mathrm{Cu}$-rich intermetallic, $\mathrm{Cu}_{3} \mathrm{Sn}$, forms at the interface between the $\mathrm{Pb}$-rich solder and the $\mathrm{Cu}$ substrate for both the electroplated and hot-dipped (@360 $\mathrm{C}$ ) pretinned specimens. Examination of metallographic cross-sections suggest the formation and growth of intermetallic phases in the solder, ahead of the planar interface. 


\section{REFERENCES}

1.) Brady, J. E., and G. E. Humiston, General Chemistry 3rd Edition, John Wiley \& Sons, 1982.

2.) Sunwoo, A. J., H. Hayashigatani, J. W. Morris, G. K. Lucey, Jr., "The Effect of Pretinning on the Solderability of Copper", Journal of Metals, June1991, pp. 21-24

3.) Frear, D. R., W. B. Jones, and K. R. Kinsman, Solder Mechanics - A State of the Art Assessment Santa Fe, NM, 1990, TMS.

4.) Yost, F. J., and A. D. Romig, Jr., "Thermodynamics of Wetting by Liquid Metals," Electronic Packaging Materials Science Materials Research Society, 1988 , p. 385.

5.) Klein-Wassinik, R. J., Soldering in Electronics, 2nd Edition, Electrochemical Publications Limited, 1989.

6.) Wetting Balance MIL-SPEC MIL-STD883C NOTICE 5 METHOD 2022.2

7.) Sunwoo, A. J., J. W. Morris, Jr., and G. K. Lucey, Jr., "The Growth of Cu-Sn Intermetallics at a Pretinned Copper-Solder Interface", Metallurgical Transactions A. Vol. 23A, April 1992, p. 1323.

8.) Massalski, Thaddeus B., Cheif Editor, Binary Alloy Phase Diagrams, American Society of Metals, Metals Park, Ohio, 1986, Vol. 1 p. 965, and Vol. 2 p. 1848.

9.) Schoenthaler, D. Chairman, "Accelerated Aging for Solderability Evaluations IPC Task Group Report Summary", WCIII-03, 1983

10.) Thwaites, C. J., "The Solderability of Some Tin, Tin Alloy and Other Metallic Coatings", Trans Inst Metal Finishing 1959, Vol. 36, No. 6, p 203-19.

11.) Ackroyd, M. L. , "A Survey of Accelerated Aging Techniques for Solderable Substrates", Tin Research Institute, 1976.

12.) Kay, P. J., and C. A. MacKay, 1976, "The Growth of Intermetallic Compounds on Common Basis Materials Coated with Tin and Tin-Lead Alloys", Transactions of the Institute of Metal Finishing, 1976, Vol. 54, P. 67 - 74

13.) Davis, P. E., M. E. Warwick, and P. J. Kay, "Intermetallic Compound Growth and Solderability", Plating and Surface Finishing 1982, Vol. 69, p. 72-76.

14.) Davis, P. E., M. E. Warwick, and S. J. Muckett, S. J. "Intermetallic Compound Growth and Solderability of Reflowed Tin and Tin-Lead Coatings",. Plating and Surface Finishing, 1983, Vol. 70, p. 49-53.

15.) Ohriner, E. K., "Intermetallic Formation in Soldered Copper-Based Alloys at $150^{\circ}$ to $250^{\circ} \mathrm{C}$ ", Welding Research Supplement, July 1987 
16.) Yiyu, Q. et. al., "A Study of the Growth of Copper-Tin Intermetallic Compounds and Solderability of Lead Wires", Brazing and Soldering. Autumn 1987, No. 13, P. 39-41.

17.) Bader, W. G., and R. G. Baker, "Solderability of Electrodeposited Solder and Tin Coatings after Extended Storage", Plating March 1973, Vol. 60 No. 3.;p 242-246.

18.) Hagge, J. K., and G. J. Davis, "Aging Solder Thickness and Solder Alloy Effects on Circuit Board Solderability", PC Fab. October 1984, p. 14

19.) Boettinger, W. J., C. A. Handwerker, and U. R. Kattner, "Reactive Wetting and Intermetallic Formation", Solder Mechanics - Wetting and Spreading TMSAIME, Warrendale, PA, 1993.

20.) Boettinger, W. J., C. A. Handwerker, and L. C. Smith, "On the Wetting of the Intermetallics $\mathrm{Cu}_{6} \mathrm{Sn} 5$ and $\mathrm{Cu}_{3} \mathrm{Sn}$ by $\mathrm{Pb}-\mathrm{Sn}$ Alloys", The Metal Science of Joining", TMS-AIME, Warrendale, PA, 1993

21.) Geist, H., and M. Kottke, "Solderability Degradation Models for Fusible Tin Alloy Coatings on Copper Substrates", IEEE Trans. on Compenents. Hybrids. and Manufacturing Technology, 1988, Vol. 11, p. 270.

22.) Tench, D. M. , and D. P. Anderson, "Electrochemical Assessment of Sn-Pb Solderability", Plating and Surface Finishing August 1990, Vol. 77, No. 8, p.44

23.) Tench, D. M., D. P. Anderson, and P. Kim, "Solderability Assessment via Sequential Electrochemical Reduction Analysis", submitted to Journal of Applied Electrochemistry, 1993.

24.) Tench, D. M. , M. W. Kendig, D. P. Anderson, D. D. Hillman, G. K. Lucey, and T.J. Gher, "Production Validation of SERA Solderability Test Method", Soldering and Surface Mount Technology February 1993, No. 13., p.46

25.) Yost, F. G., F. M. Hosking, and D. R. Frear, D. R., eds., The Mechanics of Solder Alloy Wetting and Spreading, Ch. 8 -. "Oxidation of Solder Coatings" (D. M. Tench), Van Nostrand Reinhold, 1993.

26.) Bertocci, U., et. al., "Oxidation of $\mathrm{Cu}-\mathrm{Sn}$ and Ni-Sn Intermetallic Compounds", Corrosion and Reliability of Electronic Materials and Devices, Electrochemical Society 1992.

27.) M \& T Chemicals Inc., M\&T TLF Non-Peptone Solder Plating Process. General Office Address: Rahway, New Jersey 07065-0970, Telephone: (201)499-0200.

28.) Cullity, B. D., Elements of $X$-ray Diffraction, 2nd ed. Addison-Wesley Publishing Company, Inc., 1978, p. 292 - 295. 
29.) Briggs, D. and M. P. Seah, Practical Surface Analysis. Second Edition, Vol. 1, Auger and X-ray Photoelectron Spectroscopy, John Wiley \& Sons, 1990

30.) Grivas, D., D. Frear, L. Quan, and J. W. Morris, Jr., "The Formation of Cu3Sn Intermetallic on the Reaction of $\mathrm{Cu}$ with 95Pb-5Sn Solder", Journal of Electronic Materials. The Metallurgical Society of AIME, June 1986, Vol.15, No. 6.

31.) Frear, D. R., University of California, Berkeley, Ph.D. Thesis "Microstructural Observations of the $\mathrm{Sn}-\mathrm{Pb}$ Solder/Cu System and Thermal Fatigue of the Solder Joint", June 1987 


\section{APPENDICES}

\section{Appendix A}

Calculation of Penetration Depth of X-rays for $\mathrm{Pb}$ and $\mathrm{Sn}$ Coatings. [28]

Penetration depths can be calculated for pure $\mathrm{Pb}$ and pure $\mathrm{Sn}$. X-ray penetration depths for $\mathrm{Pb}-\mathrm{Sn}$ alloys can then be interpolated.

$$
\mathrm{G}_{\mathbf{X}}=\left(1-\mathrm{e}^{-2 \mu \mathrm{X} / \sin \theta}\right) \quad \text { Equation \#1 }
$$

where $\quad G_{\mathbf{X}}=$ the fraction of the total diffracted intensity which is contributed by a surface layer of depth $x$.

$\mu=$ the linear absorption coefficient which is dependent on the material, its density, and the wavelength of the X-rays.

$\theta=$ the angle of incidence

$\mathbf{X}=\mathbf{X}$-ray penetration depth

The effective depth of penetration decreases as $\theta$ decreases.

Rearranging Equation \#1 gives

$$
\begin{array}{ll}
(2 \mu x) / \sin \theta=\ln \left[1 /\left(1-G_{X}\right)\right]=K_{x} & \text { Equation \#2 } \\
\mathbf{x}=\left(K_{\mathbf{X}} \sin \theta\right) /(2 \mu) & \text { Equation \#3 }
\end{array}
$$

\begin{tabular}{|c|c|c|c|c|}
\hline For $G_{X}=$ & 0.50 & 0.75 & 0.90 & 0.95 \\
\hline $\mathrm{K}_{\mathbf{X}}=$ & 0.69 & 1.39 & 2.30 & 3.00 \\
\hline
\end{tabular}

For a $\mathrm{CuK}_{\alpha} \mathrm{X}$-ray source:

$\mu_{\mathrm{Pb}}=2632 \mathrm{~cm}^{-1}$ and $\mu_{\mathrm{Sn}}=1847 \mathrm{~cm}^{-1}$

During the diffraction analysis $2 \theta$ ranged form $25^{\circ}$ to $80^{\circ}$

$$
\begin{aligned}
& \text { If } \mathrm{G}_{\mathrm{X}}=0.95 \quad \begin{array}{l}
\mathrm{XSn}=1.75 \mu \mathrm{m} \text { to } 5.22 \mu \mathrm{m} \\
\mathrm{XPb}=1.23 \mu \mathrm{m} \text { to } 3.66 \mu \mathrm{m}
\end{array} \\
& \text { If } \quad \mathrm{G}_{\mathrm{X}}=0.99 \quad \mathrm{XSn}=2.70 \mu \mathrm{m} \text { to } 8.02 \mu \mathrm{m} \\
& \mathrm{XPb}=1.89 \mu \mathrm{m} \text { to } 5.63 \mu \mathrm{m}
\end{aligned}
$$

